\title{
FELIPE WEINMANN
}

UNICAMP

\section{A Cláusula Final da Definição Geral do Silogismo e suas funções na silogística e nos Primeiros Analíticos I de Aristóteles}

\section{Campinas}




\section{UNIVERSIDADE ESTADUAL DE CAMPINAS \\ INSTITUTO DE FILOSOFIA E CIÊNCIAS HUMANAS \\ PROGRAMA DE Pós-GraduAÇão EM FILOSOFIA}

FELIPE WEINMANN

\section{A Cláusula Final da Definição Geral do Silogismo e suas funções na silogística e nos Primeiros Analíticos I de Aristóteles}

Orientador: Prof. Dr. Lucas Angioni

Dissertação de mestrado a ser apresentada ao Instituto de Filosofia e Ciências Humanas para a obtenção do título de Mestre em Filosofia.

ESTE EXEMPLAR CORRESPONDE À VERSÃO FINAL DA DISSERTAÇÃO DEFENDIDA PELO ALUNO FELIPE WEINMANN, E ORIENTADA PELO PROF. DR. LUCAS ANGIONI.

Campinas

2014

iii 
Ficha catalográfica Universidade Estadual de Campinas

Biblioteca do Instituto de Filosofia e Ciências Humanas

Cecilia Maria Jorge Nicolau - CRB 8/338

\begin{tabular}{|c|c|}
\hline W432c & $\begin{array}{l}\text { Weinmann, Felipe, 1985- } \\
\text { A Cláusula Final da Definição Geral do Silogismo e suas funções na silogística } \\
\text { e nos "Primeiros Analíticos" I de Aristóteles / Felipe Weinmann. - Campinas, SP : } \\
\text { [s.n.], 2014. }\end{array}$ \\
\hline & $\begin{array}{l}\text { Orientador: Lucas Angioni. } \\
\text { Dissertação (mestrado) - Universidade Estadual de Campinas, Instituto de } \\
\text { Filosofia e Ciências Humanas. }\end{array}$ \\
\hline & $\begin{array}{l}\text { 1. Aristóteles. Órganon. 2. Aristóteles. Primeiros Analíticos. 3. Lógica antiga. } \\
\text { 4. Silogismo. I. Angioni, Lucas, 1973-. II. Universidade Estadual de Campinas. } \\
\text { Instituto de Filosofia e Ciências Humanas. III. Título. }\end{array}$ \\
\hline
\end{tabular}

Informações para Biblioteca Digital

Título em outro idioma: The Final Clause of the General Definition of the Syllogism and its role within syllogistic and Aristotle's "Prior Analytics" I

Palavras-chave em inglês:

Aristotle. Orgonon

Aristotle. Prior Analytics

Ancient logic

Syllogism

Área de concentração: Filosofia

Titulação: Mestre em Filosofia

Banca examinadora:

Lucas Angioni [Orientador]

Rodrigo Guerizoli Teixeira

Marcelo Esteban Coniglio

Data de defesa: 23-05-2014

Programa de Pós-Graduação: Filosofia 
UNIVERSIDADE ESTADUAL DE CAMPINAS INSTITUTO DE FILOSOFIA E CIÊNCIAS HUMANAS

A Comissão Julgadora dos trabalhos de Defesa de Dissertação de Mestrado, em sessão pública realizada em 23 de maio de 2014, considerou o candidato FELIPE WEINMANN aprovado.

Este exemplar corresponde à redação final da Tese defendida e aprovada pela Comissão Julgadora.

Prof. Dr. Lucas Angioni

Prof. Dr. Rodrigo Guerizoli Teixeira

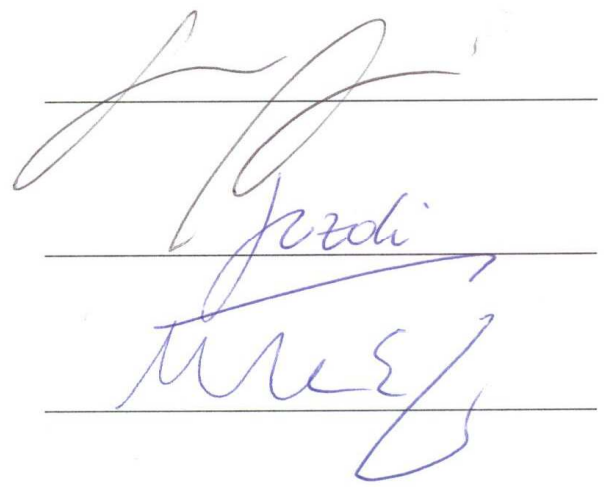

Prof. Dr. Marcelo Esteban Coniglio 


\section{$\underline{\text { Resumo }}$}

A Definição Geral do Silogismo pode ser entendida como consistindo em duas partes de sua descrição de argumentos lógicos: as Condições Inferenciais e a Cláusula Final. Embora essa distinção clássica seja amplamente conhecida, a tradição interpretativa negligencia o papel que a Cláusula Final desempenha na silogística, concentrando-se apenas nas exigências estabelecidas pelas Condições Inferenciais. Tentamos mostrar que essa negligência da Cláusula Final descaracteriza não só a silogística, como também traz resultados indesejáveis para a exegese dos Primeiros Analíticos I. Por causa dessa negligência, tentamos propor uma análise da Cláusula Final e suas consequências para a própria silogística, apresentando-a como critério adicional próprio da Definição Geral do Silogismo e como fio condutor do primeiro livro da obra.

Palavras chave: Aristóteles, Órganon, Primeiros Analíticos I, silogística, Definição Geral do

Silogismo. 


\section{$\underline{\text { Abstract }}$}

Aristotle's General Definition of the Syllogism may be taken as consisting of two parts: the Inferential Conditions and the Final Clause. Although this distinction is well known, traditional interpretations neglect the Final Clause and its influence on syllogistic. Instead, the aforementioned tradition focuses on the Inferential Conditions only. We intend to show that this neglect has severe consequences not just on syllogistic but on the whole exegesis of Aristotle's Prior Analytics I. Due to these consequences, our objective is to analyse the General Definition's Final Clause and its consequences on syllogistic. We propose a reading of the Final Clause as an additional criterion for distinguishing some arguments as properly syllogistic ones and as a main theme which connects all parts of the Prior Analytics I into one coherent piece of work.

Keywords: Aristotle, Organon, Prior Analytics, Syllogism, General Definition of the Syllogism. 


\section{Sumário}

Ficha catalográfica iv

Folha de aprovação v v

Resumo.. vii

$\begin{array}{ll}\text { Abstract. } & \text { ix }\end{array}$

$\begin{array}{ll}\text { Agradecimentos } & \mathrm{XV}\end{array}$

Abreviaturas e Símbolos xix

1. Introdução: $\quad 01$

$\begin{array}{ll}\text { 1.1 A linguagem da silogística } & 05\end{array}$

$\begin{array}{ll}\text { A predicação aristotélica } & 05\end{array}$

$\begin{array}{ll}\text { Uma interpretação lógica da predicação } & 10\end{array}$

$\begin{array}{ll}\text { Relações entre predicações } & 18\end{array}$

$\begin{array}{ll}\text { Regras de oposição } & 19\end{array}$

As regras de inferência e o estabelecimento da sintaxe 19

1.2 A Definição Geral do Silogismo: considerações preliminares 22

1.3 A(s) semântica(s) do sistema silogístico e a prova da completude 31

Problemas com a alegação da prova de completude 33

1.4 Plano Geral da Dissertação 35 


\section{Interpretações lógicas da silogística.}

A origem de um problema: $\quad 39$

2.1 A silogística como teoria lógica e como sistema lógico 42

A silogística como teoria lógica $\quad 44$

$\begin{array}{ll}\text { A teoria de Łukasiewicz-Patzig } & 48\end{array}$

A teoria de Lear $\quad 52$

A silogística como sistema lógico $\quad 55$

O sistema $S$, de Corcoran-Smiley 56

2.2 Primeiros Analíticos: dois tratados distintos ou exposição coesa? 59

2.3 Problemas para a distinção dos Primeiros Analíticos I em dois tratados $\quad 65$

3. A Cláusula Final nos Primeiros Analíticos: 67

3.1 Argumentos válidos, mas não silogísticos: o caso de $A \operatorname{Pr}$ I.4 e I.7 70

$\begin{array}{ll}\text { Falsos argumentos: Parte 1 } & 73\end{array}$

$\begin{array}{ll}\text { Falsos argumentos: Parte 2 } & 77\end{array}$

Uma comparação de $A P r$ I.4 e APr I.7 80

$\begin{array}{ll}\text { Argumentos não-silogísticos } & 85\end{array}$

Uma questão de notação

3.2 A sequência de termos em silogismos extensionalmente equivalentes 93

3.3 Algumas consequências da aplicação da Cláusula Final 100 
$\begin{array}{ll}\text { A falha do projeto reducionista para a } D G S & 100\end{array}$

$\begin{array}{ll}\text { Aspectos de lógicas relevantes e intuicionistas } & 102\end{array}$

O sentido das expressões modais de necessidade em DGS 103

$\begin{array}{ll}\text { Definição parcial da Cláusula Final } & 107\end{array}$

\section{Primeiros Analíticos I: dois tratados distintos ou uma investigação} coesa? ....

4.1 A silogística e critérios de prova. O argumento de $\operatorname{APr} \mathrm{I} .23$

A generalização da silogística ou prova? 117

Silogismos e provas. O argumento em $\operatorname{APr}$ I.23, 40b30-41a20 124

$\begin{array}{ll}\text { Provas indiretas e silogismos } & 134\end{array}$

4.2 A relação entre $C A G$ e $C A E+138$

A relação entre duas cláusulas. O caso de $A \operatorname{Pr}$ I.25 138

A Cláusula Final como fio condutor para APr I 142

Algumas consequências de nossa investigação 144

5. Considerações Finais 147

$\begin{array}{ll}\text { Apêndice } & 155\end{array}$

Referências Bibliográficas $\quad 165$ 


\section{$\underline{\text { Agradecimentos }}$}

Deve ser uma das tarefas mais difíceis expressar em poucas linhas todo o impacto que poucas pessoas tiveram sobre nós. Decerto, eis o problema com o qual me deparo agora, pois não consigo encontrar palavras que estejam a altura daquilo pelo qual eu devo ser grato. Eu tive um raro privilégio de ter sido acolhido e conviver com dois grupos de pesquisadores muito motivados, os quais não poupavam esforços em me ajudar nas frequentes dificuldades que eu tinha ao longo desse período.

Agradeço, primeiro e sobretudo, ao meu orientador, professor Dr. Lucas Angioni. Agradeço por ter me acompanhado e me apoiado durante o vagaroso desenvolvimento de minha carreira acadêmica desde a minha graduação até o presente trabalho. Atribuo a ele todas as melhores qualidades que eu tenha desenvolvido, porventura, como profissional dessa área, apesar de meus defeitos. O mesmo se deve ao presente trabalho: reconheço que o professor Dr. Lucas Angioni é o maior responsável pelos possíveis méritos e atribuo a mim mesmo todos os erros que, porventura, forem descobertos. Agradeço, ainda, por sua disponibilidade e atenção, sempre lendo os meus textos e dando sugestões e críticas fundamentais, que me auxiliaram em todos os aspectos profissionais.

Agradeço, também, aos meus colegas Dr. Mateus Ricardo Fernandes Ferreira, Dr. Wellington Almeida Damasceno, Fernando Martins Mendonça, Breno Andrade Zuppolini, Francine Maria Ribeiro, Dr. Tiago Silva Freitas Oliveira, Filipe M. Martone e Gustavo Rafael Bianchi Azevedo Ferreira, integrantes do grupo de pesquisa coordenado pelo Prof. 
Dr. Lucas Angioni. A experiência de participar desse grupo que sempre se destacou por sua preocupação sincera em compreender e debater os diversos objetos de pesquisa apresentados ao grupo e por sua dedicação à pesquisa, constam entre os privilégios dos quais pude usufruir. Cada um de seus integrantes me serviu de inspiração e de motivação para continuar em minhas pesquisas, bem como não poupava esforços para me auxiliar em minha pesquisa, estando sempre atentos aos meus resultados a oferecendo críticas muito proveitosas. Sou muito grato a cada um, especialmente, pela amizade que todos eles me estenderam.

Agradeço aos membros do Centro de Lógica e Epistemologia que me acolheram e providenciaram um meio em que a qualidade de pesquisa e a elevada motivação muitas vezes foram de importante inspiração para o desenvolvimento de meu trabalho.

Devo agradecer ao professor Dr. Marcelo Esteban Coniglio por sua atenção e pelo tempo dedicado auxiliando-me, da melhor maneira possível, em minhas frequentes dificuldades a respeito da lógica.

Também agradeço ao professor Dr. Walter Alexandre Carnielli pelo constante incentivo que me tem dado em continuar o meu convívio no CLE.

Não poderia, jamais, me esquecer dos colegas que não hesitavam em dedicar seu tempo com a mesma motivação a minhas dúvidas que à pesquisa de cada um deles.

Estendo meus mais profundos agradecimentos a Dr. Leandro Suguitani, Edgar Almeida, Henrique Antunes Almeida e Newton Peron.

Agradeço a Capes, pelo auxílio que recebi durante esse período do meu mestrado.

Não poderia deixar de expressar os meus mais profundos agradecimentos às xvi 
seguintes pessoas, as quais têm me dado um apoio pessoal muito grande.

Agradeço, sobretudo, a Esther Ferreira Alves que me apoiou em minha decisão de fazer pesquisa e tem servido como fundação inabalável, mesmo nos momentos em que ela necessitasse mais de apoio que eu. Esse trabalho seria nada mais que uma ideia, não fosse esse seu suporte.

Agradeço aos meus pais pelo suporte que me deram, aceitando e apoiando minhas decisões profissionais e pessoais. Jamais poderia negar aquilo que aprendi com eles.

Agradeço a Valdir Cremasco por todo apoio que me tem estendido das mais diversas maneiras. Graças a esse apoio, eu pude me focar sobre os meus objetivos.

Agradeço, enfim, a Maria Isabel Ratti pela amizade. 


\section{Abreviacões e Símbolos}

Obras de Aristóteles:

$\begin{array}{ll}\text { Int } & \text { De Interpretatione } \\ \text { Met } & \text { Metafísica } \\ \text { APr } & \text { Primeiros Analíticos } \\ \text { APo } & \text { Segundos Analíticos }\end{array}$

Abreviações adotadas:
$D G S$
Definição Geral do Silogismo
$C A G$
Capítulos de Apresentação Geral (APr I.1-7)
CAE
Capítulos de Apresentação Específica ( $A P r$ I.23ss.)

Notação utilizada ao longo do texto:

\begin{tabular}{ll}
$\rightarrow$ & Implicação material \\
$\cdot$ & Pertença \\
$\cdot$ & Negação \\
$\wedge$ & Constante de falsidade \\
$\cdot$ & Conjunção \\
$\cdot$ & Quantificador universal \\
$\cdot$ & Implicação da semântica dos dicta \\
\hline & Consequência lógica
\end{tabular}

xix 


$\begin{array}{ll}\mathbb{H} \Sigma & \begin{array}{l}\text { Consequência silogística/Prova silogística } \\ \mathbb{4}\end{array} \\ \mathbb{W}^{*} & \text { Relação de oposição (contrariedade) }\end{array}$




\section{INTRODUÇ̃̃o}

Entendemos por um argumento silogístico um conjunto de termos, relacionados entre si, que obtém um novo enunciado, distinto de qualquer elemento do conjunto, como consequência lógica das relações estabelecidas entre os termos. Essa consequência ocorre em virtude de um critério, o qual determina a necessidade da relação entre conclusão e premissa. Mas a que esse critério se refere? Isto é, qual é a instrução específica que deve ser realizada para um argumento tornar-se silogístico? Ou seria o caso desse mencionado critério ser um modo de descrição irrelevante para a Definição Geral do Silogismo (DGS), tal como se apresenta no início dos Primeiros Analíticos (APr) I.1, 24b18-22, tornando-se, portanto, eliminável? Essas são algumas das questões que nos colocamos no presente trabalho.

A Definição Geral do Silogismo $(D G S)$ representa um marco para a história da lógica que, junto com o desenvolvimento da silogística, rendeu a Aristóteles o título de fundador da lógica. No entanto, a própria definição do silogismo ainda guarda certos problemas que não foram solucionados ou mesmo foram negligenciados. A questão que nos colocamos neste trabalho, “qual a definição da Cláusula Final ${ }^{1}$ ?”, consta entre os problemas negligenciados pela tradição de interpretação. Em geral, a $D G S$ se destaca por sua similaridade com descrições intuitivas de validade e de consequência lógicas, correntes atualmente na lógica ${ }^{2}$. Esse fato, a despeito de sua

1

Como iremos introduzir, apropriadamente, afrente, entendemos por Cláusula Final a última Cláusula da Definição Geral do Silogismo, a qual corresponde com o critério que mencionamos em nossa descrição acima.

2 Cf. Mates [1972], pp. 4-18.

É bastante comum descrevermos com a linguagem natural certas noções lógicas, antes de defini-las logicamente. Essas descrições se utilizam comumente de um vocabulário que não pode ser compreendido logicamente, muito 
importância e dos consideráveis avanços ocasionados por ele, corroborou com o problema a que nos dedicaremos neste trabalho.

Quais são os fatores que contribuíram para tal negligência dessa Cláusula Final? De certo modo, não se poderia negar que a própria $D G S$ tenha sido um fator contribuinte desse descaso. Ao contrário da lógica clássica, fortemente influenciada pela meta de dar fundamentos rigorosos à matemática, a silogística procede de modo radicalmente diferente: ela não se utiliza de conceitos de função, nem introduz constantes lógicas ${ }^{3}$ e suas considerações básicas, como a própria predicação, se distinguem radicalmente dos modos utilizados atualmente para o cálculo lógico. Dadas essas diferenças, uma maneira segura de se fazer uma análise rigorosa da silogística, usufruindo-se das ferramentas da lógica atual, seria principiar a investigação com pontos de maior proximidade entre essas distintas compreensões da lógica. Com isso, uma tal investigação tende a começar com a parte inicial da $D G S$, a qual apresenta uma significativa semelhança com conceitos de validade e consequência lógica.

Entrementes, os pontos de divergência da silogística com a lógica clássica começam desde a formação e interpretação de enunciados declarativos. Uma predicação aristotélica, ao contrário do cálculo predicativo clássico, não representa uma declaração como fórmula na qual um determinado predicado é instanciado por um indivíduo ou um grupo de indivíduos. Avesso a esse modo de se compreender uma asserção, a predicação aristotélica representa um enunciado declarativo como composto de três elementos: dois termos e um operador, ou functor, que os liga

embora consigam dar sentido à noção pretendida. No caso da noção de validade, a descrição corrente é que um argumento é válido se e somente se a conclusão se segue necessariamente das premissas, sendo a noção de necessidade não-lógica.

3 A notação que utilizamos para expressar as operações entre os termos não foi introduzida por Aristóteles, mas posteriormente para facilitar o cálculo silogístico.

O uso da terminologia lógica como "constante lógica" é visada apenas para apresentar com mais clareza a distinção entre os itens que constituem a linguagem da silogística. Para mais detalhes, vide Corcoran [1974], MacFarlane [2009]. 
um termo ao outro. Esse functor é usualmente denominado de cópula a que nos referiremos por operador copulativo ${ }^{4}$.

Visto que a silogística aristotélica é um cálculo tendo como base esse tipo de predicação, nota-se que a lógica de Aristóteles corresponde a uma lógica de termos-functores ${ }^{5}$, diferindo do cálculo proposicional a que somos habituados. Um cálculo de termos deve estudar certas operações e relações entre os termos, a partir das quais outros enunciados podem ser obtidos como consequência desse cômputo.

Apesar da diferença de tratamento de enunciados declarativos e a lógica correspondente, vários estudiosos propuseram diversas interpretações a fim de darem respostas a variados problemas que surgem ao longo de $A P r$. O acúmulo das interpretações lógicas não só possibilitou uma gama de interpretações de várias passagens de difícil compreensão, mas teve um efeito negativo, também. A variedade de interpretações dificultava a interpretação da obra como um tratado unitário e coeso, pois não era possível decidir qual seria a interpretação lógica mais apropriada, possibilitando interpretações não-lógicas ${ }^{6}$ de certas partes de $A P r$. Essa situação possibilitou que nós formulássemos a seguinte pergunta: afinal, o primeiro livro dos Primeiros Analíticos (APr I) poderia ser considerado como tratado unitário e coeso que versava sobre uma determinada lógica? Apesar do otimismo de muitos estudiosos, o acúmulo dos problemas de

4 Como tentaremos expor brevemente mais adiante, o item que relaciona os dois termos de uma predicação é mais que apenas um ligação entre os dois termos. A cópula exerce um papel de relação entre os termos, sem a qual as condições de verdade não podem ser satisfeitas. Isso distingue radicalmente a descrição aristotélica de predicação da descrição dada pela lógica clássica. Por isso, concordamos com Angioni [2006, p.18], quem cunhou essa descrição, em denominar a cópula de operador copulativo.

5 Uma lógica de termos-functores ou TFL (term-functor logic), consiste em uma proposta de interpretação lógica, fortemente inspirada na chamada lógica tradicional, a qual era utilizada antes da proposta de Frege para descrever enunciados lógicos. Embora não seja parte da corrente de investigação lógica, defensores como Fred Sommers têm apresentado avanços interessantes na interpretação desse tipo de lógica (TFL). Vide Sommers [1970][1990].

6 Entendemos por "não-lógico" certas noções ou conceitos que não têm uma tradução lógica imediata. 
interpretação parece sugerir o contrário. Isso nos coloca o problema de descobrir se haveria alguma espécie de fio condutor pelo qual Aristóteles teria se orientado para montar esse tratado sobre a silogística.

A partir dessa breve introdução, afirmamos que esta dissertação tem como meta versar sobre dois pontos centrais: (i) a definição do silogismo, suas implicações e peculiaridades, sobretudo no que diz respeito à Cláusula Final, e (ii) como essa investigação pode contribuir para uma interpretação coesa das duas partes de $A \operatorname{Pr}$ I. Acreditamos que o segundo ponto seja possível em decorrência dos problemas que ocorrem em função da Cláusula Final, como tentaremos indicar adiante. Se nossa leitura estiver correta, além de delinearmos com mais precisão o papel da Cláusula Final, conseguiremos representar a obra como um tratado coeso, tendo como fio condutor a satisfação de algumas exigências introduzidas exclusivamente pela própria Cláusula Final. Grosso modo, esta dissertação é uma tentativa de definir a Cláusula final e apresentá-la como o critério pelo qual $A \operatorname{Pr}$ I pode ser lido como um tratado coeso.

A fim de possibilitar o cumprimento de nossas metas, adotamos os seguintes objetivos: de início, devemos versar brevemente sobre a noção aristotélica de predicação e suas características, as quais serão fundamentais para considerações futuras de problemas que envolvem a $D G S$. Neste texto trataremos a predicação aristotélica como parte da linguagem de um sistema lógico, tal como foi apresentado originalmente por Corcoran [1972][1974b] e Smiley [1973]. Sendo assim, corroboraremos com a interpretação de que o silogismo, para Aristóteles, era um argumento lógico consistindo de diversas etapas inferenciais, em oposição à interpretação de Łukasiewicz que os entendia como enunciados condicionais universalizados ${ }^{7}$.

7 Para críticas às interpretações que compreendem a silogística como enunciados condicionais universalizados, tal como o fazem Łukasiewicz e Patzig, vide Smiley [1973], Corcoran [1974a], Ferreira [2012]. 
Após uma rápida apresentação da linguagem, adicionamos as principais regras de inferência que foram reconhecidas por Aristóteles e que utilizaremos em nossas análises futuras, ao longo deste trabalho. Após essa breve exposição das predicações aristotélicas, faremos uma apresentação inicial da Definição Geral do Silogismo $(D G S)$, expondo os problemas e como foram interpretados, caso tenham sido. Para terminarmos este primeiro capítulo, daremos uma breve descrição do projeto de interpretação semântica da silogística e como esses sistemas pretendem compreender as características da própria silogística. Feito isso, apresentaremos, enfim, os próximos passos que pretendemos dar, a fim de atingir nossas metas finais.

\subsection{A linguagem da silogística}

A predicação aristotélica: Como havíamos mencionado acima, um argumento silogístico se caracteriza por uma lógica de termos que remete à peculiar teoria aristotélica da predicação. As premissas que constituem um argumento silogístico consistem em três partes: dois termos e um operador que os liga e introduz certas propriedades que devem haver entre os termos. Aristóteles se refere a esses enunciados como protaseis e os define da seguinte maneira, em APr I.1:

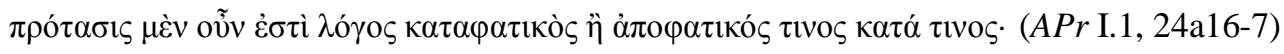

A premissa é uma asserção afirmativa ou privativa, a qual relaciona um item com outro ${ }^{8}$.

A tradução de logos por 'asserção' é intencional, pois remete claramente a uma relação estabelecida entre dois itens, afirmados ou negados um do outro, e que tenha uma pretensão de verdade $^{9}$. Aristóteles mesmo apresenta uma descrição daquilo que entende por uma asserção no

8 Tradução nossa. Daqui em diante todas as traduções serão nossas, salvo indicado o contrário.

9 Cf. Angioni [2006, p.20], Malink [2013], p.23.

Uma pretensão de verdade se caracteriza pelo uso da linguagem que se reportam a certos fatos. Se essa pretensão for bem sucedida, eles assumem um valor positivo de verdade, isto é, são verdadeiros. Caso contrário, assumem um valor negativo de verdade, ou seja, são falsos. 
tratado da Interpretação (Int), onde dá a entender que a interpretação desses enunciados declarativos deve ser feita com os três itens mencionados:

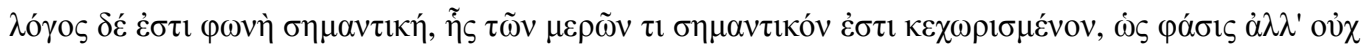

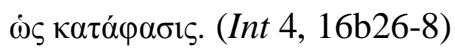

Uma asserção é uma elocução dotada de significado, da qual uma parte qualquer, separadamente, tem significado como enunciação, mas não como afirmação ${ }^{10}$.

A descrição dada em Int 4 é interessante por diversos motivos: (i) ela marca claramente o fato da predicação consistir em três itens, uma vez que dois termos distintos são relacionados para formarem um enunciado, ao qual ainda será preciso adicionar um functor para a predicação resultante ser uma afirmação ou negação; (ii) cada termo tem suas próprias condições de significação e de referência, se preciso, distinguindo-se claramente da maneira como asserções costumam ser formadas hoje em dia; e, em consequência disso, (iii) a condição de verdade da predicação aristotélica depende, efetivamente, do functor em conjunto com o significado dos termos $^{11}$ e não de uma noção de mera satisfação de um termo saturado ${ }^{12}$.

Essas divergências da predicação aristotélica com as predicações clássicas podem ser compreendidas a partir da construção fregeana de asserções. Na acepção fregeana de um enunciado predicativo, temos a combinação de dois elementos distintos: um predicado, formado a partir de uma expressão insaturada, e um argumento que equivale a uma expressão saturada. A noção de saturamento diz respeito às condições de referência de um determinado conceito. Nesse contexto, um predicado, enquanto expressão insaturada, apresenta apenas instruções adicionais para a determinação da referência, mas não é, ele mesmo, dotado de uma referência enquanto age

10 Tradução de Angioni [2006], levemente alterada.

11 Cf. Metafísica (Met) $\Delta .7,1017 \mathrm{a} 31-5$.

12 Cf. Dummett [1981]. 
como predicado $^{13}$. Sendo assim, o predicado cumpre a função primária de ser verdadeiro de um objeto. Na notação, com a qual se costuma analisar as predicações fregeanas, um predicado é representado como uma expressão do tipo:

\section{( ) [é F],}

em que o espaço entre os parênteses deve ser preenchido por um outro termo, a fim de saturar a expressão predicativa, isto é, dar o sentido que o enunciado deve adotar. Esse outro termo, por sua vez, não poderia ser uma outra expressão insaturada, mas um termo saturado. Isto é, no modelo acima, a expressão que deve preencher os parêntese é tal que seu referente já está determinado, complementando o sentido da expressão insaturada com um referente que a satisfaça. Com isso, a descrição assume o seguinte esquema:

\section{(x) [é F].}

Ao contrário da descrição fregeana, Aristóteles parece entender cada termo como dotado de suas próprias condições de sentido, as quais são relacionadas por um terceiro item. Em vez do predicado desempenhar apenas o papel de uma expressão insaturada, isto é, das condições de verificação para um termo saturado, sem referente próprio, o termo-predicado não adota essa função na teoria aristotélica da predicação. Ao contrário da interpretação clássica, os termos de uma predicação aristotélica são ambos saturados e não são relacionados um com o outro de modo a saturar as expressões. Sendo assim, a relação entre os termos não é a de saturação mas de outra natureza. Se essa análise estiver certa, a verdade de uma asserção, no sentido aristotélico, é dada pelo functor que liga um termo ao outro. A composição dos dois termos depende da operação que os liga entre si para que um juízo a respeito da verdade do enunciado possa ser tomado. Com

13 Cf. Dummett [1981]. Para a lógica predicativa clássica, o predicado é destituído de um referente próprio, mas é dotado de sentido, através do qual é possível identificar com mais facilidade o referente ou seu valor semântico. 
isso, a verdade de um enunciado predicativo se deve, sobretudo, à relação entre os dois termos dados.

Essa exata disposição dos termos se pretende como descrição que representa algum dado no mundo e, por isso, deve ser considerada enquanto pretensão de verdade. Quando uma combinação de termos recebe um operador copulativo ${ }^{14}$ afirmativo, o enunciado pretende descrever uma efetiva composição das coisas denominados pelos termos. Por sua vez, quando o operador copulativo é privativo, pretende-se que os itens denominados pelos termos estejam efetivamente separados.

Além da qualidade de ser afirmativo ou privativo, o operador copulativo pode adotar outras noções que alteram a relação a ser considerada entre os termos dispostos na predicação. Trata-se das quantificações, as quais são resumidas por Aristóteles no seguinte comentário:

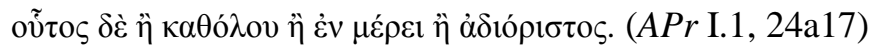

E essas relações são ou universais ou parciais ou indefinidas.

A grande diferença entre as quantificações do cálculo predicativo clássico e da predicação aristotélica se verifica, sobretudo, no escopo da quantificação. No cálculo clássico, a noção de quantidade é dada, novamente, por uma constante lógica, a qual se atribui a uma variável nãológica $^{15}$. Essa representação da quantificação se aplica sobre uma variável que representa um indivíduo ou um grupo de indivíduos, os quais satisfazem predicado em questão. Para a teoria aristotélica da predicação não há um operador separado que computa a quantificação de um termo para outro. Ao contrário disso, a predicação aristotélica assume para cada uma das três

14 Cf. Angioni [2006], pp.18-9

15 A constante referida aqui é o próprio operador de quantificação. Na lógica clássica de predicados é comum representar asserções como fórmulas atômicas que são quantificadas: $\cdot x \mathrm{P} x$ ou $\cdot x \mathrm{P} x$, respectivamente, para dizer que para todo indivíduo $x$ esse satisfaz o predicado $\mathrm{P}$, enquanto a segundo fórmula diz que existe um indivíduo $x$ tal que satisfaz P. 
noções de quantidade dois functores novos, afirmativo ou privativo.

Além dessas noções básicas se ligarem diretamente ao operador copulativo, pode-se adicionar, ainda, noções de modalidade, tais como 'necessidade', 'possibilidade' e 'contingência', ao operador. Não entraremos, neste trabalho, no mérito das interpretações do aspecto modal do functor, no entanto. Não obstante, devemos observar algo que fica evidente ao ponderar as noções modais e certamente diz respeito, também, às demais alterações que se faz sobre a predicação. O tratamento das expressões modais, como atualmente entendidas, diz respeito, sobretudo, a uma operação sobre o enunciado como um todo, isto é, expressa que o conteúdo cognoscível da asserção é necessário. No caso da predicação aristotélica, a noção de necessidade se associa, novamente, ao operador copulativo, apontando para a necessidade de uma relação entre os termos e não pretendendo apresentar apenas a modalidade do fato descrito. Aristóteles não expressa a necessidade, possibilidade ou contingência do fato de $\mathrm{A}$ ser ou não ser $\mathrm{B}$, mas descreve como A necessariamente, possivelmente ou contingentemente se relaciona com B.

Visto que a predicação aristotélica se foca sobre diversos aspectos dos operadores copulativos, que ligam um termo a outro, ela não pode ser compreendida como representação análoga ao cálculo predicativo clássico. Como é possível perceber no caso das noções modais, os enunciados predicativos clássicos têm uma pretensão que parece se ligar fortemente a estados epistêmicos ${ }^{16}$, enquanto a predicação aristotélica se foca sobre um outro aspecto, totalmente diferente. Esse aspecto se pauta claramente por critérios metafísicos, como foi apontado por Angioni [2006].

16 De acordo com certas interpretações da filosofia da lógica, a lógica clássica foi desenvolvida, em parte, com a pretensão de estabelecer regras para o pensamento puro, sem depender de outros elementos. Um exemplo disso seria o projeto de Frege. Esse modo de pensar a lógica tem seus reflexos nas investigações a respeito da lógica formal, a qual é filosoficamente justificada por um projeto que pretende explicar a lógica através de ferramentas exclusivas da própria disciplina. Um tal projeto costuma ser chamado de "projeto de demarcação da lógica".

Vide MacFarlane [2000] 
Alguns intérpretes sugerem que o compromisso metafísico da predicação seria observado mediante classificação dos termos, tal como é feita em Tópicos (Top) I.4, 101b25ss ${ }^{17}$. Aristóteles aponta, nesse capítulo, que certas composições apresentam relações reconhecidas como próprias, de gênero ou por concomitância. Mas qual seria a vantagem dessa interpretação? Alguns estudiosos reconhecem que a única vantagem efetiva em tal análise das predicações se veria na análise modal da silogística ${ }^{18}$. Em todos os demais casos, essa classificação dos termos parece não influenciar a própria relação. Esse fato se impõe como dificuldade a ser resolvida por essas interpretações. No que diz respeito ao nosso objeto imediato de estudo, nos contentamos em descrever a predicação aristotélica como sendo constituída por dois termos e um operador.

No que diz respeito aos termos relacionados em um enunciado predicativo, Aristóteles os define de modo muito direto, fundamentando a interpretação da predicação como dividida em três partes distintos:

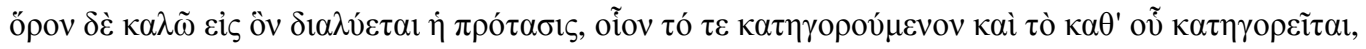

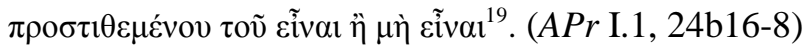

Chamo de termo aquilo em que a premissa é dissolvida, isto é, tanto aquilo que é predicado, como aquilo a respeito do qual se predica, tendo-se adicionado o ser ou o nãoser.

Um termo é aquele item da premissa que assume o papel de termo-sujeito ou de termo-predicado em uma premissa, desde que esteja relacionado com um outro termo. Apesar de sua vagueza, podemos afirmar que qualquer termo pode assumir tanto o papel de termo-sujeito como o de termo-predicado.

Um outro ponto perceptível nessa descrição que Aristóteles faz em $A P r$ I.1 é a

17 Cf. Striker [2009]; Angioni [2006]; Malink [2013].

18 Cf. Malink [2013]

19 Adotamos nesse trecho a elisão de "é diairoumenou" proposta por Ross [1946] e aceita pela maior parte das interpretações. 
pressuposição do papel que os termos desempenham dentro da predicação. Isso se evidencia com a última cláusula, em 24b18, onde os termos são relacionados pelas relações de "ser" ou "não ser". Denominemos esses termos de "termos predicativos". Um termo comum só poderá ser avaliado em seu papel de termo-sujeito ou termo-predicado, quando estiver relacionado em uma predicação. Isto é, uma vez que dois termos estiverem relacionados, eles assumem um determinado papel de termo-sujeito ou termo-predicado. Fixada a função de cada termo, a classificação das relações, tal como seria previsto em Top I.4, seria possível. Entretanto, com isso surge um problema, a saber: essa determinação entre termo-sujeito e termo-predicado ocorre devido a seu posicionamento em uma predicação ou com base em uma avaliação posterior? Como uma discussão a esse respeito seria demasiadamente longa, nos contentamos apenas com essa breve apresentação do problema, a fim de procedermos para a definição dos silogismos.

Uma interpretação lógica da predicação: Muito embora a teoria da predicação aristotélica se pretenda como uma teoria sobre asserções que podem ser valoradas e possuem um forte compromisso com conceitos metafísicos, a predicação, no contexto da silogística, costuma ser interpretada de modo mais neutro. Além de ser uma possibilidade preferível, de um ponto de vista da lógica, essa interpretação mais neutra é apoiada na comparação que Aristóteles faz em $A \operatorname{Pr}$ I.1, 24a22-b12, entre asserções científicas (hē apodeicticē protasis) e asserções dialéticas (dialecticēe protasis). Nessa comparação, Aristóteles assevera que não há diferença entre as premissas de uma demonstração científica e um argumento dialético, exceto pelo comprometimento da primeira para com a pretensão de verdade, inerente à predicação. Esse mesmo compromisso com a verdade de um enunciado estaria ausente no contexto dialético. Uma vez que tanto a ciência quanto a dialética se utilizam de silogismos, a semelhança na construção desses argumentos 
aponta para o fato que a linguagem da silogística não dependeria do conteúdo para fazer seus resultados valerem. Como não há variação no esquema em que as predicações se apresentam, podemos comparar e avaliar a predicação aristotélica a uma linguagem lógica.

O objetivo de uma linguagem lógica é possibilitar que um raciocínio possa ser expresso e qualificado sem depender de uma interpretação. Se isso valer para a linguagem da silogística, é lícito considerá-la topicamente neutra. Para atingir essa meta, esse tipo de raciocínio requer alguns itens distintos: constantes lógicas, constantes não-lógicas, as quais podem ser substituídas por variáveis lógicas. A classe de constantes lógicas costuma ser formada por algumas operações fundamentais e conectivos lógicos, os quais são invariáveis. Nos estudos lógicos atuais, essa classe é, em geral, constituída pelos seguintes elementos $\{\wedge, \vee, \rightarrow, \cdot, \neg, \cdot, \cdot, \cdot, \diamond\}$, mas pode ser reduzida a um conjunto mínimo, a partir do qual todos os demais conectivos poderiam ser definidos, chamado de assinatura.

No caso de se fazer uma interpretação da linguagem da silogística, a tradição costuma assumir as formas categóricas como uma assinatura do sistema silogístico, de modo que a linguagem é formada apenas por quatro constantes lógicas $\{a, e, i, o\}$, chamadas de formas categóricas e que desempenham o papel de functores; um conjunto, possivelmente infinito, de constantes não-lógicas $U=\left\{u_{1}, u_{2}, u_{3}, \ldots\right\}$, cada qual dos elementos pode ser substituído por termos concretos, representados por variáveis, as quais, no caso da silogística, são dadas por $\{$ A, B, C, ... . Desse modo, a composição de dois termos relacionados por uma forma categórica pode representar as seguintes predicações:

$\underline{\text { Notação }}$

$\mathrm{A} a \mathrm{~B}$ $\underline{\text { Sentido corrente }}$

Todo A é B $\underline{\text { Descrição aristotélica }}$

B pertence a todo $\mathrm{A}$ 

$\mathrm{A} e \mathrm{~B}$
Nenhum A é B
B pertence a nenhum $A$
$\mathrm{A} i \mathrm{~B}$
Algum A é B
B pertence a algum $A$
$\mathrm{A} o \mathrm{~B}$
Algum A não é B
$\mathrm{B}$ não pertence a algum $\mathrm{A}$

Com essa descrição básica, podemos apontar para algumas diferenças entre a linguagem predicativa de Aristóteles e uma linguagem da lógica clássica. O primeiro ponto que deve ser observado diz respeito à noção de negação na linguagem da silogística e na lógica clássica. A negação nesta última é definida sintaticamente da seguinte maneira:

$$
(N e g) \neg \mathrm{A}:=\mathrm{A} \rightarrow \perp,
$$

onde o símbolo $\perp$ (bottom) representa uma contradição ${ }^{20}$. Dada a definição de (Neg), revelamos

que a nossa compreensão de negação equivale, de fato, a um enunciado e deve, por isso mesmo, ser entendida como proposicional.

Para Aristóteles, entretanto, isso não seria possível por um simples motivo: a noção de negação é substituída por dois operadores copulativos subalternos, os quais descrevem a separação dos termos relacionados em uma predicação. Para a predicação aristotélica, a noção de negação não depende de um operador externo à predicação, mas descreve a separação dos itens dados no mundo. Considerando-se o modo com que a predicação aristotélica é estabelecida, uma negação proposicional clássica não é possível. Uma predicação clássica, tal como a apresentamos, adota uma negação proposicional, em virtude de seu predicado não ter um referente próprio. Como o predicado clássico equivale a uma expressão insaturada que precisa ser satisfeita, a negação decide se uma certa descrição é satisfeita ou não. Como a predicação

20 Essa definição da negação ficou sobretudo conhecida por sua aplicação nas lógicas intuicionistas, as quais definem a negação à mesma maneira. A diferença entre lógicas intuicionistas e clássicas estaria, antes, na adoção de outros princípios, feita pela lógica clássica, os quais são claramente recusados pela lógica intuicionista. 
aristotélica não precisa assumir o termo-predicado como uma expressão insaturada, a única maneira de descrever uma negação é através das noções de composição e separação.

Apesar de afirmarmos que Aristóteles não subscreve a negação proposicional em uma linguagem de primeira ordem, não quer dizer, no entanto, que a noção de negação esteja totalmente ausente. De fato, Aristóteles adota uma negação para a sua linguagem. No entanto, essa se distingue radicalmente da negação proposicional. A noção proposicional de negação, como apresentamos com (Neg), é dada por uma definição precisa e representa a falsidade do enunciado predicativo clássico. Ao contrário disso, a noção aristotélica de negação é bem distinta. Em vez de incidir sobre uma proposição, ela se aplica sobre o termo e age como princípio de indeterminação do próprio termo. Essa negação aristotélica indetermina o próprio referente do termo negado. Dada essa descrição da negação aristotélica, qual seria o sentido lógico a ela atribuível? Não se trata de uma constante lógica, pois ela não se aplica a uma das formas categóricas. Como ela se aplica aos termos, ela é uma operação sobre constantes não-lógicas. Com isso, ela varia de acordo com o valor adotado pelas constantes não-lógicas ${ }^{21}$.

Uma outra diferença entre as duas linguagens se apresenta na própria análise feita sobre o operador copulativo. Mencionamos antes que há diferenças significativas entre operações lógicas feitas a partir de conectivos e aquelas feitas a partir das formas categóricas. Em geral, uma predicação $\mathrm{A} a \mathrm{~B}$ é traduzida para a linguagem simbólica como sendo uma operação sobre duas fórmulas predicativas atômicas ${ }^{22}: \cdot x(\mathrm{~A} x \rightarrow \mathrm{B} x)$. Esse tipo de notação dos enunciados predicativos, está longe de ser neutro quanto à interpretação da relação lógica entre os termos. Comecemos pela quantificação e sua aplicação: a quantificação sobre uma variável $x$ se

21 Em termos da teoria de conjuntos, essa negação poderia ser compreendida como o complemento de um conjunto. 22 Esse tipo de representação é corrente nas interpretações de Patzig [1968]. 
compreende como quantidade de indivíduos que satisfazem essa descrição. Esse tipo de descrição é a base para uma leitura em que a extensão de uma certa propriedade é relevante para as considerações lógicas. Como veremos ao longo deste trabalho, em diversos momentos Aristóteles impede voluntariamente considerações extensionais, por diversos motivos ${ }^{23}$. Devido a esses fatos, somos forçados a negar uma interpretação extensional, pois ela parece ser incompatível com as pretensões aristotélicas $^{24}$.

Visto que é um fato da silogística que o operador copulativo resume em si aspectos como conexão lógica, quantificação, modalidade e negação, ela dá fundação, então, à interpretação que nega a cópula como mero conectivo lógico, muito embora seja interpretada como uma constante lógica. Parece, antes, que o papel desempenhado por ela é mais específico, tratando-se de uma operação específica sobre os termos. Se essa interpretação for correta, a forma categórica que representa a relação não poderia ser compreendida como um conectivo lógico simples, mas como algo a ser definido adequadamente.

Tendo em vista essas peculiaridades, qual seria o sentido dessas operações lógicas? Pesquisas recentes apontam para $A \operatorname{Pr}$ I.1, 24b28-30, como possível resposta a essa questão. Nesse trecho, Aristóteles pretende esclarecer as expressões "predicar-se de todo ou de nenhum (outro item)" (to kata pantos è mèdenos katēgoreisthai ${ }^{25}$ ) e "estar em algo como um todo" e sua negação

23 O principal exemplo com que trabalharemos neste texto é a própria $D G S$, a qual recusa enunciados logicamente válidos devido a sua extensão, mas sem qualquer valor demonstrativo. Veremos que $D G S$ recusará tautologias lógicas conhecidas por paradoxos da implicação material, entre outras recusas que se negam qualquer consideração extensional.

24 Há algumas interpretações que possibilitam uma tal interpretação. A maior parte delas está embasada em considerações algébricas e adotam uma certa ordenação entre seus termos. Em tempos recentes, uma interpretação, em particular, tem chamado atenção. Ela é considerada como interpretação não-ortodoxa do dictum de omni et de nullo. Vide Malink [2013], Ferreira [2012][2013], Barnes [2007], Mignucci [1969].

25 Cf. $A P r$ I.1, 24a14-5 
(to en holōi einai $\bar{e}$ mè tode tōide ${ }^{26}$ ). No final desse capítulo, essas duas expressões são assumidas como equivalentes e recebem uma descrição de como deveriam ser entendidos:

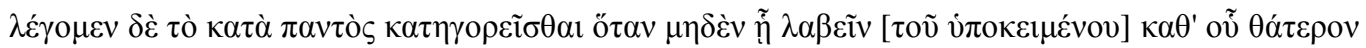

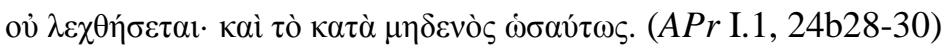

Dizemos 'predicar-se de todo' quando nada pode ser assumido [do subjacente] a respeito do qual o outro não é assumido. O mesmo dizemos a respeito do 'predicar-se de nada'.

Esse trecho, apesar de sua aparente clareza, gerou fortes discussões a respeito de como deveria ser compreendido. Para as interpretações tradicionais, eis um claro caso em que Aristóteles estava pensando em quantificação sobre indivíduos. De acordo com essa interpretação, a predicação aristotélica seria claramente extensional. Entretanto, em tempos recentes, essa afirmação de Aristóteles voltou a chamar a atenção de estudiosos, quando se levou em consideração que, ao contrário de uma simples descrição lógica, Aristóteles estava descrevendo uma relação entre proposições. Essa interpretação faz uso de uma interpretação dos medievos que caracterizou a predicação a partir da descrição do chamado dictum de omni et de nullo. Além dos primeiros dicta, subentende-se, evidentemente, os dicta de aliquo et aliquo non ${ }^{27}$.

Ao contrário de algumas leituras mais ortodoxas, uma possível interpretação dos dicta não compreende a predicação como operação sobre indivíduos quantificados, mas compreende a predicação como uma nova relação para as partes dos termos. A relação que se considera em um dictum com relação a cada termo é uma relação específica que, por conveniência, pode ser considerada como uma nova predicação ${ }^{28}$. Desse modo, uma possibilidade de se representar a própria predicação seria considerar ambos os termos de um enunciado predicativo como termospredicado de um outro item que se liga universalmente ao termo-sujeito da predicação original.

26 Cf. APr I.1, 24a13-4

27 Cf. Barnes [2007]; Malink [2013]; Ferreira [2012][2013]

28 Em geral, um functor predicativo universal afirmativo; uma a-predicação. Cf. Malink [2013]. 
Esses termos servirão de parâmetro para a operação copulativa que se apresenta entre os dois termos originais. Em geral, a relação com o parâmetro da predicação original assume uma relação equivalente a uma a-predicação ${ }^{29}$, de modo que o dictum de omni pode ser formulado da seguinte maneira: uma relação $\mathrm{A} a \mathrm{~B}$ se define por dizer que, se o termo $\mathrm{A}$ é a-predicado de todo $\mathrm{X}$, inclusive o próprio $\mathrm{A}$, então todo $\mathrm{X}$, inclusive $\mathrm{A}$, terá $\mathrm{B}$ como a-predicado. Em termos da representação formal da silogística: $\mathrm{X} a \mathrm{~A} \Rightarrow \mathrm{X} a \mathrm{~B}^{30}$.

Uma vantagem de se adotar essa leitura do dictum se apresenta tão logo o termo X, utilizado aqui, seja considerado como uma pluralidade, ao invés de indivíduos. A distinção importante que deve ser feita para essa interpretação é que o termo $\mathrm{X}$ não se reporta a um conjunto de indivíduos, pois isso seria apenas uma postergação do mesmo problema de considerações extensionais que Aristóteles acaba negando. Essa abordagem foi adotado por diversos estudiosos como Mario Mignucci, Michael Frede e Marko Malink, os quais procuravam apresentar o termo X como mesmo tipo sintático dos demais termos.

A interpretação de que o termo $\mathrm{X}$ é do mesmo tipo sintático que os demais termos da predicação se opõe, de acordo com Malink, à interpretação extensional, na medida em que os múltiplos não são exclusivamente considerados como tratando-se de indivíduos, mas de algo mais amplo ${ }^{31}$. Além dos problemas gerados na silogística, com a interpretação extensional dos termos, há alguns outros argumentos que criticam um desenvolvimento extensional, inclusive do dictum.

29 Cf. Malink [2009]. A relação de a-predicação é utilizada como descrição para o operador copulativo "a".

30 Nessa representação utilizamos uma flecha de implicação, mas não nos comprometemos em dar uma detalhada descrição de seu significado.

31 Com isso, a predicação aristotélica evita um problema de instanciação daquilo que é "neve" em uma predicação "a neve é branca". A interpretação clássica, fundadas na instanciação individual dos predicados, não consegue dar conta em apresentar uma individuação daquilo que seria neve, ao passo que, ao que aponta a interpretação de Malink, isso seria possível com a predicação aristotélica. 
Um desses argumentos se foca sobre a própria noção de indivíduo e seu papel na silogística. Como vimos anteriormente, o cálculo clássico assume que seus predicados são satisfeitos por indivíduos, representados por variáveis lógicas. Em geral, a relação é feita por intermédio de termos de tipo sintático distinto, sendo divididos em níveis distintos. O tipo sintático dos indivíduos é o mais fundamental que dos demais predicados e é representado pelas variáveis de uma fórmula lógica. Já predicados, são de um tipo sintático mais alto, pois esses reúnem em si grupos de indivíduos. A interpretação da lógica clássica assume que esses indivíduos não podem figurar como termos do próprio cálculo silogístico, devido a dois fatos: um termo predicativo deve ser capaz de assumir tanto o papel de termo-sujeito como de termopredicado; e Aristóteles teria considerado em $\operatorname{APr}$ I.27 que a silogística se preocupa, sobretudo, com termos universais ${ }^{32}$.

Há, no entanto, severas críticas a essa interpretação. Em primeiro lugar, não há evidência alguma pela qual Aristóteles teria adotado uma hierarquia equivalente à dos tipos, pela qual haveria impedimento para um indivíduo funcionar como termo-predicado. Ademais, apesar de Aristóteles efetivamente afirmar que a silogística teria uma preocupação maior com termos universais que com indivíduos, algumas interpretações sugerem que Aristóteles, de fato, teria aceito que termos individuais teriam o mesmo comportamento lógico que termos universais ${ }^{33}$, aplicando-se sobre eles um functor universal. Ora, se não for aceito que termos individuais sejam de um tipo sintático mais simples que os termos predicativos, então uma interpretação extensional da predicação aristotélica não seria frutífera. Esse resultado já seria suficiente para

32 Cf. $A P r$ I.27,

33 Cf. Almeida [2013], Malink [2013], Mignucci [1968] 
descartar a interpretação clássica dos enunciados declarativos da silogística ${ }^{34}$.

Relações entre as predicações: Em nossa breve exposição acerca da divergência entre as noções de negação e as formas categóricas negativas, mencionamos que essas últimas formas não podem equivaler à constante lógica da negação. Tentamos mostrar que a noção de negação em Aristóteles não é proposicional mas se aplica a um termo, indeterminando seu referente. Aquilo que a lógica clássica descreve como uma negação de um enunciado é tratado por Aristóteles como uma operação entre dois termos que descreve sua separação. Uma comparação entre essas duas formas de predicação com a negação só será possível mediante uma aproximação que compara a relação dessas predicações com seus opostos afirmativos. Trata-se das relações de oposição entre os enunciados predicativos. Uma relação de oposição entre dois enunciados predicativos pode ser interpretada como relação, sob a qual caem esses pares predicativos que são elementos dessa relação ${ }^{35}$. Suas definições são dadas de acordo com certas regras como as seguintes: um par de enunciados é contrário se e somente se for impossível que ambos sejam verdadeiros ao mesmo tempo, mas é possível ambos serem falsos; por sua vez, um par é contraditório se e somente se for impossível ambos serem verdadeiros e ambos serem falsos ao mesmo tempo.

A linguagem da predicação e, por conseguinte, a linguagem da silogística relaciona os tipos predicativos entre si. As relações mais importantes são dadas a partir das noções de oposições que foram descritas acima. Em vez de introduzir um operador de negação, essas noções de oposição se aproximam dos sentidos de negação dividindo-a em noções de

34 Malink [2013] fortalece essa argumentação introduzindo novos critérios como a descrição aristotélica das formas categóricas em Top II.2 e uma explicação por meio da silogística modal.

35 Cf. Whitaker [1997], Aristóteles tratou desses pares predicativos em Int 4-7. 
contraditoriedade e contrariedade, as quais podem ser interpretadas, respectivamente, a partir de duas funções de oposição: $1 . \mathbb{l}^{*}(\cdot x \mathrm{P} x)=\cdot x \neg \mathrm{P} x ; 2 . \mathbb{U}(\cdot x \mathrm{P} x)=\cdot x \neg \mathrm{P} x$.

Regras de oposição: Alguns aspectos fundamentais da teoria da predicação, que serão importantes para a silogística, se encontram no tratado da Interpretação (Int), onde Aristóteles apresenta as seguintes regras de oposição ${ }^{36}$ :

$$
\begin{array}{ll}
\mathbb{U} *(\mathrm{~A} a \mathrm{~B})=\mathrm{A} o \mathrm{~B} & , \text { sendo que } \mathbb{W} *(\mathrm{~A} o \mathrm{~B})=\mathrm{A} a \mathrm{~B} ; \\
\mathbb{U} *(\mathrm{~A} e \mathrm{~B})=\mathrm{A} i \mathrm{~B} & , \text { sendo que } \mathbb{W} *(\mathrm{~A} i \mathrm{~B})=\mathrm{A} e \mathrm{~B} ; \\
\mathbb{U}(\mathrm{A} a \mathrm{~B})=\mathrm{A} e \mathrm{~B} & , \text { sendo que } \mathbb{W}(\mathrm{A} e \mathrm{~B})=\mathrm{A} a \mathrm{~B} .
\end{array}
$$

As regras de inferência e o estabelecimento da sintaxe: Para uma linguagem ser utilizada em considerações lógicas, ela depende da adição de certas regras de inferência. Essas regras de inferência são consideradas como evidentemente válidas e não requerem comprovação, pois se seguem da própria definição de uma operação lógica. No caso da silogística não é diferente. Na interpretação corrente, a silogística é composta, fundamentalmente, por sete regras de inferência. Essas regras consistem em quatro silogismos, reconhecidos por Aristóteles como perfeitos, e as regras de conversão, introduzidas em $A \operatorname{Pr}$ I.2. A noção de perfeição costuma ser interpretada a partir de uma noção de evidência ${ }^{37}$, de modo que um silogismo perfeito prescinde de qualquer

36 Essas regras de oposição fazem parte daquilo que entrou para a história da filosofia como "Quadrado Lógico das Oposições".

Aristóteles faz uma outra distinção em termos de oposição em $A P r$ II.15. Naquele capítulo, geralmente considerado como extra-sistemático, em função de sua análise de argumentos com premissas opostas, Aristóteles faz uma distinção interessante ao considerar quatro relações de oposição de acordo com a linguagem, mas apenas três relações, de acordo com a verdade.

37 Essa interpretação é controversa. As interpretações standard que adotam essa interpretação: Corcoran 
suplementação para sua necessidade ser evidenciada ${ }^{38}$. De fato, Aristóteles não parece oferecer uma demonstração desses modos silogísticos ${ }^{39}$, assumidos como perfeitos. Entretanto, o mesmo não é feito com as demais regras de inferências, as quais são as regras de conversão. Ao contrário das regras estabelecidas pelos silogismos perfeitos, Aristóteles tenta apresentar, em $A P r$ I.2, as regras de conversão como inferências válidas, apresentando um argumento por ecthesis no primeiro caso e utilizando esses resultados para continuar com sua prova.

Seguem-se as regras de inferência:

\section{$\underline{\text { Silogismos perfeitos }}$}
(S1) Barbara:
$\mathrm{B} a \mathrm{~A}, \mathrm{C} a \mathrm{~B} \vdash \mathrm{C} a \mathrm{~A}^{40}$
(S2) Celarent:
$\mathrm{B} e \mathrm{~A}, \mathrm{C} a \mathrm{~B} \vdash \mathrm{C} e \mathrm{~A}$
(S3) Darii:
$\mathrm{B} a \mathrm{~A}, \mathrm{CiB} \vdash \mathrm{C} i \mathrm{~A}$
(S4) Ferio:
$\mathrm{B} e \mathrm{~A}, \mathrm{CiB} \vdash \mathrm{CoA}$

\section{$\underline{\text { Regras de conversão }}$}
(R1) Privativa Universal:
$\mathrm{A} e \mathrm{~B} F \mathrm{~B} e \mathrm{~A}$
(R2) Afirmativa universal:
$\mathrm{A} a \mathrm{~B} \vdash \mathrm{B} i \mathrm{~A}$
(R3) Afirmativa particular:
$\mathrm{A} i \mathrm{~B} \vdash \mathrm{B} i \mathrm{~A}$

Em geral, para argumentos ditos diretos, isto é, cuja validade pode ser verificada sem depender de um princípio lógico adicional, essas sete regras são tidas como suficientes. A silogística, no

[1972][1974]; Lear [1980], p. 5; Smith [1989], p. 110; Striker [2009], p. 82. Para uma interpretação alternativa e, ao nosso ver, mais adequada: Ferreira [2013], Angioni [2014].

38 Cf. $A \operatorname{Pr}$ I.1, 24b22-6.

39 Isso não quer dizer, no entanto, que Aristóteles os compreendera como axiomas, pois os demonstra por redução ao absurdo em $A \operatorname{Pr}$ I.

40 Utilizamos essa notação com intuito de indicar apenas o fato de haver uma inferência lógica. Não adotamos a notação que distingue consequência sintática de semântica e não pretendemos marcar com esse símbolo que se trataria de uma consequência sintática. 
entanto, apresenta dois modos particulares, os quais não podem ser demonstrados por um processo inferencial direto. Trata-se dos modos silogísticos Baroco, da segunda figura, e Bocardo, da terceira figura. A razão pela qual se justifica o fato desses modos não serem provados por raciocínio direto é muito simples: a privativa particular não é conversível e um argumento com duas premissas particulares tampouco é possível. Para provar um tal argumento, a sintaxe da silogística precisa prever uma nova regra de inferência, a saber, uma inferência indireta, cujo caso mais paradigmático é a redução ao impossível. A regra de redução ao absurdo, traduzida para uma linguagem proposicional, é a seguinte:

(RA) $\mathrm{P}, \mathrm{Q} \vdash \mathrm{R} ; \mathbb{l}^{*}(\mathrm{R}), \mathrm{P} \vdash \mathbb{l}^{(*)}(\mathrm{Q})$.

Em casos como Baroco, a prova silogística se daria da seguinte maneira:

$\underline{\text { Silogismo }} \quad \underline{\text { Etapa reductio }}$

1. $\mathrm{A} a \mathrm{~B} \quad \mathrm{~A} a \mathrm{~B} ; \quad$ repetição de 1.

2. $\quad \underline{\mathrm{CoB}} \quad \underline{\mathrm{C} a \mathrm{~A}} ; \quad$ contraditória de $\mathrm{c}$.

c. $\overline{\mathrm{CoA}} \quad \overline{\mathrm{CaB}} ; \quad$ contraditória de 2 .

Essa representação silogística da estratégia da redução ao absurdo para provar certos argumentos, pode ser reinterpretada de um modo mais familiar como cadeia de raciocínios:
1. $\mathrm{A} a \mathrm{~B}$
2. $\mathrm{CoB}$
3. $\quad$ i. $\mathrm{CaA}$
ii. $\mathrm{A} a \mathrm{~B}, \mathrm{C} a \mathrm{~A} F \mathrm{C} a \mathrm{~B}$
iii. $\mathrm{C} a \mathrm{~B}$
4. $\quad \mathrm{CoA}$
, premissa 1;
, premissa 2;
, hipótese de reductio;
, 1., 3.i., (S1);
, conclusão de 3.ii. (impossível, contraditória de 2.);
, contraditória da hipótese da reductio.

Deve-se frisar que na conclusão da reductio não há exigência daquela conclusão ser contraditória ao enunciado original. Basta que ocorra uma oposição, dentro das normas acima apresentadas, que o resultado final será possível. Um exemplo disso é dado através da demonstração por redução ao impossível dos modos Darapti e Felapton, os quais obtêm uma asserção contrária na 
conclusão da reductio:

$\underline{\text { Darapti }}$

1. $\mathrm{B} a \mathrm{~A}$

, premissa 1;

2. $\mathrm{B} a \mathrm{C}$

, premissa 2;

3. $\quad$ i. $\mathrm{CeA}$

ii. $\quad \mathrm{C} e \mathrm{~A}, \mathrm{~B} a \mathrm{C}-\mathrm{B} e \mathrm{~A}$

, hipótese de reductio;

iii. $\mathrm{B} e \mathrm{~A}$

, 1., 3.i., (S2);

4. $\quad \mathrm{CiA}$

, conclusão de 3.ii. (contrária de 1.);

, contraditória da hipótese de reductio.

O caso de Darapti ilustra bem o que se pretendia mostrar ao enunciar a regra da redução ao impossível $^{41}$.

Esse procedimento de prova, através da aplicação de (RA), só vale mediante a realização da pretensão de verdade dos enunciados predicativos. Sabe-se que argumentos válidos podem ser obtidos a partir de premissas falsas. Se esse fosse o caso da prova de modos como o Darapti, os quais resultam em contrariedade, mas não em contradição, a prova não procederia em função da própria definição de contrariedade, a qual dita que enunciados contrários não podem ser verdadeiros ao mesmo tempo, mas podem ser falsos. Ora, se a etapa da reductio prova uma falsidade, conforme Aristóteles pressupõe em $A P r$ I. $23^{42}$, e o conjunto original de premissas for falso, não se teria condições de atestar a validade do argumento, mediante tal estratégia ${ }^{43}$.

\subsection{A Definição Geral do Silogismo: considerações preliminares}

Aristóteles introduz sua Definição Geral do Silogismo $(D G S)$ após apresentar definições preliminares acerca daquilo que compõe um silogismo: as asserções. Uma vez que silogismos são

41 Daremos uma demonstração similar do modo Felapton no Apêndice A.

42 Cf. APr I.23, 41a21-3.

43 Como a predicação sustenta essa pretensão de verdade e esta, por sua vez, é fortemente emabasada em considerações metafísicas, poder-se-ia suspeitar que (RA) não seria apenas uma regra lógica, mas uma regra com dependência metafísica. Não entraremos no mérito dessa questão, pois uma discussão plena envolveria também a recusa dessa regra em contextos como aquele dado em $A P r$ II.15. 
compostos por asserções e essas são interpretadas de maneiras diferentes, pode-se inferir que a própria $D G S$ consta entre os trechos mais discutidos da obra

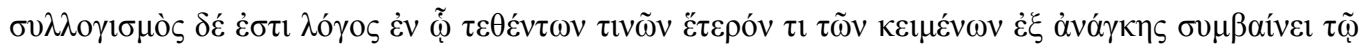

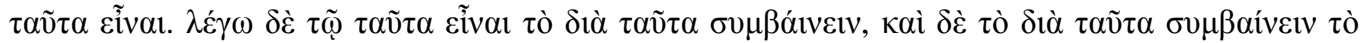

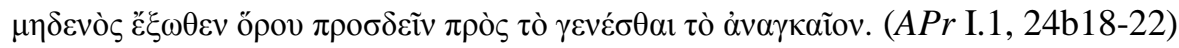

O silogismo é um argumento em que, [i] certas coisas tendo sido estabelecidas, algo distinto se segue por necessidade, [ii] em virtude de serem tais coisas. Digo por 'em virtude de serem tais coisas' ser por causa dessas mesmas coisas que a conclusão decorre, e 'por causa dessas mesmas coisas que a conclusão decorre' entendo não ser preciso adicionar outro termo para o necessário ser engendrado ${ }^{44}$.

A $D G S$ se destaca por sua surpreendente similaridade com intuições clássicas de validade e consequência lógica. A semelhança entre a $D G S$ e a noção de consequência lógica de um argumento é tamanha que certos pontos problemáticos na $D G S$, como a descrição daquilo que se segue por necessidade das premissas, poderiam ser adequadamente interpretados a partir de um projeto reducionista. Em outras palavras, essas expressões da $D G S$ seriam explicadas por modelos que seriam do domínio da lógica clássica ${ }^{45}$.

No caso da silogística, acredita-se que a $D G S$ seja tão semelhante a descrições de validade e de consequência lógica, que seu conteúdo pode ser explicado a partir de uma interpretação clássica dessas noções. Caso essa estratégia se mostre consistente e as provas lógicas sejam completas, então uma tal interpretação apresentaria uma definição desse conteúdo. Em particular, como a noção de consequência lógica é dada por uma expressão modal de necessidade, a qual difere dos usos previamente indicados, se espera, com o projeto reducionista, que essa expressão

44 Tradução nossa. Daqui em diante iremos nos referir à definição do silogismo como Definição Geral do Silogismo. Referiremos às partes da definição como Parte Inicial, a qual descreve a noção de consequência lógica, e Cláusula Final.

45 Um exemplo clássico desse projeto reducionista se nota na definição semântica da verdade, a qual é apresentada por um modelo de noções simples e iterativas, a partir das quais se poderia obter uma interpretação da noção original da verdade, para a qual não tinha um tratamento lógico. Vide Etchemendy [1990] 
possa ser definida logicamente.

Entrementes, aquilo que garante a semelhança com as noções supracitadas é a primeira parte da $D G S$, a qual apresenta uma descrição de uma conclusão seguindo-se precisamente de certas condições satisfeitas. Assim sendo, a presença de uma cláusula que destoa da definição clássica desses conceitos lógicos parece suscitar um problema. De fato, essa é a principal diferença da $D G S$ com as descrições de validade e de consequência lógica. Esse fato permite analisar a DGS como consistindo de duas partes: (i) a primeira parte da descrição consistindo de Condições Inferenciais e (ii) a Cláusula Final, o tōi tauta einai. Visto que as interpretações tradicionais assumem um certo modelo interpretativo para provarem que a $D G S$ apresenta uma descrição de validade e consequência lógica, se a Cláusula Final for um elemento comprovadamente distinto em $D G S$, então essa geraria um problema para o projeto reducionista. Por sua vez, sem o projeto reducionista, a interpretação tradicional não seria capaz de apresentar uma definição de validade e consequência silogística. Com isso, ela se veria forçada a considerar a Cláusula Final como um elemento redundante e eliminável. De fato, a Cláusula Final tende a ser negligenciada pela grande maioria dessas interpretações.

A interpretação tradicional depende desse enfraquecimento para compreender a silogística com as ferramentas lógicas disponíveis. Como foi mencionado antes, o principal ponto da contenda é a expressão modal de necessidade que é utilizada pela $D G S$ para identificar a relação de consequência lógica. Essa noção de necessidade, distinta da noção modal, dada por um operador ou uma característica predicativa, é vaga e gera problemas na tentativa de se definir apropriadamente o silogismo.

A estratégia de reduzir uma noção ou descrição a um modelo diferente revela, em geral, um projeto filosófico dos intérpretes da silogística aristotélica, no qual a importância dada à 
lógica é significativa ${ }^{46}$. A interpretação dada por esses projetos tenta identificar as características propriamente lógicas das quais Aristóteles teria se valido no estabelecimento de sua silogística. Essas leituras, portanto, podem ser identificadas por um deflacionismo lógico ou como projeto reducionista. Dada a importância de se isolar aspectos propriamente lógicos na interpretação da silogística, ocorreu um contínuo desprezo da Cláusula Final. De acordo com essa tendência de interpretação, essa Cláusula Final é interpretada apenas como marca de ênfase de um aspecto que já estaria presente na parte inicial. De certo modo, essas interpretações apontam para uma tendência que considera a Cláusula Final como um mero reforço, sob outra expressão, de modo redundante e eliminável, do mesmo conteúdo já expresso pelas Condições Inferenciais ${ }^{47}$.

Se essa interpretação for confirmada, qual seria o item da $D G S$ para o qual a Cláusula Final dá ênfase? É ponto passivo que aquilo que essa Cláusula Final não representa é a verdade das premissas $^{48}$, pois Aristóteles trabalha, em diversos capítulos, silogismos válidos com premissas falsas ( $A P r$ II.2-4). Além dessa delimitação negativa, tende-se a interpretar a Cláusula Final como requisito para explicitação de todas as etapas inferenciais que levam à determinada conclusão. Isso no entanto, enfrenta algumas dificuldades com a afirmação expressa de Aristóteles em APr I.32 que certas conclusões se seguem por necessidade, apesar de uma ou mais de uma premissa terem sido negligenciadas. Sendo assim, a Cláusula Final só teria um sentido privativo para marcar sua ênfase.

46 Como mencionamos antes, na nota $\mathrm{X}$, o projeto reducionista procura apresentar o mesmo conteúdo por uma outra forma, que seja mais simples logicamente. Para a filosofia da lógica, a redução de conceitos não-lógicos a modelos lógicos simples manifesta uma pretensão de demarcar o que é propriamente lógico em um sistema e, com isso, excluir todos os elementos que não são relevantes, logicamente.

47 Essa atitude se mostra em diversos momentos na literatura: Mignucci [1968] não destacou a Cláusula Final em sua tradução, omitindo qualquer comentário; Striker [2009] reafirma que essa Cláusula retoma a noção de argumentos válidos e destaca como a descrição paralela em Top I.1 é mais precisa de compreensível, sem se preocupar muito mais com a importância da Cláusula Final.

48 Cf. Striker [2009], p.81-2. 
Na contramão dessa atitude de interpretação, alguns estudiosos, como Robin Smith [2012], entendem que a Cláusula Final serve como espécie de restrição que poderia ocorrer em um de três modos: (a) argumentos em que a conclusão não é relevante para as premissas, isto é, que se segue de um conjunto inconsistente de premissas $^{49}$ (ex falso quodlibet); (b) argumentos que se seguem de quaisquer premissas (tautologias); e (c) argumentos com premissas supérfluas $^{50}$. Dessas três opções, a última seria, de acordo com Smith, a mais interessante em decorrência do comprometimento de Aristóteles com uma lógica relevantista. Essa possibilidade, levantada por Smith, difere, porém, das demais interpretações na medida em que a Cláusula Final não se apresenta, ela mesma, como superficial e eliminável da $D G S$.

A leitura na qual a Cláusula Final é assumida como critério de relevância das premissas encontra respaldo na própria $D G S$, em que a noção de necessidade, em 24b22, geralmente atrelada à noção de inferência lógica, exige que as premissas sejam determinantes para a conclusão ser obtida. Ora, essa mesma concepção de necessidade já seria dada nas Condições Inferenciais. Sendo assim, no entanto, surge a questão se um tal critério precisaria ser apresentado como uma condição adicional. Se a Cláusula Final acaba sendo equivalente à própria descrição de inferência silogística, aquela que "segue por necessidade", então não haveria diferença entre elas, levantando-se a possibilidade da mesma se confirmar como sendo supérflua e, por conseguinte, eliminável.

Em decorrência disso, a própria concepção da Cláusula Final como critério de relevância precisaria de ser cuidadosamente justificada. Das três razões apresentadas por Smith, pelas quais a Cláusula Final poderia ser considerada como critério de relevância, duas concepções - (b) e (c)

49 Aristóteles, em $A P r$ II.15, claramente não adota esse princípio. Não trabalharemos esse aspecto, porém, neste texto.

50 Cf. Smith [2012]. 
- podem ser obtidas com uma análise das Condições Inferenciais de DGS. Além da diferença dada pela expressão modal de necessidade que incide sobre a noção de consequência lógica, a $D G S$ apresenta outros pontos de divergência dos quais uma interpretação tradicional diferiria, a saber: a exigência da conclusão ser distinta das premissas das quais ela se segue; o número de premissas deve ser maior que uma premissa ${ }^{51}$.

Dessas características que Aristóteles aponta repetidamente ${ }^{52}$, a primeira é surpreendentemente poderosa. Trata-se da restrição a argumentos cuja conclusão é diferente de qualquer elemento dado no conjunto de premissas. Intuitivamente, a recusa de argumentos, cuja conclusão repete uma das premissas, faz sentido e está completamente de acordo com critérios de relevância. No caso de haver uma repetição qualquer na conclusão de um enunciado que é sua condição, qualquer outro enunciado passaria a ser uma informação irrelevante à inferência lógica. Intuitivamente, assumir um argumento como "P se conclui logicamente de P" não se apresenta como um argumento, por mais que seja evidente. Como esses exemplos podem constar como argumentos, no entanto, podemos afirmar que, de um ponto de vista lógico, uma tal exigência estabelece, de imediato, que considerações extensionais são insuficientes para satisfazer plenamente todas as condições inferenciais da silogística.

Já a segunda característica, embora na própria $D G S$ não pareça ter tanta importância, faz parte de um argumento de Aristóteles desenvolvido em $A P r$ I.23 em que ele atesta a importância da presença de um terceiro termo, a saber, aquilo que ficou conhecido na história da filosofia como termo médio. Como a silogística consiste de uma lógica de termos, a introdução de um terceiro elemento no cômputo do argumento não poderia ser feito a partir de uma só premissa,

51 Vide: $A \operatorname{Pr}$ I.23, 40b31-6.

52 Cf. Top I.1, 100a25-7; RS 1, 165a1-2 
por diversas razões: se o enunciado fosse o mesmo da premissa, não se trataria de um silogismo, muito embora o argumento fosse válido, em função de desrespeitar a DGS; se o enunciado fosse outro, não haveria silogismo, pois nenhuma relação poderia ser estabelecida entre os termos da conclusão $^{53}$. Sendo assim, o único modo de satisfazer as Condições Inferenciais, seria ter um argumento com mais de uma premissa sem que a conclusão repetisse uma delas.

Devemos apontar para o fato que o requisito da conclusão ser distinta de qualquer elemento do conjunto de premissas é, por si só, um requisito de relevância para as premissas. Além disso, esse requisito restringe argumentos válidos, uma vez que os argumentos que apresentam a repetição das asserções são recusados ${ }^{54}$. Um outro motivo para assumir esse critério como exigência de relevância se encontra na própria formalização dos argumentos que falham em cumprir esse critério. Uma grande parte dos argumentos válidos que falham nesse ponto é reconhecida por lógicas relevantistas como paradoxos de implicação material ou da implicação estrita $^{55}$

Sendo assim, se a distinção da conclusão com relação às premissas for aceita, as próprias Condições Inferenciais descritas em DGS serão restritivas da classe dos argumentos válidos, em geral. Partindo dessas considerações, a Cláusula Final não poderia ser considerada apenas como critério da restrição de argumentos, a não ser que seu escopo fosse precisamente determinado. Grosso modo, a fim de avaliar se a Cláusula Final é um critério adicional à $D G S$ ou apenas uma ênfase de sua primeira parte, é preciso determinar todos os limites das Condições Inferenciais de $D G S$.

53 Tentaremos desenvolver esses argumentos em nosso quarto capítulo.

54 Entre outros, esses argumentos podem ser os seguintes: $\mathrm{p} \vdash \mathrm{p} ; \mathrm{p}, \mathrm{q} \vdash \mathrm{p} ; \mathrm{p}, \mathrm{q} \vdash \mathrm{q} ; \neg \mathrm{p} \vdash \mathrm{p} \rightarrow \mathrm{q}$.

$55 \mathrm{Cf}$. nota anterior. Esses argumentos, por uma simples regra lógica, podem representar os seguintes enunciados lógicos: $(\mathrm{p} \rightarrow \mathrm{p}),(\mathrm{p} \rightarrow(\mathrm{q} \rightarrow \mathrm{p})),(\mathrm{p} \rightarrow(\mathrm{q} \rightarrow \mathrm{q})),(\neg \mathrm{p} \rightarrow(\mathrm{p} \rightarrow \mathrm{q}))$. 
Um dos maiores problemas é encontrar um critério pelo qual a Cláusula Final se destaca em $D G S$ como critério próprio e não como um ponto de repetição, o qual fosse, por isso mesmo, eliminável. A opção apresentada por Smith como sendo a mais interessante está na terceira possibilidade, a saber, que um silogismo não poderia conter premissas supérfluas. Esse ponto é interessante, pois pode ser respaldada com evidências em Top VIII.11. Entretanto, isso não lhe garantiria, ainda, o papel de ser um critério isolado dentro da própria DGS. Isso se deve, basicamente, à recusa de argumentos cuja conclusão é uma reiteração de uma de suas premissas. Qualquer argumento que tiver uma das premissas repetidas como conclusão do argumento, se for um argumento com mais de uma premissa, essa repetição tornará as demais premissas supérfluas, o que se rejeita com a Cláusula Final. Como o tipo de inferência sempre será de um enunciado para o mesmo, todos os demais casos, serão descartados por não participarem do argumento. Sendo assim, a Cláusula Final nada mais seria que uma justificativa para o critério presente na primeira parte de $D G S^{56}$.

Esse resultado, por outro lado, contrasta com a própria tentativa de Aristóteles de explicar a Cláusula Final em $A P r$ I.1, 24b20-2. Se Aristóteles exige que silogismos não podem ser formados por argumentos cuja conclusão é a mesma de uma das premissas, então a Cláusula Final não poderia explicar esse fato, uma vez que sua própria definição não seria satisfeita. Em

56 A evidência em Top VIII.11 permite, no entanto, uma defesa da interpretação de Smith. No argumento em que as Condições Inferenciais assumem o mesmo papel dado pela Cláusula Final, consideramos apenas casos em que a conclusão repete o conteúdo de uma premissa, deixando quaisquer outras premissas como irrelevantes. No caso em Top VIII.11 o contexto sugere que um argumento propriamente silogístico já tenha sido obtido, cumprindo todos os aspectos de um argumento relevante e silogístico. No entanto, esse não poderia ser considerado um silogismo, pois uma premissa supérflua está inserida em tal argumento.

Isso poderia sugerir um critério que seria próprio à Cláusula Final, fundando a interpretação de Smith, no entanto, não podemos considerar essa evidência como suficientemente boa para destacá-la. Isso se deve a diversos motivos: ela não é suficiente para explicar por que Aristóteles descreve a Cláusula Final como o faz em 24b20-2; ademais, embora o próprio exemplo em Top VIII.11 seja bem claro, o contexto em que essa ocorrência se encontra é de difícil interpretação, prejudicando a compreensão de seus limites e, por conseguinte, a possibilidade de a assumirmos como evidência para a interpretação de Smith. 
APr I.1, 24b22, Aristóteles afirma que para a Cláusula Final valer, nenhum item deveria ser adicionado para "aquilo que é necessário" ser engendrado. O referido item é muitas vezes considerado como se tratando de um termo, de uma premissa ou de um passo inferencial em um argumento. Ora, se argumentos com premissas repetidas, aos quais nada mais precisaria ser adicionado para considerar sua validade lógica, são recusados, então seria preciso alterar as premissas, a fim de se obter um argumento silogístico.

Aparentemente, apesar da tentativa de destacar a Cláusula Final como um ponto relevante à $D G S$, esse destaque não é fundado pela própria descrição que poderia defini-la bem. Disso se segue que a própria $D G S$ não apresenta elementos suficientes para dar sentido à Cláusula Final, sendo preciso buscar evidências para além da $D G S$. O problema que a Cláusula Final enfrenta no próprio contexto da $D G S$ é a vagueza com que ela é descrita e a possível introdução de novos conceitos igualmente obscuros. Um desses conceitos se liga à noção de causalidade, em que a Cláusula Final deve equivaler à descrição do fato das premissas serem causa, seja qual for o sentido, da conclusão ${ }^{57}$. Ora, embora essa noção pareça bastante comum, mesmo que seja apenas de modo intuitivo, em vez de explicar o papel da Cláusula Final em $D G S$, ela prejudica sua interpretação.

A partir desse contexto, formulamos a nossa primeira - e principal - meta que pretendemos cumprir neste trabalho, a saber: uma compreensão da Cláusula Final do silogismo. Essa cláusula, embora passe por duas tentativas de esclarecimento, não elucida satisfatoriamente a instrução que ela impõe e, por conseguinte, como essa deve ser compreendida no contexto da silogística. Um outro problema a que devemos prestar atenção é a própria $D G S$. Ocorrências

57 Outras descrições em que as premissas são tomadas como causa da conclusão: Fis II.3; APo II.11; Top ; Met $\Delta .2$, $1013 \mathrm{~b} 20$; 
anteriores da DGS não adotam a mesma cláusula, presente em 24b20, mas partem para uma outra descrição ${ }^{58}$, onde o correspondente à Cláusula Final passa a ser "através dos itens dados" (dia tōn keimenōn). Essa mudança permite que se estabeleça a questão se a $D G S$ em $A P r$ I equivale à descrição das demais passagens. Brunschwig, por exemplo, em seus comentários à diferença das duas cláusulas no contexto dos Tópicos, adota certa cautela ao compará-las, abrindo a possibilidade que essas cláusulas se diferenciem em termos de sua abrangência. Grosso modo, sua diferença seria dada pela seguinte descrição: a definição em Top I.1, supostamente por envolver critérios não-lógicos, deveria apresentar condições de argumentos não-lógicos serem considerados como argumento em um debate; por sua vez, a definição em $A \operatorname{Pr}$ I.1 não teria essa preocupação e poderia se restringir apenas a argumentos lógicos. Não há evidências textuais suficientes para decidir se ambas as descrições tenham os mesmos resultados em vista ou se são efetivamente diferentes.

Tudo que se pode afirmar é que, embora a descrição da Cláusula Final em APr I.1, 24b202, apresente alguns avanços, ela não é satisfatória para decidir se a Cláusula Final é redundante e, por conseguinte, eliminável. Para decidir esse ponto, é preciso investigar outras passagens que se remetam diretamente à Cláusula Final, a começar por $A P r$ I.4, 26a2-6, onde Aristóteles retoma a Cláusula Final. Nesse contexto, o descumprimento da Cláusula Final é apresentado como justificativa para um determinado conjunto de premissas não obter uma conclusão silogística.

Cremos que uma análise detida dessa passagem, em comparação a outras similares, possibilita aproximar a compreensão da Cláusula Final ao que foi pretendido em sua descrição na $D G S$. Em consequência dessa análise, acreditamos na possibilidade de justificar, também, a presença de modos silogísticos extensionalmente equivalentes, mas que foram distinguidos entre 58 Cf. Top I.1, 100a25-7; RS 165b20; APr I.4, $26 \mathrm{a} 8$. 
si por causa da Cláusula Final. Esse tipo de investigação pretendemos levar a cabo no capítulo terceiro deste trabalho.

\subsection{A(s) semântica(s) do sistema silogístico e a prova de completude}

Sistemas semânticos são estabelecidos, tendo em vista um tratamento lógico e precisamente determinado de noções que, a princípio, não pertencem à lógica. Conceitos como validade lógica e, decorrente dessa, de consequência lógica são obtidos através de uma análise de um sistema semântico e sua adequação à sintaxe. Essa adequação costuma ser dada em termos de uma prova de completude a qual, grosso modo, prova a correlação entre semântica e sintaxe $\mathrm{e}^{59}$.

No caso da interpretação da silogística aristotélica, a interpretação predominante é feita em termos de análises semânticas e se deve, sobretudo aos trabalhos de Smiley e Corcoran, os quais defendiam a interpretação dos silogismos como argumentos lógicos e não enunciados condicionais universalizados. As motivações para essa defesa, contra as críticas prévias de lógicos como Łukasiewicz combinam justificativas de cunho filosófico, bem como motivos lógicos. A principal pretensão desse tipo de investigação é retratar a silogística como lógica subjacente às outras ciências. Essa teria sido a motivação do próprio Aristóteles ao enunciar que o estudo da silogística serviria para se chegar no estudo de provas científicas (apodeixeis) e do conhecimento científico (epistēmē apodeiktikē). Outra motivação, de um ponto de vista lógico, era apresentar a silogística como um sistema de inferências simples e intuitivas, similar à dedução natural, ao invés de depender de uma teoria sintaticamente sofisticada, como era a teoria de Łukasiewicz-Patzig.

A interpretação da silogística como sistema lógico requer a definição de uma semântica,

59 Cf. Lear [1980], Dummett [1981] 
além da linguagem e das regras de inferências, para que certas noções podem ser definidas nessas análises. Como mencionamos antes, entre os conceitos que dependem de um tal sistema constam noções como validade lógica e consequência lógica, a qual depende da noção anterior. Um sistema semântico, em geral, apresenta essas noções mediante funções de verdade, as quais estabelecem certas condições de verificação da linguagem. É através dessas funções que a verdade pode ser atribuída a tais enunciados.

A interpretação de Corcoran-Smiley apresenta um sistema semântico embasado na teoria de conjuntos. A interpretação da linguagem é dada em termos de operações sobre conjuntos, os quais representam as constantes não-lógicas da linguagem. A partir dessas operações sobre os conjuntos podemos relacioná-los como critério de satisfação para as funções de verdade $(V)$ da linguagem silogística:

\begin{tabular}{|c|c|c|c|}
\hline \multirow[t]{2}{*}{1.} & $V(\mathrm{~A} a \mathrm{~B})=$ & 1 & se A $\square \mathrm{B}$, \\
\hline & $V(\mathrm{~A} a \mathrm{~B})=$ & 0 & se A $\square \mathrm{B}$. \\
\hline \multirow[t]{2}{*}{2.} & $V(\mathrm{~A} e \mathrm{~B})=$ & 1 & $\operatorname{se} A \cap B=\varnothing$ \\
\hline & $V(\mathrm{~A} e \mathrm{~B})=$ & 0 & $\operatorname{se} A \cap B \neq \varnothing$ \\
\hline \multirow[t]{2}{*}{3.} & $V(\mathrm{~A} i \mathrm{~B})=$ & 1 & se $A \cap B \neq \varnothing$ \\
\hline & $V(\mathrm{~A} i \mathrm{~B})=$ & 0 & se $A \cap B=\varnothing$. \\
\hline \multirow[t]{2}{*}{4.} & $V(\mathrm{~A} o \mathrm{~B})=$ & 1 & se $\mathrm{A} \square \mathrm{B}$, \\
\hline & $V(\mathrm{~A} o \mathrm{~B})=$ & 0 & se A $\square$ B. \\
\hline
\end{tabular}

A interpretação de Corcoran e Smiley representou um avanço significativo nos estudos da silogística em virtude de terem alcançado um estudo rigoroso da silogística, representando-a como um sistema de dedução natural, onde cada silogismo seria um esquema inferencial e não 
um enunciado lógico.

A semântica de Corcoran-Smiley não é o único sistema semântico proposto, havendo uma variedade significativa de sistemas que procuram revelar certas características da silogística. Cada sistema semântico apresenta critérios de satisfação para as funções de verdade, utilizandose de sistemas algébricos60, semântica de modelos61 ou as semânticas do dictum de omni et de nullo62. Não temos, porém, a pretensão de fazer um estudo dos diversos sistemas. Nosso interesse, por ora, se concentra no fato de que cada um desses sistemas procede do mesmo modo que a semântica de Corcoran-Smiley ao estabelecer condições para averiguação dos valores de verdade, através de funções de verdade.

Como uma interpretação semântica de um sistema lógico introduz certas noções antes ausentes, cumpre ao proponente de tais sistemas determinar qual a relação entre a sintaxe e a semântica que deve interpretá-la. Eis que surgem as provas de completude dos sistemas silogísticos, fortemente inspirados na afirmação aristotélica em $A P r$ I.23 de que todos os argumentos, em geral, poderiam ser retratados à maneira silogística.

Problemas com a alegação da prova de completude: Vimos acima que a principal referência textual a que se atribui o meta-teorema da completude da silogística é $A \operatorname{Pr}$ I.23, onde Aristóteles alega que, "em geral, todo syllogismos pode ser reduzido a uma das três figuras" (APr I.23, 40b20-2). Tradicionalmente, essa asserção é interpretada como uma pretensão entusiasmada de que, em geral, toda sorte de inferências lógicas poderia ser traduzida para a silogística ${ }^{63}$. Esse

60 Cf. Martin [2004]

61 Cf. Andrade-Lotero [2007]

62 Cf. Malink [2013], Ferreira [2012]

63 Cf. Striker [2009], p.170. 
projeto aristotélico mostraria uma preocupação clara com problemas da meta-lógica, muito embora tenha fracassado, como o próprio Aristóteles pareceria admitir em $A P r$ I.45. Entretanto, essa tentativa de introduzir à silogística uma interpretação como completude lógica enfrenta algumas dificuldades.

A partir de $D G S$, como se viu, essa alegação não poderia valer para todas as inferências lógicas válidas, em geral: todos os casos em que há a repetição de uma das premissas na conclusão, o argumento não poderia ser considerado silogístico e falharia no teste proposto pelas Condições Inferenciais da $D G S$. Ademais, se a pretensão for, efetivamente, demonstrar que qualquer argumento pode ser interpretado como um silogismo, então a própria prova da completude, dada inicialmente por Corcoran [1972] e seguida por numerosas propostas distintas, não satisfaria a alegação apresentada em $A P r$ I.23, uma vez que esse tipo de prova já fora promovida anteriormente em $A \operatorname{Pr}$ I.7.

Esse cenário representa um problema exegético para o conjunto de $\operatorname{APr} \mathrm{I}$, a saber, uma separação da obra em diversas partes, sendo que apenas a primeira parte, englobando os capítulos I.1-22 $2^{64}$, poderia ser interpretada como um tratamento propriamente lógico. Esse resultado já tinha sido mencionado em Striker [1997], onde ela defende uma distinção radical entre essas partes da obra e as preocupações que Aristóteles manifestava nelas. De acordo com Striker [1997], de $A P r$ I.23 em diante, muito embora o tema central ainda fosse o silogismo, o foco de atenção da análise aristotélica mudaria de escopo, passando a se preocupar com uma teoria geral de argumentação. Isso se colocaria em claro conflito com a parte referente ao conjunto de capítulos $A \operatorname{Pr}$ I.1-22, onde Aristóteles teria uma nítida preocupação lógica.

64 Para os objetivos desta dissertação, não abordaremos a parte dita modal da silogística, salvo raras exceções em que nos beneficiamos de distinções e exemplos interessantes, presentes nos capítulos I.3,8-22. 
Esse descompasso gerado entre as duas partes levanta a questão de qual seria o item, se houver, entre essas partes, que funciona como fio condutor que estabelece uma coesão para toda obra. Com a interpretação de Striker, o próprio silogismo seria insuficiente para essa tarefa, exigindo que outro item, eventualmente, pudesse assumir esse papel. Interpretações anteriores, sob a alegação de avaliarem o projeto de prova da completude da silogística, mesmo que problemática, tentavam estabelecer uma relação em que a primeira parte de $A \operatorname{Pr}$ I fosse tida como uma análise sintática e a segunda parte, como análise semântica da lógica aristotélica. Mas se essa interpretação se mostra pouco satisfatória, seria o caso de abandonar a interpretação de $A \operatorname{Pr}$ I como um projeto coeso? Esse ponto se configura como nossa segunda meta para este trabalho.

Nesta dissertação, procuramos estabelecer através da análise da Cláusula Final de $D G S$ condições que tornem uma tal leitura de $A \operatorname{Pr}$ I possível. Nosso objetivo é argumentar que algumas condições introduzidas pela Cláusula Final como critério de constituição da silogística são trabalhados com mais detalhes nos capítulos centrais, sobretudo $A \operatorname{Pr}$ I.23, 25, 27-8. Se nossa leitura estiver correta, o projeto filosófico de Aristóteles para a análise da silogística poderia ser entendido como uma investigação coesa, focando-se, em particular, sobre a definição da Cláusula Final e de características próprias à silogística, requisitadas pela mesma.

\subsection{Plano Geral da Dissertação}

Nessa introdução tivemos a pretensão de apresentar dois problemas que nos são de interesse: (I) a definição da Cláusula Final da Definição Geral do Silogismo e (II) uma investigação a respeito da coesão entre duas partes do primeiro livro de APr. Como apontamos acima, o ponto (II) depende fortemente da interpretação das condições dadas pela Definição Geral do Silogismo e, em particular, pela Cláusula Final. Como tentamos mostrar, uma tal 
interpretação da Cláusula Final não pode ser feita a partir da sua ocorrência em $D G S$, sendo preciso buscar outras evidências. Sendo essa a nossa meta para este trabalho, temos por objetivo proceder com uma análise de uma ocorrência da Cláusula Final, em APr I.4, 26a4-5. Neste contexto, Aristóteles apresenta um par de premissas que é inconclusivo e justifica esse fato com a Cláusula Final. No entanto, percebemos que isso só pode ser o caso se e somente se a ordem dos termos estiver determinada, pois em $A \operatorname{Pr}$ I.7, Aristóteles confirma que o mesmo par pode obter uma conclusão válida, embora essa não seja silogística.

A partir dessa observação, nos colocamos as questões de qual seria a importância de uma sequência de termos para a silogística e qual seria a relação que essa ordem teria com a própria Cláusula Final. Se a sequência dos termos é suficiente para determinar se um argumento válido é silogístico ou não, ela deveria ser justificada logicamente. Para testar essa hipótese, procuramos avaliar as consequências dela com casos de silogismos reconhecidos, os quais são extensionalmente equivalentes, como é o caso de Cesare, Camestres, da segunda figura silogística, e Datisi e Disamis, da terceira figura. Notamos que uma mera análise extensional como pretendida pela semântica de Corcoran-Smiley não é suficiente para justificar a distinção desses argumentos em duas formas silogísticas distintas.

Tentaremos justificar a distinção assumida por Aristóteles como consequência irrevogável da determinação prévia da sequência em que os termos devem aparecer na conclusão, de acordo com a Cláusula Final. Também tentamos mostrar que a Cláusula Final não só exige uma distinção entre argumentos extensionalmente equivalentes, como também impede, por definição, que esses sejam assumidos como um único. Acreditamos mostrar, com essas análises, que a Cláusula Final seja consistente para com os argumentos silogísticos. De fato, esse tipo de restrição que a Cláusula Final impõe, distinguindo argumentos válidos em silogísticos e não-silogísticos, indica 
que a Definição Geral do Silogismo, ao contrário do que a tradição costuma assumir, se restringe a argumentos silogísticos e não serve, portanto, para uma classe mais ampla de argumentos válidos.

Esses resultados têm severas consequências, a saber: (1) o próprio projeto deflacionista de reduzir as Condições Inferenciais a uma descrição mais simples e cognoscível falha em seu objetivo, em função de não serem equivalentes; (2) em consequência de (1), a noção precisa daquilo que é "se seguir por necessidade", a qual pretendia ser precisamente definida por esse projeto deflacionista, falha e torna uma interpretação das noções de validade e consequência silogística impróprias. Esses resultados negativos se seguem, como procuramos mostrar, da negligência constante da Cláusula Final. Pretendemos realizar essa análise no terceiro capítulo de nossa dissertação.

Os resultados obtidos de nossa análise da Cláusula Final, por mais que sejam embasados por nossa análise, levantam o seguinte problema: afinal, qual é o elemento que permite a Aristóteles assumir tanto, através da Cláusula Final? Não se pode tratar apenas dos termos, por mais que possam corroborar para uma tal interpretação ${ }^{65}$, pois eles não poderiam determinar por si só a sequência em que irão aparecer. A partir dessa observação, consideramos que tal resultado só pode ser obtido a partir de certas condições: a presença de um termo comum cuja relação precisa com cada um dos termos determinará o resultado pretendido. Ao contrário do que afirmam as interpretações tradicionais, o papel desempenhado por essa função de mediação é relevante não só para a obtenção do resultado, mas para sua justificativa e adequação lógica ${ }^{66}$.

Uma tal análise está, notadamente, ausente no conjunto dos primeiros capítulos de $A \operatorname{Pr}$ I.

65 Vide as interpretações de Malink [2013] e Ferreira [2012], os quais defendem uma semântica com base nas relações distinguidas em Tópicos.

66 Essa noção de adequação se converterá, posteriormente, em adequação explanatória. 
Mas começa a ganhar evidência em capítulos da segunda parte dessa obra, particularmente, em APr I.23; o capítulo a que se atribuiu a tese da completude silogística. Junto com os capítulos I.27-28, podemos analisar com mais precisão as pretensões de Aristóteles com relação à Cláusula Final, a partir de uma análise da função de mediação. Justificamos essa nossa análise com base no procedimento adotado por Aristóteles para defender a presença do mediador em todas as estratégias de prova concebíveis, tal como entendemos a suposta prova da completude.

Este argumento não se caracteriza como um argumento lógico, se for tomado como a tradição o entende, a saber, que "todos os argumentos, em geral, poderão ser demonstrados como silogísticos". Se isso valesse, estratégias de redução ao absurdo e argumentos hipotéticos ou seriam um subconjunto dos silogismos, ou haveria uma espécie de indução a partir dos silogismos para as demais formas de prova. A própria prova, no entanto, se liga aos requisitos da Definição Geral do Silogismo, refutando ponto a ponto todas as possíveis formas de conceber um argumento sem a função de mediação e mostrando que cada um desses pontos remete a uma parte da própria $D G S$.

Se todos esses objetivos forem realizados, teremos atingido a nossa segunda meta, a saber, de mostrar que o primeiro livro dos Primeiros Analíticos consiste em um tratado coeso e unitário da silogística, sem se distinguir em tratados de lógica ou de argumentação geral. Com isso, essa será a última análise nossa a ser apresentada neste texto, no capítulo 4. Passemos, então, a considerar a origem desse problema no próximo capítulo, tratando do desenvolvimento das interpretações e suas consequências. 


\section{Interpretações lógicas da silogística. A origem de um problema}

O problema de uma definição satisfatória para a Cláusula Final não se restringe apenas à Definição Geral do Silogismos $(D G S)$, como havíamos retratado anteriormente. Ela pode ter desdobramentos significativos para as demais partes da obra. No caso das interpretações de $A P r$ I, isso não poderia ser mais verdadeiro. Cada uma das diversas interpretações que foram apresentadas para um estudo da silogística teve as mais diversas consequências em diversos aspectos teóricos e a respeito da interpretação da própria obra. Um caso desses está ligado ao problema que pretendemos tratar neste capítulo: o debate entre duas tradições de interpretação lógica da silogística aristotélica. Ainda nos é lícito tratar os principais desenvolvimentos na investigação da silogística aristotélica sob o prisma de duas interpretações: a tradição de interpretá-la como uma (i) teoria lógica e a tradição de compreendê-la como (ii) sistema lógico.

Os embates entre os defensores de cada linhagem eram condicionados por diversos interesses, entre os quais constam a preocupação em apresentar qual seria o correspondente lógico mais próximo ao que Aristóteles denomina de silogismo. Para as interpretações da silogística como teoria lógica, a principal preocupação que essa investigação manifesta é com a construção lógica dos silogismos. Embora a meta, em última análise, era fundar silogisticamente argumentos lógicos, nem sempre a própria silogística precisaria assumir as propriedades argumentativas. De modo geral, o que une essas interpretações é um forte comprometimento da lógica com critérios puramente sintáticos, evitando-se quaisquer considerações semânticas.

Por sua vez os proponentes da interpretação da silogística como um sistema lógico tinham

como objetivo apresentar os silogismos como argumentos lógicos e não como fórmulas 
correspondentes a argumentos. Essa visão, embora seja uma das mais antigas, só conseguiu se impor como interpretação dominante com os avanços lógicos, sobretudo no campo de sistemas semânticos. Não é de se estranhar, portanto, que essa tendência interpretativa atribua à silogística uma distinção entre considerações lógicas sintáticas e semânticas. Embora essa interpretação consiga reduzir o número de etapas inferenciais para apresentar suas provas, ela se vê forçada a introduzir na silogística um estudo que relaciona aspectos semânticos à linguagem da silogística.

Mas quais seriam as consequências dessa distinção? Parte desse conteúdo já vimos no capítulo anterior. O problema que pretendemos delinear neste capítulo é consequência do constante embate entre as interpretações da silogística como teoria lógica ou como sistema lógico. Em particular, as divergências quanto à análise do meta-teorema da completude, atribuído a Aristóteles em virtude de seu comentário em $A P r$ I.23, culminou no ponto em que houve uma ruptura da obra entre Capítulos de Apresentação Geral $(C A G)$, os quais abrangem todos os capítulos iniciais da obra, de $A P r$ I.1a I.22, e Capítulos de Apresentação Específica (CAE), os quais são constituídos pelos demais capítulos da obra, $A P r$ I.23 a I.46 ${ }^{67}$.

De acordo com essa consequência, $C A G$ consistiria do tratamento propriamente lógico da silogística, enquanto $C A E$ diz respeito a um tratamento totalmente distinto, como teoria geral da argumentação. Como pretendemos mostrar, essa limitação interpretativa de $A P r$ I é fruto das diversas compreensões que se teve de $D G S$, todos as quais tinham em comum a negligência da Cláusula Final. Negligenciar um ponto tão importante para a própria interpretação daquilo que deveria ser compreendido como um silogismo, além de problemas para a própria compreensão da

67

Esse resultado foi obtido por Striker [1997], a qual teve como objetivo mostrar, em nossa opinião, corretamente, que Aristóteles não poderia ser interpretado como um lógico, no atual sentido da palavra. 
definição, traz consequências para os demais campos que se ligam diretamente à silogística. No caso de $A \operatorname{Pr} \mathrm{I}$, um resultado extremo foi a desconexão que se gerou entre as diversas partes que constituem toda a obra de $A P r$ I.

As interpretações lógicas da silogística, embora negligenciassem a definição da Cláusula Final, consideravam que havia uma unidade entre $C A G$ e $C A E$, a qual poderia ser representada em termos lógicos. No entanto, as dificuldades de se gerar algum consenso a respeito dos capítulos de $C A E$ possibilitou que uma interpretação como a de Striker enunciasse claramente a distinção radical entre esses capítulos, abrindo com isso um problema exegético. Esse problema exegético pode ser, em decorrência disso, formulado como a seguinte questão: qual seria a relação entre $C A G$ e $C A E$ ? Essas partes teriam um tratamento único e seriam coesas ou se trataria, antes, de dois temas radicalmente distintos, a saber, uma abordagem lógica da silogística que se concentra em $C A G$ e uma abordagem da silogística como teoria de argumentação geral, presente em CAE?

O problema da falta de coesão entre $C A G$ e $C A E$ é oriunda de uma antiga discussão filosófica, cuja preocupação se foca sobre como a própria filosofia deveria tratar assuntos lógicos. Nessa discussão, propõe-se, por um lado, que a lógica seja vista como ferramenta da filosofia, por outro lado, que ela seja objeto de escrutínio filosófico. Como foi apontado, de forma resumida, esse embate filosófico chegou aos nossos dias como distinção entre teoria lógica e sistema lógico. Mostraremos, a seguir, em que consistem essas compreensões da silogística e como elas se diferem entre si. Cumprida essa etapa, pretendemos apontar como esse embate resultou na desconexão radical entre as partes de $A \operatorname{Pr}$ I, focando no artigo de Striker [1997] que colhe esses resultados negativos. Nosso objetivo para esse capítulo é reconstituir as características gerais dos principais tratamentos dispensados à silogística, observando que esses tratamentos 
descaracterizavam a própria definição de silogismo ao negligenciarem a Cláusula Final.

Nossa expectativa, com essa reconstituição, é facultar, mais a frente, no capítulo quarto, à Cláusula Final o papel de fio condutor entre $C A G$ e $C A E$. Com isso teremos satisfeito a segunda meta desta dissertação, a saber: apresentar o texto do primeiro livro de $A P r$ como tratamento coeso e unitário da própria silogística. Entendemos que a vantagem de se tratar a análise da silogística desse modo está na fundação de demonstrações científicas e não meramente lógicas.

\subsection{A silogística como teoria lógica e como sistema lógico}

Desde a antiguidade, a lógica era observada através do prisma de duas concepções filosóficas distintas ${ }^{68}$ : sua concepção como objeto de escrutínio filosófico ou como ferramenta potente para auxiliar nas investigações filosóficas. Mas qual dessas duas maneiras de compreender a lógica seria a mais apropriada? Essa preocupação tem seus reflexos nas investigações lógicas atuais, as quais costumam ser denominadas de teoria lógica e sistema lógico, respectivamente. Resumidamente, a formulação de uma teoria lógica guarda o objetivo filosófico de se compreender como um tipo de investigação cujo objeto de estudo é a própria lógica. Uma teoria lógica se caracteriza, em geral, por um grau elevado de sofisticação sintática, procedendo por um número mínimo de regras de inferências e provando diversos teoremas lógicos com base em certas tautologias, as quais podem ser reconhecidas como axiomas ou, em geral, fórmulas recursivas.

Por sua vez, a compreensão de que a lógica serviria como ferramenta para as investigações da filosofia, cujo objeto de estudo não é a própria lógica, se caracteriza como

68 Cf. Alexandre [1883], que introduz o estudo à silogística a partir dessa discussão se a lógica seria "parte ou ferramenta" da filosofia. 
interpretação predominante da silogística, nos dias de hoje. Um sistema lógico se caracteriza não mais por fórmulas cujo valor lógico é demonstrado por si mesmo, mas por outros fatores. Ao contrário da interpretação da silogística como teoria lógica, um sistema lógico deve dar conta de conceitos não-lógicos que nele serão introduzidos. Essa introdução é natural, visto que a concepção da lógica como ferramenta para as demais ciências requer que conceitos próprios a essas ciências sejam operados pela lógica. Não apenas isso, mas a própria lógica deve ser capaz de computar conceitos como verdade de modo rigoroso. Com o estabelecimento dessa exigência, sistemas lógicos têm de formar um composto de dois sistemas distintos, a saber: uma linguagem, dotada de certas regras de inferências, o que estabelece uma sintaxe, e um sistema que visa dotar essa sintaxe de uma interpretação, reconhecida como semântica. Como mencionamos acima, a distinção das considerações lógicas em dois aspectos distintos faz com que a lógica não mais seja o objeto de estudo dessa investigação, mas a relação entre a linguagem e suas interpretações.

Pelo lado das interpretações da silogística como uma teoria lógica, os maiores destaques se devem a lógicos como Łukasiewicz, Patzig, os quais entendiam o silogismo como proposição condicional universalizada, embasada em alguns axiomas, e Lear, o qual tentou defender essa interpretação não com base em uma axiomática, mas o fez considerando os ditos silogismos perfeitos como funções recursivas indemonstráveis. Por sua vez, as interpretações que defendem que a silogística seria antes um sistema lógico enfatizam que essa interpretação permite compreender o silogismo efetivamente como um argumento, fundado em diversas etapas inferenciais.

A seguir, iremos apresentar, em linhas gerais, algumas das principais interpretações da silogística e como elas culminaram na distinção entre $C A G$ e $C A E$. Introduziremos, primeiro, as interpretações da silogística como teoria lógica e, em seguida, trataremos das interpretações da 
silogística como sistema lógico. Por fim, apresentaremos a origem do problema que consiste como segunda meta para o presente trabalho, a saber: se há um item que ligue ambas as partes de $A P r$ I e se esse item corresponde à Cláusula Final.

\section{A silogística como teoria lógica}

Para interpretar-se a silogística como teoria lógica, surgiram duas posições que merecem destaque na história da lógica: a teoria de Łukasiewicz-Patzig e a teoria de Lear. Como foi indicado acima, a grande motivação filosófica de se interpretar a lógica como uma teoria lógica é que ela se torne um objeto de estudo da própria filosofia ao invés de ser considerada apenas como ferramenta dela. Esse objetivo se mostra com muita clareza nas primeiras interpretações da silogística que se beneficiaram dos avanços lógicos ${ }^{69}$. Para os estudiosos que mantinham essa posição, com exceção de Lear $^{70}$, a silogística não poderia consistir de argumentos, uma vez que se vislumbrava a própria silogística como estudo que fundasse os argumentos.

A relação intuitiva que estabelecemos entre um argumento e a teoria que deve analisá-lo é curiosa e remete às noções mais primitivas daquilo que retrata a validade lógica de um argumento. Para uma teoria lógica, um argumento se diz válido se e somente se ele é passível de

69 Os avanços lógicos aos quais nos referimos são, fundamentalmente, as investigações lógicas fortemente influenciadas pelo rigor da matemática, cujo objeto principal, inclusive, passou a ser a própria matemática, tentando explicar seus fundamentos, com uma base lógica rigorosa.

Não pretendemos dizer com essa nossa afirmação que antes desses avanços, não houve uma interpretação lógica da silogística. Pelo contrário, muitas investigações da silogística se preocupavam em apresentar uma interpretação rigorosa dos $A P r$ I. Entretanto, a principal diferença entre essas estudos e as interpretações feitas após as investigações de Łukasiewicz era na ferramenta utilizada. Enquanto as interpretações anteriores insistiam em dar uma interpretação da silogística, através da lógica chamada tradicional, isto é, uma lógica de termofunctores, a inovação introduzida por Łukasiewicz era o uso dos métodos desenvolvidos mais recentemente. Cf. Łukasiewicz [1957]; Patzig [1968]; Boger [1998].

70 Como iremos apresentar mais adiante, Lear não precisa adotar uma interpretação axiomatizada dos silogismos, como faz a interpretação de Łukasiewicz-Patzig. Ele assume, a partir da descrição daquilo que "segue por necessidade", que os modos silogísticos ditos perfeitos são análogos a funções recursivas, a partir das quais todos os demais argumentos poderão ser obtidos. 
representação por uma tautologia ${ }^{71}$. Grosso modo, um argumento é válido se ele equivale a uma verdade lógica e inválido se o mesmo não ocorrer. Um enunciado lógico se torna uma verdade lógica quando, sob qualquer hipótese, não for possível dar um contra-exemplo. Isto é, esse tipo de enunciado exaure as possibilidades de valoração, sendo sempre verdadeiro.

De um ponto de vista técnico, a vantagem de se operar com tais intuições é a independência de outro sistema capaz de introduzir noções não-lógicas no cálculo lógico, tais como a própria noção de verdade. Historicamente, como no início do desenvolvimento da lógica clássica, havia muita desconfiança em métodos semânticos para verificar noções não-lógicas como verdade, preferia-se fundar a própria investigação sobre procedimentos que poderiam ser justificados rigorosamente, sem depender dessas interpretações. Para esses intérpretes, a única maneira de interpretar um argumento com base em uma noção de verdade é se não houver dependência de se definir a noção de verdade ${ }^{72}$. Sendo assim, todos os argumentos válidos, os quais nós reconheceríamos como sendo silogísticos, são tratados como fórmulas tautológicas que os representem e a partir dos quais esses argumentos podem ser avaliados em sua correção.

Ainda dentro desse panorama, um argumento que reconhecemos como silogístico, por exemplo:

$$
\text { Q é R }
$$

71 Cf. Mates [1972], pp.7ss.

Vale ressaltar que para a interpretação de Łukasiewicz não era o caso da silogística não ter qualquer relação com argumentos válidos. De fato, ela deveria representá-los, avaliando-os com base em axiomas. Łukasiewicz chega a mencionar que Aristóteles estabelece uma teoria de dedução. Cf. Łukasiewicz [1957], pp. 79ss.

72 A noção de verdade, uma vez que não é um conceito da lógica requer uma definição de modo que pudesse ser operada logicamente. O primeiro desenvolvimento nessa direção foi dado, efetivamente, com Tarski e seus trabalhos sobre a noção de verdade. Tarski é considerado o fundador da teoria de modelos, mediante os quais ele tentou aplicar uma análise rigorosa do conceito de verdade. Antes de Tarski, porém, a única maneira de operar com a noção de verdade era através daquilo que ficou conhecido como verdade lógica. Uma verdade lógica é um enunciado que representa uma tautologia, tal como $\mathrm{p} \rightarrow \mathrm{p}, \mathrm{p} \rightarrow(\mathrm{q} \rightarrow \mathrm{p}),((\mathrm{p} \rightarrow \mathrm{q}) \&(\mathrm{q} \rightarrow \mathrm{r})) \rightarrow(\mathrm{p} \rightarrow \mathrm{r})$ etc. Essas verdades são chamadas de lógicas, pois independente da interpretações que se dê a seus elementos o enunciado será verdadeiro. 


\section{Pé Q}

Pé R

poderia ser interpretado na teoria de Łukasiewicz-Patzig como válido se e somente se o seu enunciado correspondente for uma tautologia:

$$
((\mathrm{Q} \rightarrow \mathrm{R}) \wedge(\mathrm{P} \rightarrow \mathrm{Q})) \rightarrow(\mathrm{P} \rightarrow \mathrm{R})^{73}
$$

Esse enunciado, embora já se afigure como uma tautologia, é uma maneira abreviada de representação dos enunciados apresentados no argumento acima. O modo extenso, de acordo com a interpretação de Łukasiewicz-Patzig seria feito através de uma interpretação extensional com ênfase na quantificação sobre indivíduos. Essa interpretação adota operadores de quantificação, assumindo a seguinte descrição lógica:

$$
\left(\cdot x(\mathrm{Q} x \rightarrow \mathrm{R} x) \wedge^{\cdot} x(\mathrm{P} x \rightarrow \mathrm{Q} x)\right) \rightarrow \cdot x(\mathrm{P} x \rightarrow \mathrm{R} x)^{74}
$$

A partir de enunciados como esse que acabamos de apresentar, adicionado de um número mínimo de regras de inferência, podemos inferir outros enunciados que serão correspondentes a outros argumentos lógicos. Assim sendo, essas fórmulas lógicas compostas, a partir das quais se demonstra outros enunciados semelhantes, passam a ser fundamental em uma estratégia de provas e recebem o título de axioma, enquanto os demais enunciados serão reconhecidos como teoremas, apenas. A única diferença entre esses tipos de enunciados é que o axioma é um teorema que não requer uma prova para atestar sua conclusão, sendo sua verdade atestada pela

73 Deve-se asseverar que o argumento na primeira apresentação não seria um silogismo para a interpretação Łukasiewicz-Patzig, mas seria o equivalente ao silogismo que é o enunciado, mediante o qual a validade do argumento é atestada.

74 A notação polonesa, utilizada por Łukasiewicz é bem diferente, na medida em que reconhece a predicação aristotélica como uma relação termo-functor, o que a presente apresentação de Patzig evita. Para Łukasiewicz, o enunciado silogístico era uma composição de termos e functores, os quais representavam os cálculos silogísticos. Embora ele mesmo reconheça que sua proposta de notação seja um análogo à notação acima, sua interpretação filosófica parece ser mais adequada que a de Patzig. Um Barbara, na notação polonesa seria descrita à seguinte maneira: CKAbaAcbAca. 
considerações dos próprios conectivos ${ }^{75}$.

A teoria de Łukasiewicz-Patzig obteve grande sucesso na demonstração da validade dos argumentos equivalentes aos teoremas silogísticos, mas passou a ser duramente criticada por defensores da interpretação da silogística como sistema lógico. Para esses intérpretes, a interpretação dos silogismos como um enunciado lógico condicional não era uma representação adequada, preferindo retratar a silogística como argumentos lógicos com várias etapas interpretativas. Para esses intérpretes, a silogística apresenta semelhanças significativas com sistemas de dedução natural. As interpretações que resultam dessa crítica adotam considerações lógicas mais recentes, bem como técnicas introduzidas posteriormente, as quais procuram simplificar a sintaxe da silogística.

Essas críticas foram muito eficazes e conseguiram reconstituir a interpretação da silogística como argumentos lógicos. Ao contrário, porém, das interpretações tradicionais antes da investigação de Łukasiewicz, essas novas considerações da silogística como sistema lógico eram fundadas em um tratamento lógico rigoroso. Mesmo assim, essas interpretações encontraram forte resistência, por muito tempo. Em particular, essas investigações foram alvo de dura crítica por Jonathan Lear [1980], o qual, apesar de não se opor à visão que um silogismo seja, de fato, um argumento lógico, resistia fortemente à introdução de duas noções distintas de consequência lógica. Sua motivação para tão forte resistência às interpretações da silogística como sistema lógico se deve ao fato da introdução tardia de noções semânticas na lógica, a qual só ocorreu após da criação da teoria de modelos com Tarski.

Como Lear concorda com o fato da silogística consistir de argumentos lógicos e não de enunciados condicionais universalizados, ao contrário da teoria de Łukasiewicz-Patzig, ele se vê

75 No caso desse axioma, em particular, a prova é feita a partir da transitividade da implicação material. 
forçado a adotar uma outra estratégia para sua interpretação. A fim de evitar a criticada distinção entre os tipos de consequência, sua solução é considerar a relação dada pela descrição aristotélica daquilo que "se segue por necessidade" como uma função recursiva primitiva. Apesar de Lear não apresentar uma análise formal das implicações dessa proposta, podemos compreender intuitivamente seu propósito. Funções recursivas primitivas são funções computáveis, isto é, funções que se orientam por um certo algoritmo que as representa. Esse tipo de função é primitivo se e somente se forem observados como óbvios e não requerem provas para serem atestados como tais.

Lear defende sua posição com base nessa noção de obviedade, pois traça um paralelo com a, assim chamada, perfeição do silogismo. Alguns silogismos são considerados perfeitos, em virtude de nada mais ser preciso adicionar aos mesmos para sua validade ser assumida como óbvia $^{76}$. Isto é, a perfeição de um silogismo se daria por um critério de obviedade que se assemelha à noção atribuída a certas funções recursivas, já que algumas delas são indisputáveis.

A teoria de Lukasiewicz-Patzig: Uma das primeiras interpretações da silogística com o arcabouço teórico da lógica clássica foi apresentada por Łukasiewicz que foi posteriormente seguido por Patzig ${ }^{77}$. Ao contrário do que é feito hoje em dia, isto é, justificar certas relações com base em uma semântica, a qual se vale de conceitos como validade lógica e verdade dos enunciados, Łukasiewicz mantinha uma forte suspeita com relação a essas noções e se

76 Cf. $A P r$ I.1, 24b22-4.

77 Embora ambas as teorias sejam bastante próximas e, de certo modo podem ser correspondentes, há uma diferença fundamental entre elas: enquanto Łukasiewicz lida com as formas categóricas como functores, Patzig tenta simplificá-los, ao representá-los como conectores lógicos quantificados. De certo modo, por assumir as formas categóricas como functores, Łukasiewicz estava muito mais próximo às interpretações tradicionais que o ficava Patzig. Para efeitos práticos de nossa análise, porém, não precisamos levar essa diferença em consideração, pois chegaríamos aos mesmos resultados, independente da interpretação adotada. 
preocupava com aspectos puramente lógicos que pudessem garantir os mesmos resultados.

A sua interpretação da silogística recebeu o mesmo tipo de preocupação. As noções apresentadas pela $D G S$, bem como a expressão modal de necessidade, tinham que ser garantidas sem reduzir as noções lógicas a modelos mais simples para sua interpretação. Com isso em mente, a interpretação da Łukasiewicz tentava captar a base do sistema dedutivo de Aristóteles, interpretando a silogística como proposições condicionais universalizadas e rejeitando sua compreensão como argumento lógico.

Esse tipo de interpretação se insere bem, como havíamos mencionado, na interpretação da lógica como parte da filosofia, pois a pretensão de uma interpretação da silogística como teoria lógica seria a tentativa de dar um tratamento formal àquilo que na linguagem natural serve como argumentação. A correção desses argumentos não dependeria de sua interpretação, mas de uma correspondência entre os argumentos e as proposições que, no caso da silogística, são consideradas todas como verdades lógicas, isto é, tautologias. Com isso, a silogística não seria um estudo de argumentos e sua validade, mas de seus fundamentos que permitem estudá-los e interpretá-los.

O modo pelo qual a teoria lógica de Łukasiewicz opera é sobre axiomas, duas regras de inferência e um sistema auxiliar, para dar conta de certas demonstrações. O fato da silogística estar fundada em uma axiomática, não quer dizer que ela não tenha a pretensão de representar uma teoria de dedução. A única diferença substancial estaria na consideração do que seria a fundação lógica que permite a justificação de deduções lógicas. Łukasiewicz descreve sua teoria da dedução como sendo constituída pelos seguintes elementos:

\section{Definições:}


(Df1) $\mathrm{A} e \mathrm{~B}=\neg \mathrm{A} i \mathrm{~B}$

(Df2) $\quad \mathrm{A} o \mathrm{~B}=\neg \mathrm{A} a \mathrm{~B}$

\section{Axiomas:}

(A1) $\quad(\mathrm{B} a \mathrm{~A} \wedge \mathrm{C} a \mathrm{~B}) \rightarrow \mathrm{C} a \mathrm{~A}$;

(A2) $\quad(\mathrm{B} a \mathrm{~A} \wedge \mathrm{CiB}) \rightarrow \mathrm{CiA}$

(A3) $\quad \mathrm{A} a \mathrm{~A}$

(A4) $\quad \mathrm{A} i \mathrm{~A}$

\section{Regras de Inferência:}

Modus ponens $\quad$ (MP) se $\alpha \rightarrow \beta$, $\alpha$, então, $\beta$

Regra de substituição (RS) $\quad \alpha_{1}\left|\beta_{1} \ldots \alpha_{\mathrm{n}}\right| \beta_{\mathrm{n}}$, onde $\alpha$ é uma fórmula sentencial e $\beta$ é uma predicação aristotélica $(\mathrm{S} x \mathrm{P})$.

\section{Sistema auxiliar [L1957, p.89]:}

(S01) $\mathrm{p} \rightarrow(\mathrm{q} \rightarrow \mathrm{p})$

(S02) $(\mathrm{p} \rightarrow \mathrm{q}) \rightarrow((\mathrm{q} \rightarrow \mathrm{r}) \rightarrow(\mathrm{p} \rightarrow \mathrm{r}))$

(S03) $(\mathrm{p} \rightarrow(\mathrm{q} \rightarrow \mathrm{r})) \rightarrow(\mathrm{q} \rightarrow(\mathrm{p} \rightarrow \mathrm{r}))$

(S04) $(\mathrm{p} \rightarrow(\neg \mathrm{p} \rightarrow \mathrm{q}))$

(S05) $((\neg \mathrm{p} \rightarrow \mathrm{p}) \rightarrow \mathrm{p})$

(S06) $(\mathrm{p} \rightarrow \mathrm{q}) \rightarrow(\neg \mathrm{q} \rightarrow \neg \mathrm{p})$

$($ S07 $) \quad((\mathrm{p} \wedge \mathrm{q}) \rightarrow \mathrm{r}) \rightarrow(\mathrm{p} \rightarrow(\mathrm{q} \rightarrow \mathrm{r}))$

(S08) $\mathrm{p} \rightarrow((\mathrm{p} \wedge \mathrm{q}) \rightarrow \mathrm{r}) \rightarrow(\mathrm{q} \rightarrow \mathrm{r}))$

$($ S09 $) \quad(s \rightarrow p) \rightarrow(((p \wedge q) \rightarrow r) \rightarrow((s \wedge q) \rightarrow r))$

$($ S10 $)((\mathrm{p} \wedge \mathrm{q}) \rightarrow \mathrm{r}) \rightarrow((\mathrm{s} \rightarrow \mathrm{q}) \rightarrow((\mathrm{p} \wedge \mathrm{s}) \rightarrow \mathrm{r}))$

$(\mathbf{S 1 1}) \quad(\mathrm{r} \rightarrow \mathrm{s}) \rightarrow(((\mathrm{p} \wedge \mathrm{q}) \rightarrow \mathrm{r}) \rightarrow((\mathrm{q} \wedge \mathrm{p}) \rightarrow \mathrm{s}))$

$($ S12) $\quad((\mathrm{p} \wedge \mathrm{q}) \rightarrow \mathrm{r}) \rightarrow((\mathrm{p} \wedge \neg \mathrm{r}) \rightarrow \neg \mathrm{q})$ 
$(\mathbf{S 1 3}) \quad((\mathrm{p} \wedge \mathrm{q}) \rightarrow \mathrm{r}) \rightarrow((\neg \mathrm{r} \wedge \mathrm{q}) \rightarrow \neg \mathrm{p})$

(S14) $((\mathrm{p} \wedge \neg \mathrm{q}) \rightarrow \neg \mathrm{r}) \rightarrow((\mathrm{p} \wedge \mathrm{q}) \rightarrow \mathrm{r})$

Łukasiewicz observa que a presente teoria não é um retrato histórico fidedigno da silogística, uma vez que o próprio Aristóteles teria reconhecido, de acordo com ele, apenas os modos Barbara e Celarent como axiomas, além de duas regras de conversão78. A partir desses exemplos, dever-se-ia provar certos teoremas como a lei da identidade (A $a \mathrm{~A})$. Mesmo assim, a fim de provar todos os modos, a partir desse conjunto de axiomas, Aristóteles teria de insistir na adoção de um sistema auxiliar. Esse sistema auxiliar poderia ser obtido a partir de uma teoria mínima, a qual estaria contida no sistema apresentado acima. Eis o caso com os axiomas (S02), (S04) e (S05), os quais formam uma teoria mínima de dedução lógica, comprovada originalmente por Łukasiewicz79. Uma justificativa para a adoção de uma teoria mínima se dá em função da tentativa de uma teoria dedutiva minimizar o número de axiomas necessários para fazer todas as demonstrações80.

A partir desse conjunto de axiomas e leis lógicas Łukasiewicz e Patzig procedem a provar teoremas da silogística. O procedimento padrão, empregado na prova desses teoremas, está na adoção de um enunciado do sistema auxiliar e no emprego das variáveis proposicionais $\{\mathrm{p}, \mathrm{q}, \mathrm{r}$, $\mathrm{s}\}$ e sua substituição por predicações aristotélicas, isto é, enunciados na forma $\mathrm{A} a \mathrm{~B}$ ou $\mathrm{A} i \mathrm{~B}$.

78 Cf. Łukasiewicz [1957], p.73.

79 Cf. Łukasiewicz [1957], p.73.

80 Uma possibilidade de avaliar a diferença entre essas estratégias lógicas é ao apresentar os dois extremos dessa relação: uma teoria axiomática radical, como a axiomática de Hilbert, pode conter inúmeros axiomas, mas utiliza apenas uma regra de inferência (modus ponens); um sistema dedutivo radical, por sua vez, é totalmente destituído de axiomas, mas possui um número elevado de regras de inferências.

No caso da interpretação de Łukasiewicz, o número de axiomas é reduzido a quatro e o número de regras de inferência seria, em princípio, dois, colocando sua interpretação dentro desse intervalo. 
Dadas as definições (Df1) e (Df2), todos os modos silogísticos podem ser representados a partir dessa teoria.

Apesar da tentativa de manter o número de axiomas necessários para executar todas as demonstrações em quantidade mínima, cada demonstração depende de certa sofisticação sintática para que todas as etapas lógicas sejam contempladas. Sendo assim, a interpretação de Łukasiewicz e Patzig se tornam mais complexas, em comparação às interpretações consideradas tradicionais, em que silogismos são reconhecidos como inferências lógicas, procedendo em várias etapas. As interpretações tradicionais, apesar de não terem apoio das ferramentas lógicas, consideravam os silogismos como argumentos e processos inferenciais. Voltaremos à interpretação da silogística como argumentos lógicos mais adiante. Por ora, convém confirmar a complexidade de uma prova de um dito teorema silogístico na teoria de Łukasiewicz-Patzig. Para isso apresentaremos a prova da conversão da forma categórica "i”".

\section{Teorema 2.1.1: $\mathrm{A} i \mathrm{~B} \rightarrow \mathrm{B} i \mathrm{~A}$.}

Prova: Assuma os seguintes enunciados lógicos: $(\mathrm{A} i \mathrm{~B} \rightarrow \cdot \mathrm{C}(\mathrm{C} a \mathrm{~B} \wedge \mathrm{C} a \mathrm{~A}))$ e $(\cdot \mathrm{C}(\mathrm{C} a \mathrm{~B} \wedge \mathrm{C} a \mathrm{~A})$

$\rightarrow \mathrm{A} i \mathrm{~B}) 81$. Consideremos, também, a lei da comutatividade da conjunção: $(\mathrm{p} \wedge \mathrm{q}) \rightarrow(\mathrm{q} \wedge \mathrm{p})$. Com isso, a prova pode proceder da seguinte maneira:

1. $\mathrm{C} a \mathrm{~B} \wedge \mathrm{C} a \mathrm{~A} \rightarrow \mathrm{C} a \mathrm{~A} \wedge \mathrm{C} a \mathrm{~B}$

2. $\cdot \mathrm{C}(\mathrm{C} a \mathrm{~B} \wedge \mathrm{C} a \mathrm{~A}) \rightarrow \cdot \mathrm{C}(\mathrm{C} a \mathrm{~A} \wedge \mathrm{C} a \mathrm{~B})$
, $\mathrm{p}|\mathrm{C} a \mathrm{~B}, \mathrm{q}| \mathrm{C} a \mathrm{~A}$ sobre comutatividade;

, introdução de existencial;

81 Esse tipo de notação se assemelha muito ao dictum de aliquo. Há duas interpretações dos dicta: a leitura extensional, ortodoxa, e a leitura não-extensional, heterodoxa. A notation original de Łukasiewicz

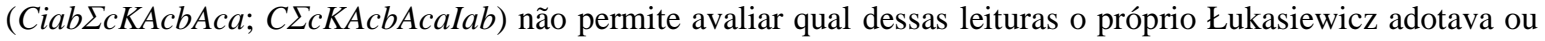
se ele pretendia se manter neutro a esse respeito. Em uma notação análoga à de Patzig, seria mais claro que ele pensava de forma extensional, pois sua notação seria da seguinte maneira: $(\mathrm{AiB} \rightarrow \cdot x(x \mathrm{aB} \wedge x \mathrm{aA})$ ) e $(\cdot x(x \mathrm{aB} \wedge x \mathrm{aA}) \rightarrow \mathrm{AiB})$. 


$$
\begin{array}{ll}
\text { 3. }(\mathrm{p} \rightarrow \mathrm{q}) \rightarrow((\mathrm{q} \rightarrow \mathrm{r}) \rightarrow(\mathrm{p} \rightarrow \mathrm{r})) & \text {, (S02)/silogismo hipotético; } \\
\text { 4. } \mathrm{A} i \mathrm{~B} \rightarrow \cdot \mathrm{C}(\mathrm{C} a \mathrm{~A} \wedge \mathrm{C} a \mathrm{~B}) & \text {, substituição sobre antecedente, 3.; } \\
\text { 5. } \cdot \mathrm{C}(\mathrm{C} a \mathrm{~A} \wedge \mathrm{C} a \mathrm{~B}) \rightarrow \mathrm{BiA} & \text {, substituição sobre consequente, 3.; } \\
\text { 6. } \mathrm{A} i \mathrm{~B} \rightarrow \mathrm{B} i \mathrm{~A} . &
\end{array}
$$

De modo bastante similar a esse, uma interpretação da silogística como teoria axiomatizada da lógica teria que proceder com base nesses sistemas que constituem a teoria, tornando-a sintaticamente rigorosa, mas pouco intuitiva.

A teoria de Lear: Uma outra opção para interpretar a silogística é apresentada por Jonathan Lear [1980], como havíamos mencionado. Lear foi um dos grandes opositores à interpretação da silogística como um sistema lógico que consistia de duas noções distintas de consequência lógica, a saber, a noção de consequência sintática e a de consequência semântica, como fora defendido por Corcoran e Smiley, entre outros. Uma das razões pelas quais Lear critica a interpretação da silogística como sistema lógico é que o conjunto de ferramentas lógicas imprescindíveis a essa interpretação não poderia fazer parte da lógica de Aristóteles, uma vez que a dependência de uma semântica seria extremamente anacrônica.

De fato, a rigor, uma tal introdução técnica da semântica nem sequer poderia ser atribuída aos fundadores da lógica clássica, Frege e Russell, cuja concepção da lógica era bem distinta daquela que se tem hoje em dia ${ }^{82}$. A introdução de sistemas lógicos com base na dedução natural se deve, sobretudo, à implementação bem sucedida de noções não-lógicas no cálculo lógico. De fato, o estudo efetivo desses sistemas se tornou possível após a introdução de conceitos

82 Cf. Chateaubriand [2001][2005]. 
semânticos, isto é, conceitos não-lógicos, tais como "verdade" e "satisfação". Um desenvolvimento pleno desse tipo de interpretação tornou, então, a lógica efetivamente rigorosa com os avanços da teoria de modelos, na qual se empreende um estudo da relação dessas noções semânticas com as diversas sintaxes.

Na contramão dessas interpretações, o foco dado sobre a relação de consequência lógica como uma função primitiva, junto com as regras de conversão, possibilitaria interpretar todo o sistema da silogística sem lançar mão de concepções semânticas. Enquanto a relação de consequência silogística, a qual não foi definida, apenas descrita, for um procedimento sintático, a noção de validade lógica deve ser dada em outros termos, também. Como veremos mais adiante, nas interpretações correntes da silogística, as noções de validade lógica e consequência lógica são dadas em termos de satisfação de certas condições semânticas e funções de verdade. Como isso não se aplica à interpretação de Lear, a única possibilidade de se obter uma interpretação da validade é por intermédio de procedimentos sintáticos. A hipótese lançada nessa interpretação seria dada pelo modo intuicionista de interpretar a substituição de termos. A noção intuicionista de substituição, grosso modo, permite que para quaisquer termos, a função continua sendo a mesma. Intuitivamente, essa noção seria plausível, embora sintaticamente seja extremamente sofisticada ${ }^{83}$.

Embora Lear não tenha apresentado um sistema com o qual o estudo de sua proposta para a silogística poderia ser aprofundado, sua crítica às interpretações da silogística como sistema lógico são suficientes para decidir, em sua interpretação, qual seria o objeto de estudo da silogística: a própria lógica. Embora, em geral, sua interpretação tenha sido relegada ao esquecimento e tenha apresentado pouca repercussão como proposta séria de interpretação da

83 Cf. Dummett [2000]. 
silogística, as reações mais fortes foram com relação ao ponto descrito há pouco: a lógica como objeto de escrutínio filosófico.

A posição de Lear fica clara ao considerar os meta-teoremas que Aristóteles teria proposto em capítulos como $A \operatorname{Pr}$ I.23. Em sua interpretação, Aristóteles realmente esteve preocupado com meta-teoremas a ponto de merecer o título de 'ancestral da meta-lógica ${ }^{84}$. No entanto, esses metateoremas não poderiam propor uma noção de completude do sistema, uma vez que essa se funda sobre a distinção em duas noções de consequência lógica. A sugestão dada por Lear seria representar as provas desses meta-teoremas como provas análogas às de compacidade lógica ${ }^{85}$.

O otimismo de Lear quanto a sua interpretação da silogística foi tamanho que ele chegou a comparar o suposto meta-teorema de Aristóteles, em $A P r$ I.23, à Tese de Church, a qual é uma tese fundamental para a teoria da computabilidade lógica. A Tese de Church enuncia um procedimento formal técnico a partir do qual um resultado qualquer poderia ser representado e computado por meio de um número mínimo de operações técnicas. No caso da proposta avançada por Church, o método empregado era o cálculo- $\lambda$. A mesma tese ficaria registrada na história por seu análogo posterior, conhecido como máquina de Turing. Nesse caso, todo procedimento calculável seria computável por uma máquina de Turing, consistindo por operações primitivas, apenas, e em número limitado. A semelhança desse cenário com contexto da silogística é tamanho que Lear denomina o meta-teorema de APr I.23 de Tese de Aristóteles ${ }^{86}$.

84 Cf. Lear [1980], p.iv: "[...] simply by raising the problem, Aristotle earns the right to be considered not only the father of logic, but also the (grand)father of meta-logic".

85 Ironicamente, a compacidade pode ser intuitivamente compreendida mediante a noção de modelos e diz que para qualquer conjunto de enunciados há um modelo se e somente se qualquer subconjunto finito desse conjunto possuir um modelo. Cf. Chang \& Keisler [2012], p.67; Dummett [2000], p.205ss.

Como a noção de compacidade é interessante quando se trata de conjuntos infinitos, sua aplicação sobre a silogística se daria com número infinito de inferências lógicas, cada qual possuindo um esquema finito pelo qual está embasada.

86 É importante tomar um cuidado com outro teorema que ficou conhecido pelo mesmo nome. Não se trata da 
Um dos graves problemas dos quais Lear trata apenas superficialmente é a presença ou ausência de uma concepção semântica de consequência. A princípio ele se opõe veementemente contra a distinção de consequência sintática e semântica, propondo que há uma única concepção que não foi definida. Mesmo assim, Lear parece se comprometer com a presença de consequências semânticas reconhecidas por Aristóteles, como é o caso do argumento nãosilogístico que obtém uma conclusão válida e pode ser convertido para um silogismo em $A P r$ I. $7^{87}$. Problemas como esse resultou em um abandono de sua interpretação, restando apenas a discussão acerca da completude ou compacidade lógica.

\section{A silogística como Sistema Lógico}

Como vimos acima, a teoria lógica de Łukasiewicz-Patzig foi criticada com veemência, em virtude de sua representação dos silogismos como teoremas lógicos, isto é, expondo a silogística como condicionais universais axiomatizados. Essa crítica foi empreendida em duas etapas: (i) uma etapa exegética e (ii) uma etapa lógica. Quanto à (i), as evidências textuais fornecidas tanto por Łukasiewicz como por Patzig foram muito fracas para defender a visão deles de argumentos como enunciados lógicos. A razão disso se deve ao peso excessivo atribuído a certas expressões frequentes na enunciação dos silogismos que poderiam ocorrer na linguagem natural parecendo-se com a interpretação clássica de implicação material. Além de ser exegeticamente fraco, tinha como consequência o comprometimento com problemas lógicofilosóficos que não se poderia atribuir à silogística. Entre essas dificuldades, constam a complexidade da teoria da qual o intérprete precisaria lançar mão a fim de obter os resultados

negação aristotélica de uma certa implicação $[\neg(\mathrm{A} \rightarrow \neg \mathrm{A})]$, mas da afirmação que todos os argumentos são computáveis por um número finito de argumentos silogísticos.

87 Cf. Lear [1980], p.55, nota 1. 
desejados, como já havíamos mencionado.

O objetivo principal das interpretações da silogística como um sistema lógico é retratá-la como uma lógica subjacente às outras ciências. Em termos do jargão adotado desde a antiguidade tardia, a lógica seria uma ferramenta a serviço de outras ciências e seus objetos de estudo. Essa visão era predominante entre os intérpretes, antes do excelente trabalho de Łukasiewicz, o qual teceu duras críticas às interpretações ditas tradicionais ${ }^{88}$, uma vez que diversas considerações que essas adotavam como lógicas, nem sequer poderiam ser consideradas inferências ${ }^{89}$. A proposta de recuperar essa visão da silogística como um argumento lógico deveria ser fundada de modo que uma tal crítica não se aplicaria e isso implicava adotar os avanços mais recentes da lógica, especialmente dos estudos de sistemas de dedução natural, para reavaliar a silogística enquanto sistema lógico.

A linguagem padrão desses sistemas já foi descrita no capítulo anterior. Trata-se de uma linguagem com base nas predicações aristotélicas e adicionada de sete regras de inferência, para deduções ditas diretas, e mais uma regra de reductio, para argumentos indiretos. O ponto que merece destaque nessas interpretações é a própria semântica. Essas semânticas são interpretações da linguagem, com base em funções de verdade e a satisfação de certas condições que determinam o valor de verdade dos enunciados dentro de um argumento.

Desde a crítica de Smiley e Corcoran à interpretação de Łukasiewicz-Patzig, diversos sistemas semânticos foram propostos para a linguagem da silogística, cada qual apresentando características próprias, distinguindo-se em certo grau daquilo que poderíamos chamar de sistema

88 Em Łukasiewicz [1957], p.47, ele afirma que os filósofos deveriam ser convencidos a não escrever acerca da lógica ou de sua história, sem antes terem adquirido um certo domínio no que ele chama de lógica matemática.

89 Um dos exemplos mais claros do alvo de crítica de Łukasiewicz era o exemplo de tríades de termos concretos, utilizados por Aristóteles em $A P r$ I.4, para mostrar que duas premissas não poderiam formar um argumento lógico, muito menos formar um silogismo, mas eram retratados como argumentos por pessoas como Maier. Cf. Łukasiewicz [1957], p.68. 
Corcoran-Smiley. A variedade semântica para a interpretação da silogística não deve nos interessar para esta dissertação, uma vez que todos esses sistemas operam com a satisfação de funções de verdade, a partir das quais tanto a correção, quanto a completude do sistema pode ser verificada. Em virtude disso, caracterizaremos brevemente a semântica do sistema CorcoranSmiley e apontaremos para a consequência dessas análises.

O sistema $S$, de Corcoran-Smiley: Embora os estudiosos tenham desenvolvido esse sistema de modo independente, ambos os desenvolvimentos da semântica de Corcoran-Smiley são fundados nas mesmas concepções de critérios de satisfação para as funções de verdade, a saber: a teoria de conjuntos.

Como foi mencionado antes, um sistema semântico deve ser o equivalente aos teoremas lógicos de uma teoria para os argumentos, isto é, as condições da constatação da validade lógica dos argumentos entre outros critérios. Entrementes, surge uma exigência adicional a esse tipo de apresentação, a saber: como esses sistemas tratam de duas noções de consequência lógica distintas, uma sintática e outra semântica, é preciso uma avaliação de como esses se correspondem, se for o caso.

O sistema semântico de Corcoran-Smiley é fundado na teoria de conjuntos para estabelecer as condições de satisfação do sistema. Intuitivamente, Corcoran toma as predicações aristotélicas de modo que "todo A é B" possa ser equiparado a um conjunto A que está incluído em outro conjunto B, "nenhum A é B" como a intersecção dos conjuntos A e B sendo vazia, bem como suas negações, dadas a partir das regras de oposição. Assim sendo, o enunciado "algum A é B” equivale à intersecção entre os conjuntos A e B não ser vazia e o enunciado "algum A não é B”, ao conjunto A não estar contido no conjunto B, isto é, há uma extensão de A não contida na 
extensão de B.

Como vimos no capítulo anterior, a linguagem do sistema silogístico é simples e formada por poucos elementos: há quatro constantes lógicas, representando relações categóricas $\{a, e, i, o\}$, e um conjunto infinito de constantes não-lógicas $U=\left\{\mathrm{u}_{1}, \mathrm{u}_{2}, \mathrm{u}_{3}, \ldots\right\}$, as quais podem ser substituídas por termos definidos $x, y$, entre outros, os quais formam as variáveis.

A interpretação que se faz sobre esse sistema, o que nos deve interessar para este texto, tem que considerar não apenas as relações que cada tipo de enunciados desses oferece, mas também as condições de valoração de todos elementos da linguagem $\mathscr{L}$. Isto é, considerando os infinitos elementos de $\mathrm{U}$, os quais são substituíveis por termos concretos. A partir desses, pode-se fazer uma interpretação em diversos grupos categóricos. Há dois tipos de interpretação: uma primária $i$, a qual designa uma interpretação pretendida, isto é, que se adéqua às categorias; uma secundária $j$, a qual seria uma interpretação não pretendida. Assim sendo, a interpretação $i x$ da constante não-lógica $x$ é a extensão secundária dos termos relacionados a $x$. Isto é, $x$ é um conjunto, cujos elementos são representados por sortal universals90. Dado isso, pode-se definir uma função de verdade $V^{i}$, a qual atrela o valor adequado de verdade a cada enunciado formado na linguagem $\mathscr{L}$ :

$$
\begin{aligned}
& \text { 1. } V^{i}(\mathrm{~A} x y)=1 \text { se } i x \square i y \text {, } \\
& V^{i}(\mathrm{~A} x y)=0 \quad \text { se } i x \square i y . \\
& \text { 2. } \quad V^{i}(\mathrm{E} x y)=1 \quad \text { se } i x \cap i y=\varnothing \\
& V^{i}(\mathrm{E} x y)=0 \quad \text { se } i x \cap i y \neq \varnothing \\
& \text { 3. } V^{i}(\mathrm{I} x y)=1 \text { se } i x \cap i y \neq \varnothing \text {, }
\end{aligned}
$$

90 Cf. Corcoran [1974], p.103. 


$$
\begin{aligned}
& V^{i}(\mathrm{I} x y)=0 \quad \text { se } i x \cap i y=\varnothing . \\
& V^{i}(\mathrm{O} x y)=1 \quad \text { se } i x \square i y, \\
& V^{i}(\mathrm{O} x y)=0 \quad \text { se } i x \square i y .
\end{aligned}
$$

Esse quadro pode ser um pouco enganoso ao estabelecer as condições de verdade para a interpretação pretendida $i$. Afinal, se a interpretação pretendida é sempre satisfeita pelos termos definidos que se lhe adequam, não haveria problemas para a interpretação. Para isso, serve a consideração da interpretação $j$, a qual procura avaliar condições não-pretendidas de interpretação que poderiam eventualmente apresentar contra-exemplos ao caso pretendido.

Com isso, podemos afirmar que a pretensão da interpretação $j$ é possibilitar que a inferência lógica de um conjunto $\Gamma$ qualquer para um enunciado conclusivo $p$ sempre terá uma mesma característica e sempre será, por isso mesmo, válida. Para isso, é preciso que se consiga determinar a função de verdade $V^{j}$ de modo que $V^{j}(p)$ receba um dos dois valores de verdade. De modo geral, a interpretação $j$ tenta ampliar as condições de satisfação, dada pela própria semântica da silogística, como já foi apontada no capítulo anterior.

De certo modo, essa visão se baseia sobre uma concepção de argumentos em que todos os elementos desse argumento formam um conjunto de enunciados onde para um número arbitrário $\mathrm{n}$ de enunciados, as asserções $p_{1}$ a $p_{\mathrm{n}-1}$ serão as premissas e $p_{\mathrm{n}}$ a conclusão que delas se segue. Dada essa breve descrição, podemos formular, então, as condições de verdade para uma interpretação não-pretendida $j$ : se $\Gamma=\left\{p_{\mathrm{k}} \mid \mathrm{k} \in \mathrm{n} \wedge V^{j}\left(p_{\mathrm{k}}\right)=1\right\}$, então $j$ é uma interpretação verdadeira de $\Gamma$; se $V^{j}(\Gamma)=1 \Rightarrow V^{j}(p)=1$, então $\Gamma$ implica logicamente $p$ e $\Gamma$ k $p$ é um argumento válido tendo $p$ como consequência lógica de $\Gamma$.

A partir dessas definições, todas as regras de inferências poderiam ser verificadas com 
base no cálculo clássico e na teoria de conjuntos, para atestar cada argumento silogístico. De fato, Corcoran formula sua prova de completude a partir dessa relação entre sua semântica e os silogismos: se todos os silogismos forem demonstrados a partir das oito regras de inferência admitidas por Aristóteles, então a silogística poderia ser considerada completa. Uma demonstração com base nessa semântica pode ser dada da seguinte maneira:

\section{Teorema 2.1.2: $\quad$ (Cesare) $\mathrm{A} e \mathrm{~B}, \mathrm{C} a \mathrm{~B}=\mathrm{C} e \mathrm{~A}$.}

Prova: $\quad \operatorname{Seja} V^{j}(\mathrm{~A} e \mathrm{~B})=1, V^{j}(\mathrm{C} a \mathrm{~B})=1$, para um par de premissas $\square$ Eab,Acb $\square$. Logo, vale $j \mathrm{~A}$ $\cap j \mathrm{~B}=\varnothing$ e $j \mathrm{C} \square j \mathrm{~B}$. Ou seja, para um $y$ qualquer, elemento de $j \mathrm{C}$, vale $y \in j \mathrm{C} \cdot y \in j \mathrm{~B}$. Mas $j \mathrm{~A}$ $\cap j \mathrm{~B}=\varnothing, \operatorname{logo}, y \in j \mathrm{~A} \wedge y \notin j \mathrm{~B} \vee y \in j \mathrm{~B} \wedge y \notin j \mathrm{~A}$, portanto, $y \in j \mathrm{C} \wedge y \notin j \mathrm{~A} \quad \mathrm{e}$, consequentemente, $j \mathrm{C} \cap j \mathrm{~A}=\varnothing$.

\subsection{Primeiros Analíticos: dois tratados distintos ou exposição coesa?}

A apresentação dos diversos modos de compreensão da silogística levantou um problema considerável para a exegese dos textos em $A \operatorname{Pr} \mathrm{I}$, sobretudo no que tange às teses anunciadas a partir de $A \operatorname{Pr}$ I.23, onde apareceria o meta-teorema da completude. Após a tentativa do sistema $S$ dar um tratamento lógico rigoroso a $C A E$, uma vez que esses seriam possíveis apenas mediante uma investigação semântica, a crítica de Lear parecia que tinha derrubado com sucesso a possibilidade de uma análise do meta-teorema em $A \operatorname{Pr}$ I.23. A resposta do próprio Lear para esse cenário, isto é, considerar a compacidade da silogística, possibilitou uma interpretação lógica do mesmo meta-teorema, a custo da própria silogística não ser apenas uma ferramenta da filosofia, mas seu objeto de estudos, sobretudo.

Os resultados obtidos pela investigação de Lear mantêm a interpretação, embora ele não 
tenha desenvolvido sua proposta em uma linguagem formal, de um tratamento lógico da parte de $C A E$. Como Lear não se preocupa com o silogismo como enunciado condicional universalizado, a crítica tampouco se aplica a ele, como o faz a crítica ao sistema aristotélico. Entretanto, esses resultados apresentam um problema claro no que diz respeito aos objetivos da silogística e sua relação com a filosofia, em geral. Na interpretação de Lear, fica claro que a silogística, e, portanto, a lógica, se torna objeto de estudo para a filosofia e a impede de ser considerada como lógica subjacente de outra ciência91.

Apesar de sua proposta ter um sucesso considerável, Lear admite que um tratamento lógico de $C A E$ não pode ser levado a cabo sem alguns problemas, os quais não equivalem a tensões superficiais. O exemplo a que ele chama atenção se encontra em $A P r$ I.35, onde Aristóteles apresenta um exemplo em que uma premissa se diz imediata, isto é, para a qual não há um termo mediador a partir do qual se pudesse obtê-la, mas que pode ser provada. Trata-se de um exemplo da geometria em que a soma dos ângulos internos de um triângulo equivale à soma de dois ângulos retos. Embora isso seja um teorema da geometria que pode ser provado, não haveria como traduzir essa prova para um argumento silogístico. Esse fato gera um conflito significativo com o suposto meta-teorema de $A P r$ I.23.

Não obstante, tanto Corcoran como Lear entendem que o tratamento de toda silogística é propriamente lógico e que esse tipo de estudo continua de $A \operatorname{Pr}$ I.23 em diante. As diferenças

91 Apesar de sua crítica à interpretação da silogística como sistema lógico, motivada, sobretudo, pela introdução anacrônica de concepções lógicas que não poderiam fazer parte da silogística, como a distinção entre consequência semântica e sintática, Lear [1980] tenta atribuir à silogística uma interpretação lógica e, por conseguinte, rigorosa. Com isso, pode-se dizer que, embora resistisse a essa percepção, Lear iniciou o processo de críticas às interpretações propriamente lógicas da silogística.

Striker, ao criticar Lear, em seu artigo de 1997, não pretende voltar às interpretações anteriores que ainda apresentavam sistemas sofisticados, comparados à silogística. Para Striker, a saída era desconsiderar por completo as interpretações propriamente lógicas e assumir o silogismo como um argumento lógico, em geral, suscetível de uma interpretação mais propriamente lógica, mas radicalmente distinto em seus objetivos que o seria a lógica clássica. 
estão em como essa parte será compreendida por esses estudos. Enquanto para Lear a segunda parte de $A P r$ I consiste em um tratamento sintático, complementado por algumas estratégias para obter a construção dos silogismos, para Corcoran, a preocupação principal nessa segunda parte da obra expressaria preocupações genuinamente semânticas que Aristóteles teria para a silogística92.

No entanto, afirmações em $C A E$ que contrastam com esse otimismo lógico dessas tradições dificultam a compreensão desses capítulos como propriamente lógicos. Não só isso, mas as próprias discussões, presentes em $C A E$, sugerem que a preocupação aristotélica não teria sido propriamente a lógica, mas um tratamento muito mais próximo à dialética, tida como radicalmente distinta. Podemos dividir $C A E$ em dois temas principais, os quais receberam os nomes de parte heurística e de parte analítica, respectivamente93.

$\mathrm{Na}$ parte que trata da heurística, Aristóteles estaria preocupado em apresentar estratégias de como se pode obter certos argumentos silogísticos, estabelecendo métodos para encontrar enunciados que poderiam servir como premissas de um silogismo e afins. Muitos desses exemplos são considerados de modo que Aristóteles estaria preocupado em gerar um acúmulo de exemplos, os quais poderiam servir como casos de apoio ou evidências adicionais para aquilo que já teria sido provado por uma etapa lógica apropriada94.

Dadas essas semelhanças com o debate acerca da dialética e o problema com a consistência da interpretação lógica de $C A E$, bastaria negar a interpretação da silogística como

92 Isso deve ser considerado com o devido cuidado. Corcoran é muito cauteloso ao atribuir uma noção de semântica a Aristóteles e reconhece que isso seria um tour de force para garantir as propriedades desejadas do sistema. Não obstante, as considerações a partir de $A P r$ I.23 seriam lógicas, mas não sintáticas, sendo preciso introduzir, mesmo que de modo qualificado e brando uma noção de semântica no texto aristotélico.

93 Cf. Striker [1997].

94 Striker compreende a estratégia que Aristóteles apresenta em $\operatorname{APr}$ I.28 dessa maneira, para identificar termos e sequências de termos que podem servir de termo mediador para um certo argumento. Em seu comentário à passagem que ela afirma suportar essa visão ela menciona que essa estratégia faz sentido apenas em contexto dialético, comparando diversas passagens com os Tópicos. 
objeto de estudo da filosofia para se atestar uma distinção plena entre $C A G$ e $C A E$ de $A P r$ I. De fato, negar a interpretação de Lear impediria uma simples adoção da interpretação da silogística como sistema lógico. Com isso, Striker teve que dar um passo além na crítica iniciada por Lear e criticar a própria compreensão lógica de $C A E$, como pretendiam as interpretações anteriores.

A defesa de Striker em favor da interpretação da silogística como uma ferramenta da filosofia, opondo-se aos ataques feitos por Lear, os quais sugerem o contrário, levou ao resultado da total distinção entre $C A G$ e $C A E$. Parte das evidências utilizadas para isso está no próprio conteúdo tratado por Aristóteles em $C A E$, que se aproxima mais ao tipo de análise apresentada em Tópicos95 que ao tipo de análise anterior em APr I.1-2, 4-6. Outro ponto relevante na obtenção desse resultado foi a tensão que se gerou na tentativa de interpretar esses capítulos de $C A E$. Enquanto Corcoran entendia esses capítulos como constituindo apenas a parte semântica de seu sistema, por mais que o fizesse com cautela, ele não remetia isso a uma lógica de ordem superior ou mesmo a uma metalógica. A crítica de Lear, no entanto, assumiu exatamente o contrário, ao se opor a noção de uma separação entre sintaxe e semântica. Para a teoria de Lear, $C A E$ lida com noções metalógicas, as quais tomam a própria lógica como objeto de estudo.

Nesse sentido, a defesa de Striker à silogística como ferramenta da filosofia tem como consequência a cisão total entre esses capítulos. Graças à crítica de Lear, $C A E$ não poderia mais ser considerada como um tratamento semântico da silogística, mas como esses mesmos capítulos não podem assumir a silogística como objeto de estudo, eles nem sequer poderiam constituir um estudo na área da lógica, mas seriam técnicas de argumentação geral. Com isso, ela evita que esses argumentos mantenham seu papel de ferramenta da filosofia e critica as análises lógicas

95 Como tentaremos mostrar em nossa capítulo quarto, essa proximidade se dá especialmente com Top VIII.2 e VIII.11. 
desse conjunto de capítulos que tendem retratar Aristóteles como um lógico que, muito provavelmente, não teria sido96.

Com essa interpretação, Striker não pretendia reduzir o mérito de quem procurava tratar a silogística como um sistema de lógica formal. Bem como Lear, ela pretende apontar para o fato de que (a) as ferramentas da lógica simbólica são demasiadas complexas e dependeram de um esforço significativo em seu desenvolvimento para terem surgido tão cedo, no suposto início da lógica, mas, ao contrário de Lear, que (b) o projeto filosófico de Aristóteles seria mais amplo para se focar apenas em aspectos de um tratamento meramente simbólico de regras de raciocínio ou métodos de cálculo. Com isso, ela não nega que a silogística seja um sistema de dedução natural correto e completo, mas nega o fato de Aristóteles ser lógico em um sentido em que ele muito provavelmente não teria sido ${ }^{97}$. A exemplo da própria discussão levantada em $A P r$ I.23, a questão estaria, antes, ligada a esse objetivo maior e não à questão propriamente lógica da completude de seu sistema. Essa postura de Striker permitiu que ela pudesse conciliar tanto os resultados positivos de completude lógica, obtidos por Corcoran, quanto o resultado negativo, admitido por Aristóteles em APr. I.45, sem que essas afirmações gerassem um hiato na interpretação.

No entanto, a grande desvantagem da distinção empreendida por Striker é um vão teórico que se estabeleceria entre a silogística e a teoria da demonstração científica, arrolada a partir dos Segundos Analíticos (APo), possibilitando interpretações diversas a respeito da importância da silogística para a própria teoria da demonstração científica ${ }^{98}$. Além de justificar as mais diversas interpretações sobre a relação de $A P r$ com $A P o$, a proposta que se apresenta em algumas seções de $C A E$, como em $A P r$ I.27 a I.31, serviriam de substituto do tratamento propriamente lógico,

96 Cf. Striker [1997], p. 210.

97 Cf. Striker [1997], p. 210.

98 Cf. Barnes [1981] 
dado em $C A G$. De acordo com Striker ${ }^{99}$, capítulos como I.27 a I.31 servem como estratégias para evitar ou minimizar o esforço de se decorar a lista de argumentos válidos proposta na primeira parte da obra e não para avaliar aspectos da própria silogística. De outro modo, após a discussão efetivamente lógica, os objetivos no restante da obra se resumiriam à tentativa de mostrar como a silogística serve como ferramenta para todas as áreas, não se restringindo apenas a ciências axiomatizadas. Para cumprir com esse programa, no entanto, Aristóteles se veria forçado a reavaliar alguns pontos do sistema que acabara de estabelecer na parte precedente da obra limitando-o de certo modo. De acordo com essa interpretação, teria-se a seguinte situação entre as partes distintas: a primeira parte, $C A G$, estabeleceria o sistema; capítulos da segunda parte, $C A E$, tais como I.23-26, trabalhariam com a intuição de todas as formas de argumento se adequarem ao esquema da silogística e capítulos I.27-31 apresentariam um método para identificar premissas que formassem silogismos válidos, ou seja, reafirmariam, por outro método, o mesmo que os capítulos anteriores, e a parte final se preocuparia em analisar a linguagem comum de acordo com a silogística.

Com a breve exposição acerca desse peculiar debate que se deu no que concerne à silogística e sua função nos Analíticos surge a seguinte questão: há uma espécie de fio condutor pelo qual a discussão entre $C A G$ e $C A E$ se orienta? A questão, aqui aventada, propõe uma investigação a respeito do caso desse livro fazer uma exposição razoavelmente linear de seu conteúdo, relacionando suas respectivas partes, ou dessas partes distintas acabarem revelando-se incompatíveis entre si.

Para melhor tratar dessa questão, seria interessante fazer a análise das partes a fim de se identificar o tema central. Nosso objetivo é apontar para o fato de que é possível uma leitura 99 Cf. Striker [1997], p. 220ss. 
coesa em APr. I, asseverando que o interesse aristotélico não é o de estabelecer uma lógica, seja em sua interpretação como teoria ou como sistema, mas de apresentar a silogística como estudo da boa argumentação, apresentando resultados positivos, os quais não teriam sido previamente estabelecidos em Top.

\subsection{Problemas para a distinção dos Primeiros Analíticos I em dois tratados}

Striker parece conciliar diversos problemas de interpretação que surgiam com a silogística. Entretanto, cumpre avaliar alguns dos pontos que ela defende. Ao afirmar que a silogística é correta e completa, nos moldes apresentados por Corcoran, a defesa de uma interpretação da silogística como sistema lógico repercute na aceitação de uma análise dos argumentos por meio de duas noções distintas de consequência lógica. Sendo assim, essa distinção está apresentada em $C A G$, sobretudo em $A P r$ I.1-2, 4-7. Seria nesse grupo diminuto de capítulos que tanto a sintaxe quanto a semântica estariam desenvolvidos a contento, tendo todas as propriedades descritas satisfatoriamente100.

Entrementes, uma tal interpretação ainda falha em determinar precisamente o sentido pretendido por elementos da própria $D G S$ como é o caso da Cláusula Final. Como observamos anteriormente, uma série de lacunas se apresenta na própria definição do silogismo. A $D G S$ não é satisfatória quanto ao estabelecimento das características determinantes que fazem um argumento ser silogístico ou não. De fato, tradicionalmente a $D G S$ é lida como definição de argumento válido em geral, de modo que o número de inferências válidas fosse maior que o número dos modos silogísticos reconhecidos por Aristóteles.

100 O recente trabalho de Malink [2013] com sua análise do dictum de omni et de nullo em APr I.1, possibilita uma tal interpretação. 
Esse resultado depende claramente da suposição de que a $D G S$ satisfaz um número maior de argumentos que aquele oficialmente reconhecido por Aristóteles. Através dessa suposição, as definições de validade lógica e de consequência silogística são determinadas. Se essa suposição fosse correta, a interpretação de Striker teria um impacto significativo sobre os estudos da silogística, reduzindo significativamente a análise lógica nos problemas do corpo aristotélico101. No entanto, essa própria suposição repousa sobre um ponto extremamente delicado, a saber, a negligência da Cláusula Final como elemento determinante para a DGS. Se for possível demonstrar que a Cláusula Final assume um papel relevante no estabelecimento dos silogismos, isto é, que ela é responsável também por uma restrição dos argumentos válidos a argumentos estritamente silogísticos, tem-se a possibilidade de restituir uma relação entre as duas partes de $A \operatorname{Pr}$ I, tendo a própria Cláusula Final e as exigências por ela apresentadas como fio condutor determinante na interpretação de texto.

Sendo assim, devemos voltar à Definição Geral do Silogismo, tendo por objetivo a análise precisa de sua Cláusula Final e as consequências que uma tal análise apresenta.

101 De fato, Striker se colocaria com um argumento forte contra a própria visão que Aristóteles conquistou, como poderia ser resumido nas palavras de Gilbert Ryle: de ser uma pessoa "obcecada por um formalismo lógico". 


\section{A Cláusula Final nos Primeiros Analíticos}

Como vimos em nossa exposição, no primeiro capítulo, a Definição Geral do Silogismo (DGS) apresenta diversas características que remetem a uma interpretação relevantista do sistema lógico de Aristóteles. Notadamente, Smith tentou atribuir à Cláusula Final essa noção de relevância como critério distintivo. Apesar de ser possível apresentar a ocorrência da Cláusula Final em Top VIII.11 como evidência para essa interpretação, a referência aos Tópicos se mostrou insuficiente para dar um tratamento adequado à Cláusula Final. A interpretação de Smith enfrenta dificuldades em destacar a Cláusula Final como uma exigência particular dentro de DGS, distinta das demais exigências apresentadas. Isso decorre do fato da exigência por uma conclusão distinta das premissas apresentar, basicamente, os mesmos resultados que as exigências estabelecidas anteriormente. Ademais, a remissão a Top VIII.11 não é suficiente para estabelecer uma interpretação satisfatória da descrição dessa parte da $D G S$, em 24b20-2.

A partir desse cenário, formulamos a nossa meta principal, como apontado antes: uma determinação mais específica da Cláusula Final ${ }^{102}$. A Cláusula Final não é satisfatoriamente definida em $D G S$, apesar de fazer parte da definição daquilo que Aristóteles compreende por argumentos silogísticos. Sendo assim, se uma parte da definição não estiver clara, a própria definição do silogismo será incerta. Uma vez que a $D G S$ não é suficiente para esclarecer o sentido da Cláusula Final, devemos buscar novas evidências que poderiam contribuir para uma

102

Devemos asseverar que o objetivo de definir apropriadamente a Cláusula Final não é possível com a análise que propomos neste trabalho. Ela requer outros elementos que tornariam a investigação demasiadamente longa. 
melhor análise dela. Acreditamos ter encontrado uma tal evidência em APr I.4, logo após a apresentação dos modos universais da primeira figura.

Essa ocorrência é especialmente interessante, pois coloca em questão um projeto denominado de reducionista a partir do qual se costuma interpretar a silogística. Tradicionalmente, a DGS é interpretada como descrição de argumentos válidos em geral. De fato, é muito comum encontrar na literatura a suposição que a classe de argumentos satisfeita pela $D G S$ é significativamente maior que os modos silogísticos reconhecidos por Aristóteles ${ }^{103}$. Assumindo essas hipóteses, a interpretação tradicional entende que a $D G S$ é extremamente similar, quando não equivalente, à noção intuitiva de validade lógica ainda em voga atualmente $^{104}$. Um dos objetivos para a tradição interpretativa é dar sentido à expressão modal de necessidade que ocorre na parte das Condições Inferenciais de DGS. Como não está claro o que precisamente era pretendido por Aristóteles com o emprego dessa expressão ${ }^{105}$, caberia ao intérprete tentar expressar seu sentido de modo mais claro. Sendo assim, identifica-se a expressão modal de necessidade, por ser próxima a noções não-lógicas, como principal problema para a compreensão da $D G S$, fundada na lógica. Por conseguinte, a fim de se obter uma definição das noções silogísticas equivalentes à validade e consequência lógica, costuma-se adotar uma estratégia de interpretar essas noções difíceis por modelos lógicos equivalentes, os quais são de compreensão mais fácil. Como havíamos mencionado no capítulo primeiro deste trabalho, essa

103 Interpretações que assumem diretamente que DGS é mais ampla: Ross [1949], p.291; Mignucci [1968], p. 190; Smith [1989], pp.109-10, [2009], pp. 52-3, [2012]; Ebert \& Nortmann [2007], p.226;

Interpretações que assumem indiretamente que DGS é mais ampla: Striker [2009], pp.1, 79; Crivelli [2012], p. 125

104 Embora a tradição interpretativa reconheça que para Aristóteles essa noção não teria o mesmo peso, com encontramos hoje em dia. Como todos os silogismos são argumentos válidos, não faria sentido cunhar um nome como "silogismos válido". Isso sugere que poderia haver silogismos inválidos, o que para Aristóteles seria uma contradição em termos. Vide Ebert \& Nortmann [2007], p.226.

105 Cf. Lear [1980], pp.1-2. 
estratégia é reconhecida como projeto reducionista.

Se, no entanto, for atestado que a noção de silogismo não pode ser reduzida a uma noção de validade lógica, poderemos questionar essa estratégia. As consequências dessa crítica seriam as seguintes: em primeiro lugar, não seria possível interpretar aquilo que "segue por necessidade" a partir do projeto reducionista; segundo, a falha do projeto reducionista implicaria na impossibilidade de se definir logicamente as noções de validade e consequência lógica para a silogística. Nossa estratégia, para atingir esse objetivo, consiste na tentativa de interpretar a Cláusula Final como critério restritor, cujos resultados impedem que um argumento silogístico possa ser compreendido como argumento válido em geral.

Tendo isso em vista, pretendemos, neste capítulo, investigar o segundo e último uso que Aristóteles faz da Cláusula Final em $A P r$ I. Apesar de estar inserido em um contexto bastante disputado, essa instância da Cláusula Final tem fortes repercussões para a investigação da silogística. Em $A P r$ I.4, ela é empregada como justificativa para determinar que uma certa sequência de formas categóricas não obtém uma conclusão. Entretanto, o mesmo conjunto de premissas admite uma conclusão válida, como Aristóteles reconhece, em $A P r$ I.7, sugerindo uma distinção entre argumentos silogísticos e não-silogísticos.

Na seção 3.1, analisaremos o argumento de Aristóteles em APr I.4 e comparando-o aos comentários que ele tece em $A P r$ I.7. O resultado que obteremos nessa investigação será a exigência que a disposição dos termos na conclusão siga uma ordem específica, a qual distinguirá os exemplos dados nesses capítulos, respectivamente, em argumento inconcludente e válido. Seguindo essa sugestão tentaremos estabelecer uma comparação entre argumentos silogísticos e não-silogísticos equivalentes para especificar melhor os critérios exigidos pela Cláusula Final. Uma das consequências dessa nossa investigação dirá respeito à sequência em que as premissas 
são apresentadas. Tentaremos mostrar que essa sequência é relevante para as distinções que Aristóteles parece pressupor.

Os resultados da investigação na seção 3.1, abrem a possibilidade para uma resposta de uma difícil questão a respeito da silogística, a saber: por que Aristóteles adota dois modos silogísticos distintos para argumentos extensionalmente equivalentes? Na seção 3.2, seguiremos os critérios de ordenação, apresentados na seção anterior, a fim de certificar se eles são consistentes para toda a silogística e se são capazes de justificar a distinção de modos silogísticos extensionalmente equivalentes. Pretendemos apresentar uma resposta afirmativa para ambos os casos.

Reservamos a seção 3.3 para investigarmos as consequências tiradas das seções anteriores. Iniciaremos com a falha do projeto reducionista, o qual, em nossa opinião, não está apto para dar uma interpretação adequada da $D G S$, nem descrever adequadamente o sentido daquilo que é "seguir-se por necessidade". Em decorrência disso, visto que não conseguimos, por meios de análise lógica, compreender as ocorrências da expressão modal de necessidade em $D G S$, tentaremos apontar para duas possibilidades em que essas ocorrências podem ser interpretadas. Como a segunda ocorrência se liga diretamente a argumentos silogísticos reconhecidos por Aristóteles ${ }^{106}$, essas duas possibilidades de analisar as duas ocorrências são: (I) ambas são iguais e a $D G S$ não estabelece qualquer critério para validade ou consequência lógica, ou (II) as duas ocorrências são distintas, sendo que a primeira se refere à validade do argumento,

106 Deixamos em aberto se Aristóteles deixou de notar ou se recusou a dita quarta figura silogística. Os resultados que nós obtemos nesta investigação não são determinantes para nenhuma dessas opções e tampouco sugerem uma eventual terceira opção. Tudo que nos é lícito afirmar é que diversos resultados deste capítulo, em particular, poderiam se beneficiar das interpretações que defendem a quarta figura silogística. Mesmo assim, não acreditamos que a recusa da quarta figura silogística seria capaz de derrubar os resultados que aqui propomos para a análise da Cláusul Final.

A respeito da quarta figura silogística, vide: Ross [1949]; Łukasiewicz [1957]; Patzig [1968]; Mignucci [1968]; Rose [1968]; Ebert \& Nortmann [2007]. 
embora já restrinja a classe de todos os argumentos válidos em geral, e a segunda ocorrência exige que esses argumentos sejam propriamente silogísticos.

\subsection{Argumentos válidos, não-silogísticos: o caso de $\operatorname{APr}$ I.4 e I.7}

Sabemos, como foi visto no primeiro capítulo deste trabalho, que a Definição Geral do Silogismo $(D G S)$ não é suficiente para determinar o sentido que a Cláusula Final deve adotar. Apesar de algumas propostas tentarem isolá-la como critério autônomo em $D G S$, essas propostas não sucederam em garantir essa interpretação. Em decorrência desses fatos, cumpre ao estudioso de $A P r$ analisar as demais ocorrências da Cláusula Final que ocorrem na obra de Aristóteles.

Além de uma ocorrência em Top VIII.11, a respeito da qual já tecemos alguns comentários, há uma segunda ocorrência da Cláusula Final em $A P r$ I.4, a qual costuma ser negligenciada pela tradição de interpretação. Esse descaso ocorre, além das razões mencionadas, pelo fato dessa cláusula estar inserida em um contexto muito debatido. Trata-se da discussão acerca do uso de termos concretos como contra-exemplos para supostos argumentos da primeira figura silogística. Nesta seção propomos uma análise desta ocorrência da Cláusula Final em $A P r$ I.4, sem nos preocuparmos, de imediato, com eventuais problemas gerados pelo uso de termos concretos. Nosso objetivo para esta seção é identificar as razões que levaram Aristóteles a empregar a Cláusula Final como critério para recusar esses argumentos como silogísticos.

Sabe-se que a meta geral de Aristóteles, nos capítulos de $A \operatorname{Pr}$ I.4 a I.6, é a apresentação de todos os silogismos que ele reconhece e sugerir algumas provas para justificá-los todos. Após a introdução das noções básicas, como disposição dos termos e o posicionamento do termo comum, ele introduz os primeiros dois modos silogísticos da primeira figura: Barbara e Celarent. Como é de conhecimento comum, esses modos são formados apenas por enunciados predicativos 
universalmente quantificados. Uma vez apresentados esses dois modos, Aristóteles continua sua investigação com uma estratégia, a partir da qual os modos silogísticos serão provados por esgotamento de casos. Uma análise de casos, no contexto do início de $\operatorname{APr}$ I.4, pretende avaliar todas as demais concatenações de predicações universais, esquematicamente ordenadas em um argumento de primeira figura, para ver se alguma delas deve ser considerada como argumento silogístico. É nesse contexto que a segunda ocorrência da Cláusula Final ocorre em $A P r$ I. Por conveniência, descreveremos essas sequências atrelando as formas categóricas da seguinte maneira: sequência ${ }^{1}-a a a$, para o modo Barbara; e sequência ${ }^{1}$-eae, para o modo Celarent ${ }^{107}$.

Aristóteles inicia sua prova considerando o caso em que as formas categóricas da sequência anterior são trocadas de lugar entre as premissas. Como havia demonstrado o modo silogístico com a sequênciaำeae dessas relações, ele cogita a sequência ${ }^{1}$-aex:

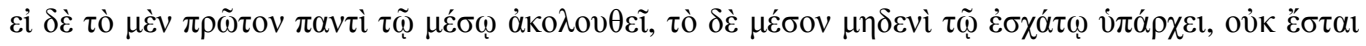

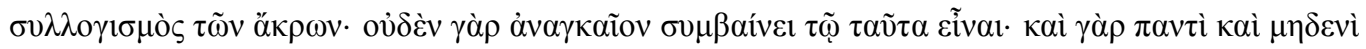

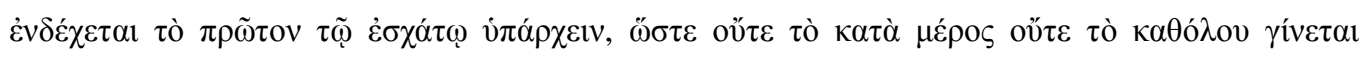

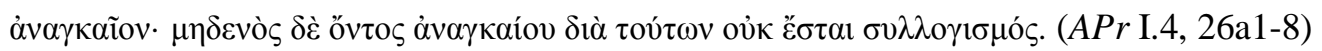

No entanto, se o primeiro se segue de todo mediador e o mediador se segue de nenhum do último, não haverá um silogismo dos termos extremos. Isso ocorre, pois nada de necessário ocorre por serem essas as premissas. Afinal, é possível que o maior se atribua ao menor tanto de modo afirmativo como de privativo, de modo que nada de necessário é engendrado nem em parte nem universalmente. Como nada é necessário, então não haverá silogismo por meio dessas.

Antes de apresentar os termos concretos para justificar sua recusa da sequência ${ }^{1}$-aex, marcando-a como inconcludente, Aristóteles desenvolve um longo argumento composto. O problema a ser demonstrado é, justamente, que a sequência ${ }^{1}$-aex não se conforma a um silogismo. Para justificar

107 Para evitarmos certas ambiguidades entre as figuras silogísticas, numeramos as sequências ${ }^{\mathrm{n}}-x y z$, onde $\mathrm{n}=\{1,2,3\}$, referindo-se à primeira, segunda e terceira figura, respectivamente, e $x, y, z \in\{a, e, i, o\}$. 
essa forte alegação, ele se utiliza de duas razões que se complementam e pelas quais essa disposição dos termos e relações predicativas falharia como argumento silogístico: (i) nada de necessário ocorre tratando-se dessa configuração das premissas (i.e., a Cláusula Final) e (ii) a partir da disposição das premissas, todas as relações predicativas entre os extremos são possíveis na conclusão, isto é, a conclusão é inconsistente.

Apesar da aparente simplicidade da estratégia da demonstração, vários pontos de dificuldade se apresentam à investigação. Em primeiro lugar, em (i) Aristóteles faz uso de uma expressão modal de necessidade, remetendo à DGS. Entretanto, a qual das duas ocorrências em $D G S$ esse uso faz remissão? Em segundo lugar, qual seria a relação entre os pontos (i) e (ii)? A própria apresentação das tríades de termos concretos visa mostrar que o critério (ii) é satisfeito, mas isso seria suficiente para provar também o critério (i)? Ou (ii) dependeria de (i) para demonstrar irrefutavelmente que uma tal disposição não se configura em um silogismo? Por outro lado, não seria possível que (ii) seja consequência de (i)? A fím de dar uma resposta apropriada para a descrição da Cláusula Final que aqui ocorre, devemos nos ater em responder essas questões.

Falsos argumentos. Parte 1: Considerando o ponto (ii) do argumento que Aristóteles apresenta, podemos inferir que as tríades de termos concretos, apresentados após a introdução da estratégia do argumento, sejam uma instanciação da sequência ${ }^{1}$-aex delineado anteriormente. Ou seja, os termos concretos apresentados servem apenas para satisfazerem a condição apresentada por (ii). Sendo assim, esse emprego de termos concretos poderia não ter sido previsto como contra-exemplo, visando provar a invalidade da sequência ${ }^{1}-a e x$, mas como razão suficiente para valer a argumentação que Aristóteles apresenta nesse trecho. Nesse caso, a estratégia é cumprida 
a partir da seguinte suposição: se um argumento obtiver conclusões inconsistentes, isto é, se as conclusões forem opostas, então não haverá silogismo. Ora, se Aristóteles for capaz de mostrar que um argumento pode chegar em dois enunciados opostos em uma suposta conclusão, ele terá satisfeito a condição (ii) e deve ser capaz de provar o restante.

De fato, o critério (ii) parece apontar para o caso de um suposto argumento ser compatível com conclusões opostas, o que seria suficiente para não ser um silogismo. Mais ainda, esse caso é condição suficiente para que Aristóteles confirme que "nada de necessário seja engendrado" e isso, por sua vez, ocorre devido à Cláusula Final. Se essa análise for correta, poderemos reinterpretar essa parte do argumento de Aristóteles da seguinte maneira: "nenhum argumento com conclusões inconsistentes engendra algo necessário, por causa da Cláusula Final”. Isto é, nenhum suposto argumento com essas características satisfaz as exigências da Cláusula Final. Parece, pois, que se o critério (ii) for condição suficiente para provar aquilo que Aristóteles pretende, então o critério (i) passa a ser condição necessária para um argumento "engendrar o necessário".

Essa primeira parte do argumento só pode ser reconstituída silogisticamente através de um Camestres, visto que a conclusão desse argumento é privativa. Ademais, não é possível que um suposto argumento com premissas inconsistentes satisfaça a Cláusula Final, o que constituiria a premissa menor. Mencionamos que esse argumento é apenas uma reconstituição parcial do argumento completo de Aristóteles. Afinal, queremos provar que argumentos com tais características não formem silogismos.

O principal passo do argumento de Aristóteles é dado em $A P r$ I.4, 26a7-8, onde ele conclui que não é possível formar um silogismo se nada de necessário for engendrado. Ora, queremos mostrar, justamente, que um suposto argumento que satisfaz conclusões inconsistentes 
não pode formar um silogismo. Sendo assim, podemos formular a seguinte asserção: "nenhum argumento que satisfaça conclusões inconsistentes é um silogismo, porque nada de necessário é engendrado". Como já obtivemos a relação entre o fato de um argumento satisfazer conclusões inconsistentes e o fato de nada de necessário ser engendrado no argumento anterior, podemos reconstituir o silogismo que prova que um tal argumento não é um silogismo. Sendo assim, a conclusão do argumento anterior se apresenta como premissa menor, resultando em mais um silogismo no modo Camestres.

Reconstituindo o argumento na linguagem própria à silogística, podemos estabelecer a seguinte análise. Sejam as seguintes variáveis substituídas por esses termos correspondentes:

$$
\begin{aligned}
& \text { A - "silogismos" } \\
& \text { B - "engendrar o necessário" } \\
& \text { C - "argumentos com conclusões inconsistentes" } \\
& \text { D - "Cláusula Final" }
\end{aligned}
$$

Dados esses termos e assumindo que nossa análise prévia esteja correta, então o argumento de Aristóteles procede da seguinte maneira:

\section{$\underline{\mathrm{C} e \mathrm{D} \quad \mathrm{B} a \mathrm{D}}$}

$$
\begin{array}{ll}
\mathrm{CeB} & \mathrm{A} a \mathrm{~B} \\
& \mathrm{CeA}^{108} .
\end{array}
$$

Essa é a reconstituição do argumento que Aristóteles esboçou em $A \operatorname{Pr}$ I.4, 26a2-8, e pretende instanciar, ao apresentar as tríades de termos apontando para esse cenário, se nossa leitura estiver correta.

108 Esse argumento dedutivo foi estabelecido de modo que à esquerda estivesse a premissa menor, que infere o termo-sujeito da conclusão, e ao lado direito estivesse a premissa maior, que infere o termo-predicado da conclusão. Sendo assim, o primeiro argumento obtém como conclusão a premissa menor do segundo argumento. 
Após essa longa apresentação do argumento, devemos voltar nossa atenção à Cláusula Final, a qual, afinal, deve ser o nosso foco, por ora. No próprio argumento apresentado acima, a Cláusula Final foi introduzida como termo mediador do silogismo que obtém a premissa menor do argumento principal. A primeira questão que devemos levar em consideração é qual a relação que a Cláusula Final tem com a expressão modal de necessidade e, por sua vez, a que essa noção de necessidade remete. Ora, essa questão pode ser respondida a partir da própria Cláusula Final em 24b22. Naquele trecho se estabelece, por definição, uma clara correlação entre a Cláusula Final e a expressão modal de necessidade. Afinal, essa cláusula se apresenta quando o “necessário é engendrado". Visto que não é certo que a Cláusula Final mantenha a mesma relação com o primeiro uso da expressão de necessidade em $D G S$, podemos afirmar que a descrição da premissa maior do primeiro argumento faz remissão, pelo menos, ao segundo uso em $D G S$.

A segunda questão com a qual nos deparamos nesse argumento é a seguinte: visto que a Cláusula Final não faz parte do argumento principal, isso a torna menos relevante ao argumento? Não temos condições suficientes para dar uma resposta satisfatória para essa questão, por ora. Entretanto, podemos aproveitar as premissas lançadas nesse argumento para verificarmos a relação que o silogismo tem com a Cláusula Final: combinando a premissa maior da primeira parte do argumento com a premissa maior da segunda parte do argumento, obtemos por Barbara que todo silogismo é (satisfaz a) Cláusula Final.

Essa conclusão parece trivial. Dada a $D G S$, é evidente que todo silogismo satisfaz a Cláusula Final. Ademais, visto que o silogismo foi definido como um argumento que satisfaz a Cláusula Final, essa conclusão pareceria como tautológica. A partir de $D G S$, podemos afirmar que há uma correspondência entre a Cláusula Final adicionada de outros critérios e argumentos 
silogísticos ${ }^{109}$. Porém, por si só, isso não garante que haja uma coextensão entre argumentos silogísticos e a Cláusula Final. Se assumirmos esse Barbara, no entanto, teremos o seguinte argumento: "tudo que engendra o necessário satisfaz a Cláusula Final”, "todo silogismo engendra o necessário", logo, “todo silogismo satisfaz a Cláusula Final”. Afinal, há uma coextensão direta entre um argumento ser silogístico e satisfazer a Cláusula Final?

A interpretação tradicional, tal como expomos no capítulo anterior, não aventa essa possibilidade, pois considera que a $D G S$, apesar de algumas restrições, aceita um número maior de argumentos como silogísticos que o número reconhecido por Aristóteles. Visto que a tradição apresenta a DGS como sendo mais ampla em relação aos silogismos reconhecidos, consequentemente, a extensão da Cláusula Final teria de ser maior que a extensão dos silogismos. De acordo com a tradição, a Cláusula Final seria coextensiva com aquilo que Aristóteles designa com a expressão modal de necessidade e faria remissão a inferências lógicas em geral. Embora essa interpretação seja compatível com o Barbara que formamos a partir do argumento acima, não há evidências suficientes para sustentar que a Cláusula Final sirva para todos os casos de inferência lógica. Manteremos, então, essa questão em suspenso por mais algum tempo.

Falsos argumentos. Parte 2: Apresentamos acima a estrutura geral do argumento que visa justificar o fato de uma sequência ${ }^{1}$-aex de relações predicativas não estar apta a formar um argumento silogístico. O raciocínio básico é que essa particular sequência, bem como a sequência ${ }^{1}-e x^{110}$, não satisfaz a Cláusula Final, o que justifica, em duas etapas, o fato desse argumento não poder ser um silogismo. Após a apresentação de sua estratégia, Aristóteles

109 Podemos conceber esquematicamente a DGS da seguinte maneira: S (silogismo) daf A (argumento)[C1 (cararacterística 1) + C2 (característica 2) + Cláusula Final]. 110 Em geral, isso vale para sequência ${ }^{\mathrm{n}}$-eex, cf. $A \operatorname{Pr}$ I.7, 29a20-1. 
apresenta as duas tríades, as quais devem instanciar o argumento anterior. Essas tríades se apresentam como supostos $\operatorname{argumentos}^{111}$ com sequência ${ }^{1}$-aex de formas categóricas, cada um apresentando conclusões que são opostas entre si:

\section{Pseudo-Silogismo 1:}

Todo homem é animal

$\underline{\text { Nenhum cavalo é homem }}$

Todo cavalo é animal

Pseudo-Silogismo 2:

Todo homem é animal

$\underline{\text { Nenhuma pedra é homem }}$

Nenhuma pedra é animal

\section{Esquema do Pseudo-Silogismo 1:}

$\mathrm{B} a \mathrm{~A}$

$\underline{\mathrm{C} e \mathrm{~B}}$

$\mathrm{C} a \mathrm{~A}$

\section{Esquema do Pseudo-Silogismo 2:}
$\mathrm{B} a \mathrm{~A}$
$\underline{\mathrm{C} e \mathrm{~B}}$
$\mathrm{C} e \mathrm{~A}$.

Os falsos argumentos que obtemos através da substituição dos termos no esquema argumentativo pretendido revela um aspecto perturbador. Consideremos o seguinte critério de invalidade para um argumento lógico: um argumento é inválido se e somente se a conclusão for falsa e as premissas, verdadeiras. Se considerarmos esse critério de invalidade, então esses argumentos não poderiam ser invalidados mediante uma tal apresentação dessas tríades de termos concretos. A rigor, se for utilizado apenas um critério para a validade lógica, esses exemplos concretos não constituem contra-exemplos de uma regra, como se assumiu pela tradição. Para esses exemplos constituírem contra-exemplos de algo, é preciso que uma consideração adicional seja levada em consideração ${ }^{112}$. Como nosso objetivo é fazer um estudo da silogística sem turvar

\footnotetext{
111 Devemos enfatizar o fato que essas sequências não são argumentos silogísticos. Eles são apresentados como se o fossem apenas como instância do argumento anterior. De outro modo, não faria sentido que esses fossem representados como tal. Vide Łukasiewicz [1957] e sua crítica a Maier.

112 Na tradição da lógica, esse item seria reconhecido como forma lógica. Projetos filosóficos, reconhecidos por sua preocupação em demarcar a lógica, tentam isolar esse polêmico conceito de forma lógica para melhor compreender os procedimentos propriamente lógicos. Vide: MacFarlane [2000][2009], Novaes [2012]. Para uma
} 
nossa interpretação com considerações da filosofia da lógica clássica, evitaremos tais considerações.

Tampouco podemos imputar a Aristóteles a falha de não conseguir formar contraexemplos para essas supostas regras inferenciais. Pouco antes, em $A P r$ I.2, ele introduzira as conversões das predicações e rejeitara, através do uso de contra-exemplos, a conversibilidade de enunciados predicativos privativos particulares. Além desse ponto, surge como problema a consciência de Aristóteles, como ele mesmo demonstra em $A P r$ II.2 a II.4, que a validade dos argumentos pode ser verificada verofuncionalmente. Naqueles capítulos, Aristóteles faz uso das noções de verdade aplicando-as em um modelo muito similar às tabelas de verdade, utilizadas hodiernamente para a determinação da validade lógica de um argumento. De acordo com esses fatos, não seria possível imputar a Aristóteles o erro de não conseguir estabelecer um contraexemplo em $A \operatorname{Pr}$ I.4.

Visto que Aristóteles não poderia ter errado quanto ao estabelecimento de contraexemplos, não se pode afirmar que a preocupação em fornecer casos concretos servia para rejeitar a validade do argumento. Ora, se o uso desses exemplos não se destina à emissão de qualquer juízo a respeito da noção de validade lógica, então fica em aberto a questão a respeito de qual seria a intenção de Aristóteles. As únicas duas possibilidades de fazer algum sentido desses exemplos estão assumidas no argumento acima: (i) supostos argumentos com conclusões inconsistentes não são silogismos, porque não engendram o necessário; (ii) tais argumentos não engendram aquilo que é necessário, porque falham em cumprir a Cláusula Final. Mas o que se pretende dizer, exatamente, com a expressão "aquilo que é necessário"?

Como mencionamos previamente, a tradição entende que essa expressão, uma vez que posição crítica, vide: Szabó [2014]. 
não pode denotar o mesmo que a noção lógica da modalidade, faz remissão à própria inferência lógica de um argumento. Essa tradição entende que tais pseudo-argumentos não são silogismos por falharem em apresentar uma relação única com a conclusão e, em função disso, a apresentação das tríades serviria como contra-exemplo a um argumento silogístico. Entretanto, para a interpretação tradicional se manter consistente, ela terá de aceitar que essas tríades servem de contra-exemplos apenas para um argumento silogístico e não para um argumento válido, em geral. É justamente nesse ponto que a tradição passa a enfrentar dificuldades em sua interpretação desses exemplos, pois falham em marcar uma distinção entre argumentos silogísticos e nãosilogísticos $^{113}$.

Um outro raciocínio que nos permite levantar a consideração que Aristóteles não estava preocupado com a validade lógica do argumento, mas com algo distinto, é que esse conjunto de premissas obtém uma conclusão válida, reconhecida por Aristóteles. Como veremos a seguir, Aristóteles volta a esse exemplo em $A \operatorname{Pr}$ I.7, mostrando que com essa concatenação de premissas sempre é possível obter uma conclusão.

Uma comparação de $A \operatorname{Pr}$ I.4 e $\boldsymbol{A P r}$ I.7: $\quad$ Em $A P r$ I.7, após a apresentação de todos modos silogísticos reconhecidos, Aristóteles volta sua atenção, outra vez, para os supostos argumentos discutidos em $A P r$ I.4. Ao contrário da discussão anterior, Aristóteles reconhece a possibilidade de, a partir do conjunto de premissas em questão, obter uma conclusão lógica, contrariando, aparentemente, suas próprias afirmações prévias. A conclusão que segue logicamente desse

113 De certo modo, um fator contribuinte para essa situação é falta de um vocabulário técnico no texto de Aristóteles. O termo syllogismos pode remeter a várias noções, variando entre o sentido de um argumento propriamente silogístico ou simples inferência lógica, entre outros sentidos que pode adotar. Pretendemos arguir a favor da interpretação que Aristóteles não poderia pensar no sentido de inferência lógica, quando emprega a Cláusula Final em $A P r$ I.4. 
conjunto de premissas é da forma predicativa "A $o \mathrm{C}$ ", em vez de ser "C $x \mathrm{~A}$ ”.

De acordo com a interpretação tradicional, como vimos há pouco, um argumento com conclusões inconsistentes não pode constituir um silogismo, em virtude de ser incapaz de apresentar uma conclusão necessária. Em $A P r$ I.4, isso teria sido o ponto, precisamente, para recusar a sequência ${ }^{1}$-aex como silogística. No entanto, uma vez que Aristóteles acaba reconhecendo uma conclusão para esse conjunto de premissas, estaria todo o argumento de I.4 fadado ao fracasso? De acordo com a própria interpretação tradicional, a resposta a essa questão tem de ser afirmativa. Supondo que o argumento seja avaliado apenas extensionalmente, o fato desse conjunto de premissas possibilitar uma inferência lógica válida, isto é, o engendramento daquilo que é necessário, é suficiente para servir de contra-exemplo à própria interpretação de $\operatorname{APr} \mathrm{I} .4^{114}$.

Esse problema é reflexo da proposta tradicional de se assumir aquilo que é necessário, justificado pela Cláusula Final, em $A \operatorname{Pr}$ I.4, como mera inferência lógica. Esse, pois, é um desafio com o qual teremos que lidar. Voltemos a nossa atenção para a descrição que Aristóteles nos apresenta em $A P r$ I.7:

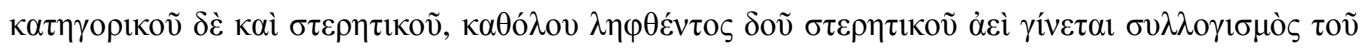

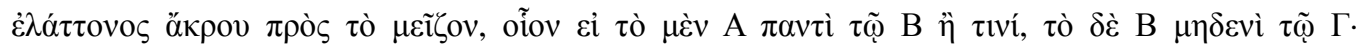

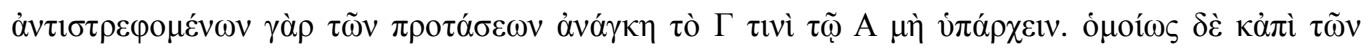

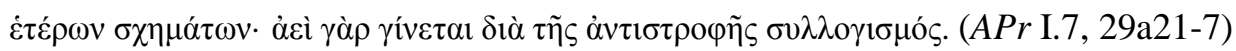

Mas da combinação de uma afirmativa e de uma privativa, sendo a privativa assumida universalmente, sempre haverá uma inferência do extremo menor para o maior. Por exemplo, se todo B é A e nenhum C é B, convertendo-se as predicações, é necessário que

114 Alguns intérpretes como Striker [2009], p.96, atribuem essa falha ao próprio Aristóteles. De acordo com seu comentário, o fato de Aristóteles ter se focado apenas sobre casos em que o termo A servisse como predicado, ele não percebeu que uma conclusão teria sido possível; um problema que ele remediou em $A \operatorname{Pr}$ I.7.

Discordamos de Striker no que diz respeito a Aristóteles não notar uma certa possibilidade. Como iremos demonstrar a seguir, a preocupação de Aristóteles era distinguir, mediante a Cláusula Final, argumentos válidos em silogísticos e não-silogísticos. 
algum A não seja C. O mesmo ocorre também com as demais figuras, uma vez que sempre se obtém um silogismo através da conversão.

Nesse trecho, Aristóteles parece apelar para as regras de conversão a fim de provar que uma conclusão é possível, bem como sempre será o caso. Isto é, há uma conclusão que é necessária, de acordo com a interpretação tradicional. O argumento aristotélico é bastante sintético e faz uso de conceitos cujo sentido não é especificado. Um exemplo disso é o próprio caso da conversão que ele menciona. A conversão não pode se referir apenas às regras de conversão que Aristóteles introduz em $A \operatorname{Pr}$ I.2, mas deve se referir à alteração na disposição dos termos e das relações predicativas desse mesmo conjunto de premissas, como parece defender em APr II.8-10.

Considerando-se essa estratégia, porém, obtém-se um ponto curioso: um argumento antes tido como inválido é validado por um procedimento não diferente daquele aplicado aos silogismos no chamado "aperfeiçoamento" dos argumentos. Certamente, isso não é o ponto relevante para aquilo que Aristóteles havia pretendido nessa apresentação. Por sua vez, o texto é muito sucinto para identificar-se o ponto relevante nesse trecho, de modo que a única estratégia para se fazer uma comparação bem sucedida com o argumento desenvolvido em $A P r$ I.4 é comparar dois argumentos equivalentes. A fim de conseguirmos avaliar esses argumentos, no entanto, precisamos buscar critérios nos trechos mencionados.

Partindo desse pressuposto, devemos iniciar com as afirmações de Aristóteles a respeito da formação dos silogismos. Com base nessas asserções, apresentadas em $A P r$ I.4, podemos afirmar duas coisas: que, em geral, o silogismo se dá em virtude da Cláusula Final e que na ocasião do capítulo de $A P r$ I.4 não era possível obter uma conclusão a partir da sequência ${ }^{1}$-aex, pois a Cláusula Final não permite a obtenção de uma conclusão para seu conjunto de premissas

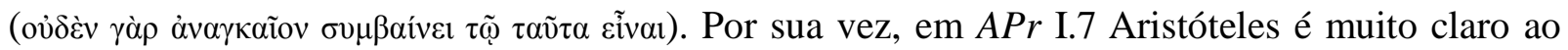




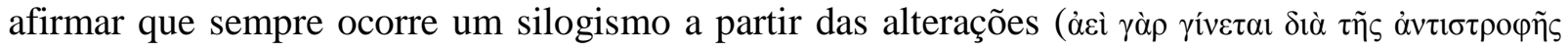
$\left.\sigma 0 \lambda \lambda \mathrm{o} \gamma \mathbf{i} \sigma \mathrm{ó}_{\varsigma}\right)$. Como essas duas asserções, aparentemente contraditórias, podem tratar do mesmo caso?

A resposta para essa pergunta está em um pequeno detalhe que pode fazer a diferença em nossa investigação. Quando Aristóteles apresenta a possibilidade de se ter uma conclusão em $A P r$ I.7, ele o faz com os termos extremos invertidos (AoC) e não com a disposição que se esperaria em $A \operatorname{Pr}$ I.4 (CxA). Nas palavras do próprio texto, "sempre haverá consequência do extremo menor para o extremo maior" ( $A P r$ I.7, 29a22-3). O ponto parece ser pouco relevante, a princípio, mas a única razão pela qual o suposto argumento era considerado inconclusivo se devia à disposição em que os termos extremos se encontravam nas premissas, sugerindo uma conclusão em CxA.

Tanto mais surpreendente essa sucinta observação passa a ser, quando voltamos ao argumento em $A P r$ I.4 e verificamos que a razão pela qual aquilo que é tido como necessário não ocorria estava na própria Cláusula Final. Ora, se a Cláusula Final da DGS serve como critério para garantir essa característica em um argumento, podemos inferir que a mesma determina que a conclusão apresente a mesma ordenação dos termos das premissas. Considerando o caso de estudo, o Fresison invertido, a disposição dos termos e das premissas não forma um argumento silogístico, nessa exata disposição. Para ser considerado um silogismo, a ordem dos termos extremos, tal como estabelecida nas premissas, deve ser preservada na conclusão. Seguindo essa linha de raciocínio, a disposição do termo dito maior e, por conseguinte, do menor já está determinada. No caso do Fresison invertido, portanto, a sequência a ser obtida deveria ser CxA.

A introdução de uma ordenação das premissas soa contra-intuitiva e enfrenta uma série de dificuldades. Por exemplo, interpretações que consideram apenas três figuras silogísticas podem 
defender sua posição ao desprezarem a ordem das premissas $^{115}$. Sendo assim, uma objeção possível à interpretação de se impor uma sequência das premissas seria a incapacidade, efetiva, de decidir a respeito da admissão da suposta quarta figura silogística. Por sua vez, quem defende a existência da quarta figura silogística poderia defender que o argumento em $A P r$ I.7 não se afigura como um argumento não-silogístico, pois é um argumento da quarta figura com premissas invertidas. De fato, caso se admitisse a quarta figura silogística, esse exemplo seria uma instância dessa figura, muito embora suas premissas estivessem alteradas. Ambas as objeções, no entanto, não podem menosprezar o fato que há uma diferença entre dois argumentos, cujo conjunto de premissas é idêntico, mas se diferenciam quanto a sua conclusão.

Retornemos ao argumento dos supostos contra-exemplos em APr I.4. Como mencionamos, a tradição interpretativa entende o exemplo com as tríades de termos concretos como instâncias de um mesmo argumento, cada uma obtendo uma conclusão distinta ${ }^{116}$. Sendo assim, o suposto argumento seria inconsistente. Ressaltamos para o fato que a tradição interpretativa entende o uso de termos concretos como contra-exemplo à sequência1-aex de modo que nenhuma conclusão seja possível. Sendo assim, a interpretação tradicional assume que o uso de supostos contra-exemplos seja suficiente para negar o caso de uma consequência válido, deixando de reconhecer, no entanto, que a conclusão apresenta os termos em uma ordenação específica. O ponto principal para a crítica feita por Aristóteles, em $A \operatorname{Pr}$ I.4, não é o fato daquele conjunto de premissas ser inconcludente, por apresentar conclusões que sejam inconsistentes, mas por não apresentarem uma conclusão em uma determinada sequência dos extremos.

115 Cf. Striker [2009].

116 Devemos apontar que com esse raciocínio, as interpretações dependem de um critério adicional para avaliarem a validade lógica de um argumento, o que reflete o projeto filosófico de seus intérpretes. Considerar que esses supostos contra-argumentos são uma instância de algo que foge à regra é porque há uma regra previamente determinada. No caso das interpretações lógicas, trata-se da noção de forma lógica. Cf. MacFarlane [2000][2009], Novaes [2012]. 
$\mathrm{O}$ fato de Aristóteles reconhecer aquele conjunto de premissas como formando um argumento válido, embora não seja silogístico, nos possibilita arguir contra a interpretação da validade lógica como preocupação primordial do contexto, como é mantido pela interpretação tradicional. De acordo com as afirmações de Aristóteles, não se trata do conjunto de premissas ser inconcludente. $\mathrm{Na}$ reconstituição que fizemos do argumento aristotélico em $A P r$ I.4, fica claro que, uma vez descumprida a Cláusula Final, o argumento que se segue não pode ser um silogismo. Em decorrência disso, acreditamos que Aristóteles não tinha a pretensão de atestar se um certo conjunto de premissas era inconcludente, mas distinguir quando um argumento é silogístico ou não.

Disso resulta que o argumento apresentado tanto em $\operatorname{APr}$ I.4 como em I.7, não é um silogismo, muito embora possa ser manipulado de modo a se obter um argumento silogístico equivalente. Isto é, considerando-se as mesmas premissas e a mesma conclusão, podemos formar um argumento silogístico, o qual é extensionalmente equivalente ao argumento não-silogístico, porque ambos obtêm a mesma conclusão de premissas que apresentam o mesmo conteúdo. Isso gera uma dúvida, a saber: se um argumento não-silogístico pode ser alterado de modo a se tornar um silogismo, qual seria, então, o critério que distingue ambos os argumentos?

Antes de aventarmos qualquer hipótese a respeito dessa questão, vale retomar alguns pontos que deixamos em suspenso no início da seção. Após da análise do argumento em APr I.4, incluindo os exemplos fornecidos por Aristóteles, podemos conjecturar algo sobre as relações entre os fatos (i) e (ii), afirmados no início do argumento. Como vimos naquela ocasião, estas são as duas condições pelas quais um argumento não seria silogístico: (i) nada de necessário ocorre devido à Cláusula Final e (ii) a partir da disposição das premissas, as conclusões que podem ser sustentadas, com uma sequência determinada dos termos extremos, serão inconsistentes. Após a 
análise do argumento, podemos considerar o seguinte: a razão (i), a qual envolve a Cláusula Final, foi responsável por demonstrar que um argumento inconsistente estaria destituído daquilo que é necessário. Por sua vez, o fato de um argumento ser inconsistente, implica, por (ii), que um argumento não é silogístico. Com isso, temos uma clara relação em que (i) implica (ii) e essa relação se mostra como contra-positiva do Barbara que construímos naquela ocasião, com a conclusão que se a Cláusula não for satisfeita, então o argumento não será silogístico. De acordo com essa análise, nenhuma outra relação pode ser atestada. Isso implica que a questão a respeito de uma eventual co-extensão entre argumentos que satisfazem as Condições Inferenciais e argumentos que satisfazem também a Cláusula Final não pode ser confirmada, nem reprovada.

Argumentos não-silogísticos: Vimos, acima, que para um argumento ser silogístico, não basta satisfazer certos critérios que poderiam ser observados a partir das Condições Inferenciais da $D G S$. A disposição dos termos na conclusão, isto é, sua sequência determinada, é relevante a fim de possibilitar a discussão que foi desenvolvida acima. Mas qual é o critério que determina essa sequência dos termos no silogismo? Observamos que, em geral, o termo-predicado é introduzido na premissa maior e o termo-sujeito na premissa menor. De fato, parece haver uma correlação entre a disposição das premissas e a sequência esperada dos termos na conclusão. Entretanto, uma tal observação está longe de constituir uma razão apropriada, pela qual esses termos tenham sua sequência determinada.

A fim de obtermos um resultado mais promissor, devemos adotar uma nova estratégia de análise. No caso do argumento apresentado em $A \operatorname{Pr}$ I.7, a disposição dos termos na conclusão foi suficiente para distinguir o argumento entre inconcludente e argumento válido. Entretanto, essa mera inversão dos termos é suficiente para garantir tais resultados? Em princípio, a resposta a 
essa questão seria negativa. Uma maneira de verificar essa alegação, no entanto, é comparando o argumento em $A P r$ I.7 com argumentos extensionalmente equivalentes. Entendemos por argumentos extensionalmente equivalentes aqueles argumentos que são formados pelas mesmas premissas e obtêm a mesma conclusão. A única diferença entre esses argumentos está no esquema lógico no qual são apresentados ${ }^{117}$.

Podemos assumir o seguinte como hipótese inicial: a disposição das premissas é relevante para a obtenção da conclusão silogística. O fato de Aristóteles reconhecer que aquele conjunto de premissas obtém uma conclusão válida o compromete com a distinção entre argumentos silogísticos e não-silogísticos. Isso seria o caso, sobretudo, se a hipótese inicial for confirmada. Assumamos a existência de argumentos não-silogísticos e consideremos alguns deles como passíveis de alteração. Dessa maneira, esses argumentos serão convertidos em um silogismo, o qual prova a conclusão que esses argumentos não-silogísticos adotam. Com isso, podemos justificar a hipótese que aventamos: em todas as alterações possíveis para obter um argumento silogístico, a ordem das premissas é alterada. Ademais, as próprias premissas são convertidas, na maior parte dos casos, a fim de se obter um silogismo ${ }^{118}$.

Entretanto, se o critério for apenas a disposição das premissas, então essa hipótese estaria sujeita a fortes críticas por parte da tradição interpretativa. A interpretação tradicional reconhece o argumento em $A P r$ I.7 como silogístico, apesar de não sê-lo naquela disposição em que se encontra. Para essa interpretação, a disposição de termos teria relevância antes para fins

117 Casos de silogismos extensionalmente equivalentes: Celarent, Cesare, Camestres; Darii, Disamis, Datisi.

118 A única excessão à exigência de converter as premissas se daria, caso a quarta figura silogística fosse levada em consideração. No que tange à ordem das premissas, porém, todos os argumentos silogísticos, inclusive a suposta quarta figura, apresentam uma correspondência entre premissa maior e termo-predicado, premissa menor e termo-sujeito.

A rigor, isso pode ser considerado como o argumento obtendo sua conclusão indiretamente, já que ele não se afigura como silogismo. 
estilísticos que para fins propriamente lógicos ${ }^{119}$. Em virtude dessa interpretação, não se poderia negar como consequência a invalidação total do argumento que Aristóteles estabelece em $A P r$ I.4, onde procura provar a inconsistência das conclusões como razão suficiente para um argumento não ser silogístico. Mais ainda, essa interpretação teria que admitir que a conclusão obtida em Barbara que todo silogismo é marcado pela presença da Cláusula Final não se segue e que, em última análise, a $D G S$ é, ela mesmo, inconsistente.

Uma vez que tais consequências não são aceitáveis, o reconhecimento da quarta figura pela interpretação tradicional, considerando apenas a inversão da sequência de premissas, não nos impede de compararmos ambos os argumentos com a mesma sequência dos enunciados. De fato, o reconhecimento da suposta quarta figura apenas contribui para o ponto que defendemos, a saber, de haver uma ordem nas premissas ${ }^{120}$. Ora, se as premissas são ordenadas, então nos é lícito considerar que Aristóteles reconhece a validade do argumento em $A \operatorname{Pr}$ I.7 e que, mesmo formando um argumento da suposta quarta figura, ele não pode ser silogístico nessa ordenação de suas premissas. Sendo assim, apesar do reconhecimento da quarta figura, não se pode negar que Aristóteles apresenta duas noções distintas de consequência lógica ${ }^{121}$.

O fato de Aristóteles reconhecer duas classes de argumentos válidos nos possibilita fazer uma comparação entre argumentos silogísticos, argumentos não-silogísticos e pseudoargumentos. Voltemos, por ora, ao exemplo de $A P r$ I.7. Aristóteles reconhece dois casos de argumentos válidos de uma só vez ao dizer, em $A P r$ I.7, 29a22-3, que não importava se a premissa maior fosse formada por uma $i$-predicação ou uma $a$-predicação. Desde que a privativa

119 Cf. Rose [1973]

120 Striker [2009] confirma nosso ponto pela afirmação contra-positiva, dizendo que se as premissas no conjunto não são ordenadas, poder-se-ia descartar a quarta figura silogística.

121 Muito embora tenha falhado em sua análise a respeito desse trecho, comprometendo sua própria interpretação, Lear reconhece, corretamente, em nossa opinião, qur Aristóteles tinha consciência de que não se tratava da mesma noção de consequência lógica. 
fosse considerada universalmente, a conclusão dessa combinação de premissas seria sempre aquela em que o termo maior fosse sujeito do termo menor. A partir disso, poderemos montar um estudo de casos de argumentos que seriam equivalentes no que diz respeito a sua extensão. Porém, um desses argumentos seria silogístico enquanto o outro seria não-silogístico. Assumimos para tal estudo os casos de Ferio, como caso de controle, e adotamos os argumentos Fresison com a sequência de premissas invertidas e o mesmo conjunto de premissas inconcludente, na medida em que se pretende como argumento na primeira figura silogística.

Todos esses argumentos ou pseudo-argumentos têm, extensionalmente, as mesmas premissas, embora em alguns casos haja conversão dos termos, e todos estarão dispostos no esquema da primeira figura silogística:

$\begin{array}{ccc}\text { Disposição 1 (silogismo) } & \text { Disposição 2 (extensão) } & \text { Disposição } 3 \text { (non sequitur) } \\ \mathrm{BeC} & \mathrm{BiA} & \mathrm{BiA} \\ \mathrm{AiB} & \underline{\mathrm{CeB}} & \underline{\mathrm{CeB}} \\ \mathrm{AoC} & \mathrm{AoC} & \mathrm{CxA}\end{array}$

Nosso interesse é encontrar uma razão para a distinção desses argumentos em silogísticos e nãosilogísticos. Como a distinção desses argumentos se deve à Cláusula Final da $D G S$, podemos dizer que essa investigação tem por meta compreender melhor o funcionamento da própria Cláusula Final.

As três disposições aqui apresentadas mostram exatamente o cenário que antes mencionamos: temos um silogismo, um argumento não-silogístico e um pseudo-argumento. Todas essas disposições têm, extensionalmente, as mesmas premissas com o mesmo termo comum. Os dois argumentos válidos, ainda, apresentam a mesma conclusão. A única diferença, aparentemente, é sua configuração das premissas, sendo que na disposição 1 (Ferio) o termo maior equivale ao termo menor do argumento na disposição 2 (Fresison invertido). O argumento 
na disposição 2 só é aparentemente um argumento configurado na primeira figura silogística, como podemos verificar na disposição 3 (non sequitur). De acordo com o critério de satisfação da Cláusula Final, a disposição 3 - mas não a disposição 2 - poderia se candidatar para ser um argumento na primeira figura silogística, mas acaba violando a própria Cláusula Final. O argumento na disposição 2 seria provado apenas indiretamente por um silogismo.

Considerando as regras da conversão ${ }^{122}(\mathbf{R} 1)$ e $(\mathbf{R 3})$, poderíamos afirmar, em princípio, que a única diferença efetiva entre os argumentos da disposição 1 e disposição 2 é a disposição dos termos extremos e das formas categóricas, ambos invertidos. De acordo com essa observação, tanto quanto a disposição dos termos na conclusão pode introduzir uma distinção entre um argumento ser válido ou deixar de ser um argumento de modo geral, a disposição das próprias premissas parece fazer diferença entre um argumento ser silogístico ou não. Embora ambos os argumentos sejam extensionalmente equivalentes e estejam na mesma disposição esquemática, isso não os torna um mesmo silogismo, porque a conclusão do argumento na disposição 2 é obtida indiretamente.

De fato, a nossa descrição de como a conclusão é obtida através de um procedimento indireto é motivada pelo comentário de Aristóteles a respeito da conclusão. Em 29a22-3, ele anuncia qual o tipo de conclusão que esses argumentos em $\operatorname{APr}$ I.7 podem apresentar. Dada a disposição dos termos no esquema silogístico da primeira figura, a única conclusão possível seria obtida ao relacionar o termo maior enquanto sujeito do termo menor (aei ginetai syllogismos tou elattonos acrou pros to meizon). $\mathrm{O}$ argumento não procede diretamente, como nos demais casos de argumentos silogísticos, mas depende de uma inversão no cálculo. Essa inversão se mostra na disposição dos termos da conclusão. O termo que deveria ser o predicado passa a ser o sujeito e 122 Cf. Capítulo 1, p.19. 
vice versa.

Sem considerar as provas indiretas, por estabelecimento de outros silogismos como o próprio Ferio, é possível obter essa mesma conclusão com raciocínio extensional. A etapa mais importante para se chegar à conclusão do argumento é, precisamente, o momento em que se inverte o termo-predicado e se passa a considerar a relação inversa dos functores. Independente da extensão do predicado A, a única possibilidade que temos para obter uma conclusão é considerar aquele elemento de $\mathrm{A}$, isto é, aquele $\mathrm{B}$, que não pode ser $\mathrm{C}$, já que nenhum $\mathrm{C}$ é $\mathrm{B}$. No entanto, havíamos negado a possibilidade de fazermos cálculos a partir das extensões no contexto da lógica aristotélica. Para evitar considerações extensionais, faremos uma demonstração similar com base na semântica dos dicta.

\section{Teorema 3.1.1: $\quad \mathrm{B} i \mathrm{~A}, \mathrm{C} e \mathrm{~B} F \mathrm{~A} o \mathrm{C}$.}

\begin{tabular}{|c|c|c|}
\hline \multirow[t]{2}{*}{ Prova: } & 1. $\exists \mathrm{X}(\mathrm{X} a \mathrm{~B} \wedge \mathrm{X} a \mathrm{~A})$ & , premissa 1 \\
\hline & 2. $\cdot \mathrm{Y}(\mathrm{Y} a \mathrm{C} \cdot \neg(\mathrm{YaB}))$ & , premissa 2; \\
\hline & 3. $\mathrm{ZaC} \cdot \neg(\mathrm{Z} a \mathrm{~B} \wedge \mathrm{ZaA})$ & $, \mathrm{LC}, 1,2$ \\
\hline & 4. $(\mathrm{ZaB} \wedge \mathrm{ZaA}) \cdot \neg(\mathrm{ZaC})$ & , contra-positiva de 3 \\
\hline & 5. $\cdot \mathrm{X}((\mathrm{X} a \mathrm{~B} \wedge \mathrm{X} a \mathrm{~A}) \wedge \neg(\mathrm{X} a \mathrm{C}))$ & , introdução de existencial, instanciação 4; \\
\hline & 6. $\cdot \mathrm{X}(\mathrm{X} a \mathrm{~A} \wedge \neg(\mathrm{X} a \mathrm{C}))$ & , regra de eliminação (LC), 5 . \\
\hline
\end{tabular}

Tal como havíamos apontado anteriormente, a satisfação da Cláusula Final apresenta certos fatos que devem ser observados. Fato 1: Um silogismo obtém sua conclusão dentro de uma determinada ordenação dos termos extremos. Fato 2: A ordem das premissas deve refletir a sequências dos termos da conclusão. No entanto, as observações desses fatos não passam de uma 
constatação e não constituem, em si mesmos, uma razão que os justifique. Ou seja, apesar de termos identificado esses fatos da silogística em nossa discussão anterior, esses não constituem razões suficientes para determinar a consequente distinção entre tipos de argumento e tipos de consequência lógica.

Nesse tipo de investigação, um elemento do argumento se destaca, a saber: o termo comum a ambas as premissas. Como vimos na comparação entre os argumentos Ferio e o argumento apresentado pela inversão do Fresison, a única diferença que podemos identificar está na inversão da relação atribuída ao termo mediador. Com isso, podemos identificar que a nossa questão a respeito do critério que distingue um argumento silogístico de um não-silogístico se liga fortemente ao papel a ser desempenhado pelo termo mediador. Podemos utilizar a nossa prova, acima, do Fresison invertido, para elucidar o ponto que pretendemos firmar. A única inferência direta que podemos estabelecer não é entre o termo C e o termo A, mas entre o termo C e o composto BA, o qual, a partir da algumas aplicações de regras lógicas, pode ser reduzido ao termo A. Isso quer dizer que o papel a ser desempenhado pelo termo mediador, de fato, é desempenhado por um conjunto de regras que incidem sobre o composto BA, tornando o termo B eliminável. Sendo assim, sua função não é de mediação, mas apenas de restrição semântica do termo A.

Buscar uma justificativa no termo mediador parece ser a solução mais apropriada, muito embora deva ser feito com muita cautela, pois corre-se o risco de descaracterizar o próprio mediador. Por ora, podemos apresentar o termo mediador como critério exigido pela Cláusula Final, como hipótese de trabalho. Pretendemos confirmar essa hipótese de trabalho em nossa análise dos capítulos $A \operatorname{Pr}$ I.23 e I.25, no próximo capítulo deste trabalho. 
Uma questão de notação: Em nossa descrição anterior, chegamos a resultados que diferenciam argumentos lógicos válidos em silogísticos e não-silogísticos. Vimos, também, que parte da razão para tal fato está no posicionamento das próprias premissas, indicando claramente que a disposição das premissas era fundamental para um argumento ser visto como silogismo, ou não. Formulamos, também, uma hipótese de trabalho que identifica a função de mediação, desempenhada pelo termo comum, como critério da Cláusula Final.

A fim de facilitar a exposição dos silogismos, entendemos que seria vantajoso introduzir uma notação para destacar os diversos argumentos que formulamos acima. Como foi visto, há uma distinção entre aquilo que chamamos de consequência silogística e consequência lógica. Essa distinção foi possível apenas mediante o estabelecimento das premissas e a fixação de uma ordem das premissas. Tal aspecto é tão marcado que poderemos considerar o conjunto de premissas de um argumento silogístico como um par ordenado em que a premissa maior ( $\left.\mathrm{p}_{1}\right)$ e a premissa menor $\left(\mathrm{p}_{2}\right)$ sejam relacionadas de seguinte maneira: $\square \mathrm{p}_{1}, \mathrm{p}_{2} \cdot$. Se esse par ordenado apresentar todas as propriedades mencionadas, inclusive da Cláusula Final, então poderemos demarcar a consequência desse par por meio de um símbolo de consequência silogística: $\square \mathrm{p}_{1} \mathrm{p}_{2} \cdot \|_{2} \mathrm{c}$.

A discussão em $A \operatorname{Pr}$ I.7, sugere que certos conjuntos de premissas, se considerados como pares ordenados, não formam um silogismo, mas obtêm uma conclusão válida. Os argumentos correspondentes a esses pares estabelecem uma inferência não silogística que pode ser notada com o seguinte símbolo de consequência lógica: $\square \mathrm{p}_{1} \mathrm{p}_{2} \cdot$ - c. Com essa notação não pretendemos decidir acerca da noção se essa consequência lógica seria uma consequência 
sintática ou semântica123. Nosso único intuito é apresentar uma notação em que a diferença entre consequência silogística e consequência não-silogística é marcada claramente.

Devemos frisar que, no caso da silogística, essa notação é apenas um artifício para facilitar a compreensão de certos problemas de ordem lógica, ou para visualizar propriedades que poderiam ser relevantes na compreensão do próprio cálculo silogístico. Embora, enquanto notação, pretenda satisfazer os critérios estabelecidos pela silogística, ela não tem a pretensão de ser um substituto fiel desse cálculo. Para Aristóteles, a ordem dos enunciados de um argumento silogístico é irrelevante, como se pode ver no próprio texto aristotélico124. Referimos-nos à ordem das premissas pelas razões expostas acima, as quais diferenciam argumentos de mesma extensão. Isso é visto, sobretudo, no que diz respeito à razão que distingue esses tipos de inferência. Nos deparamos com esse problema ao compararmos argumentos como Ferio e o Fresison invertido. Nesse caso, podemos apenas marcar o fato que $\square \mathrm{B} e \mathrm{C}, \mathrm{A} i \mathrm{~B} \cdot \|_{2} \mathrm{~A} o \mathrm{C}$ e

$\square \mathrm{B} i \mathrm{~A}, \mathrm{C} e \mathrm{~B} \cdot \quad$ - $\mathrm{A} o \mathrm{C}$, mas essa notação não evidencia uma razão para visualizar o problema, com o qual nos deparamos.

Utilizamos mais um recurso para a notação nas provas silogísticas. A semântica heterodoxa do dictum de omni considera uma distinção entre as duas premissas de um argumento silogístico. Enquanto a primeira é exposta de modo similar às teorias ortodoxas, a segunda considera que o termo menor está diretamente ligado ao mediador125. Grosso modo, o termo

123 Lear se manifesta a respeito disso, atribuindo a essa consequência o papel de ser semântica. Cf. Lear [1980], p.55 n.1.

124 Cf. $A P r$ I.6, 28a17-22.

125 Os sistemas semânticos que avançam tal interpretação se baseiam em um argumento avançado por Aristóteles em sua parte modal: $A \operatorname{Pr}$ I.9, 30a21-3. 
menor é parte do termo maior126. Como se aplica uma certa noção de quantificação às premissas e a relação admitida na linguagem da semântica adotada, $\{a\}$, é tomada como base para a interpretação da linguagem, é preciso introduzir duas notações adicionais que podem ser atreladas ao termo menor. Trata-se de operadores como o $\lambda$, o qual informa que o termo menor se associa como um todo ao termo mediador, e o $\mu$, o qual informa que o termo menor se associa parcialmente com o mediador.

\subsection{A sequência de termos em silogismos extensionalmente equivalentes}

O fato surpreendente que tentamos apresentar na seção anterior se deve à capacidade de um critério da Cláusula Final ser suficiente para determinar se um argumento é silogístico ou não. Vimos que a única razão pela qual o par de premissas, apresentado em $A P r$ I.4, pode ser visto como estéril é considerando-se a fixação dos termos extremos em uma sequência determinada. Caso contrário, não seríamos capazes de sustentar a afirmação de que os exemplos apresentados em 26a8-9 não formariam um argumento lógico. Afinal, como foi visto em APr I.7, Aristóteles reconheceu que esse argumento é possível, quando a sequência dos termos da conclusão é invertida. A inversão da conclusão é justificada por Aristóteles, como vimos, pela descrição de que um silogismo é possível através da alteração do par de premissas (dia tēs antistrophēs). Essa alteração pode ser efetuada por intermédio da conversão de certas premissas ou da inversão do par de premissas.

A partir dessa observação, consideramos lícito formular a seguinte questão: se a sequência dos termos é suficiente para determinar se um conjunto de premissas forma um argumento válido

126 Essa noção intuitiva de parte foi chamado de 'membro da multiplicidade associada a' por Malink [2013]. Ferreira adotou essa mesma interpretação para as premissas menores com o objetivo de expor razões para estabelecer um critério lógico para a dita perfeição do silogismo. 
ou não, mesmo que esse não seja silogístico, seria possível o mesmo critério ser relevante na distinção de argumentos silogísticos? Para dar uma resposta a essa questão propomos uma análise de argumentos silogísticos que são extensionalmente equivalentes entre si e, por essa característica, podem servir como parâmetro à nossa pesquisa. Trata-se dos argumentos Cesare e Camestres, da segunda figura silogística, bem como Datisi e Disamis, da terceira figura silogística.

Ao contrário do par de premissas apresentado em APr I.4 e I.7, os silogismos mencionados são constituídos por pares de premissas praticamente idênticas. A única diferença que lhes pode ser atribuída é das operações peculiares a cada termo mencionado. Não obstante, podemos tomar como exemplo o caso dos silogismos Cesare e Camestres, pelos seguintes motivos: se a conclusão, digamos, $\mathrm{C} e \mathrm{~A}$ for extensionalmente equivalente a $\mathrm{A} e \mathrm{C}$, então essa segunda versão poderia substituir a primeira como conclusão do par de premissas $\square \mathrm{A} e \mathrm{~B}, \mathrm{C} a \mathrm{~B} \square$. Como o valor de verdade não se altera após a conversão, o argumento continuará válido. Mas esse argumento seria um silogismo?

Para ser um silogismo, o argumento, além de ser válido, deve ser tal que, sob hipótese alguma contraria qualquer parte de DGS, incluindo-se a Cláusula Final. Tendo essa consideração prévia em vista, pode-se perguntar o seguinte: o par de premissas $\cdot \mathrm{A} e \mathrm{~B}, \mathrm{C} a \mathrm{~B} \square$ conclui silogisticamente o enunciado $\mathrm{A} e \mathrm{C}$ ? Em termos formais, essa questão equivale a $\cdot \mathrm{A} e \mathrm{~B}, \mathrm{C} a \mathrm{~B} \square \|_{\Sigma}$ $\mathrm{A} e \mathrm{C}$ ? Um defensor da interpretação de Corcoran-Smiley assentiria com resposta afirmativa, uma vez que sua semântica não poderia contestar essa inferência lógica. Entretanto, essa concordância provoca um problema de não haver critérios satisfatórios que justifiquem a distinção proposta por 
Aristóteles em dois modos silogísticos distintos. Sendo assim, a questão acima equivale à seguinte pergunta: os silogismos $\cdot \mathrm{A} e \mathrm{~B}, \mathrm{C} a \mathrm{~B} \square \|_{\Sigma} \mathrm{C} e \mathrm{~A}$ (Cesare) e $\cdot \mathrm{C} a \mathrm{~B}, \mathrm{~A} e \mathrm{~B} \square \|_{\Sigma} \mathrm{A} e \mathrm{C}$ (Camestres) são o mesmo silogismo ou deveríamos considerar a forma mais branda - $\mathrm{A} e \mathrm{~B}, \mathrm{C} a \mathrm{~B} \square$ - $\mathrm{A} e \mathrm{C}$, apenas?

Caso a resposta à primeira parte dessa disjunção for afirmativa, ter-se-á como consequência a adoção de modos silogísticos redundantes e, portanto, elimináveis. Na tentativa de evitar esse impasse, poder-se-ia adotar uma análise similar àquela efetuada na seção anterior, onde a inversão da sequência dos termos era suficiente para estabelecer-se uma distinção entre argumentos válidos e argumentos não-concludentes. A dificuldade, nesse caso, é o fato da inversão na disposição dos termos na conclusão não estabelecer a mesma distinção. De fato, ela nem sequer altera a figura silogística, na qual o argumento é apresentado. Sendo assim, deve-se perguntar se há algo que essa disposição altera, quando os termos da conclusão são invertidos.

Tal como Aristóteles apresenta os silogismos, uma resposta óbvia, mas pouco esclarecedora, seria que a mudança dos termos extremos altera, sim, o modo silogístico em que o argumento é apresentado. Uma tal resposta, no entanto, não explica como uma tal mudança pode ser justificada. Sabe-se que, em termos extensionais, tal como obtemos pela semântica $S$, de Corcoran-Smiley, não há diferença entre esses modos silogísticos. Por que, afinal, Aristóteles reconhece modos silogísticos que são supérfluos de um ponto de vista extensional?

As interpretações tradicionais falham em dar a devida atenção a esse fato curioso. A única interpretação capaz de dar conta desse problema seria a interpretação dos dicta de omni et de 
nullo, ou uma interpretação análoga ${ }^{127}$. Como vimos no primeiro capítulo deste trabalho, o dictum de omni et de nullo se apresenta como relação entre os termos de uma predicação e é interpretada como equivalendo a expressões merológicas ${ }^{128}$. Como vimos, os termos da predicação são considerados como predicados na interpretação do dictum, em que uma relação específica com um desses dois termos predicativos seria suficiente para estabelecer uma relação com o outro termo, desde que observasse as regras do próprio dictum.

Tendo isso em mente, podemos avaliar o caso do argumento $\cdot \mathrm{A} e \mathrm{~B}, \mathrm{C} a \mathrm{~B} \square+\mathrm{A} e \mathrm{C} . \mathrm{Em}$ princípio, considerando-se a primeira premissa, se esperaria que a conclusão fosse da forma $\mathrm{CeA}$, porque a interpretação seria da seguinte maneira:

Teorema 3.2.1: $\quad \cdot \mathrm{A} e \mathrm{~B}, \mathrm{C} a \mathrm{~B} \square+\mathrm{A} e \mathrm{C}$

Prova: $\quad$ 1. $\cdot \mathrm{X}(\mathrm{XaA} \cdot \neg(\mathrm{X} a \mathrm{~B})) \quad$, premissa 1, dictum de nullo;

2. $\lambda \mathrm{C}(\mathrm{CaB}) \quad$, premissa 2 ;

3. $\cdot \mathrm{X}(\mathrm{X} a \mathrm{~B} \cdot \neg(\mathrm{X} a \mathrm{~A}))$, contra-positiva de 1 ;

4. $\lambda \mathrm{C}(\mathrm{C} a \mathrm{~B} \cdot \neg(\mathrm{C} a \mathrm{~A})) \quad$, instanciação de 2sobre 3;

5. $\lambda \mathrm{C} \neg(\mathrm{Ca} \mathrm{A}) \stackrel{\text { sef }}{=} \mathrm{Ce} \mathrm{A}, \mathrm{LC}$ (modus ponens), 4, 2;

6. $\mathrm{AeC}$, passo adicional, (R1).

127 Cf. Fred Sommers é conhecido como defensor de uma interpretação das predicações como lógica de termos e functores (Term-Functor Logic ou TFL). Sua interpretação se aplica, também, à silogística, a qual ele defende como principal modo de raciocínio lógico a ser utilizado. Sommers se utiliza das semelhanças com operações algébricas para representar as predicações e reconstituir, a partir disso, algebricamente a silogística. Sendo que suas interpretações diferem radicalmente de outras interpretações algébricas dos silogismos, podemos aferir que podem servir de possíveis candidatos para uma tal análise. Entrementes, não é nosso objetivo fornecer uma tal análise, satisfazendo-nos com a descrição obtida a partir das relações estabelecidas pelos dicta de omni et de nullo.

128 Cf. $A \operatorname{Pr}$ I.1, 24b26-8; I.25, 42a9-12; I.32, 47a10-4. Para uma interpretação da silogística como consistindo da enunciação de uma das regras dos dicta e uma instanciação dessas regras, vide Ferreira [2012], p.75. 
Comentário: Estejam dados os enunciados predicativos $\mathrm{A} e \mathrm{~B}$ e $\mathrm{C} a \mathrm{~B}$. Assim, pelo dictum de nullo, vale a seguinte interpretação: $\mathrm{A} e \mathrm{~B} \stackrel{\text { def }}{=} \mathrm{X} a \mathrm{~A} \cdot \neg(\mathrm{X} a \mathrm{~B})$. Ora, mas a segunda premissa diz que $\mathrm{C} a \mathrm{~B}$, o que contradiz o consequente do dictum. Então, por contra-positiva, deve valer $\mathrm{C} a \mathrm{~B}$ - $\neg(\mathrm{C} a \mathrm{~A})^{129}$, o que, pela definição do dictum de nullo, equivale a $\mathrm{B} e \mathrm{~A}$. Ora, visto que deve valer $\mathrm{B} e \mathrm{~A}$ e $\mathrm{C} a \mathrm{~B}$, obtemos por Celarent, $\mathrm{C} e \mathrm{~A}$. A partir disso, aplica-se a regra de conversão (R1) para obter AeC.

Em si, a prova é evidente e não precisava de ter sido apresentada. Bastava que se utilizasse a estratégia aristotélica de "redução" ao Celarent, adicionado pela regra de conversão sobre a conclusão.

Nosso objetivo, no entanto, ao apresentar essa prova com mais detalhes é verificar se a partir das regras do dictum de nullo seria possível justificar a obtenção direta da conclusão em AeC, de modo a justificá-la como conclusão silogística. Como vimos, isso não ocorre com as regras do dictum de nullo, uma vez que essas são muito específicas quanto à disposição dos termos e sua interpretação. Ou seja, a conclusão em AeC, embora pareça evidente, nem sequer é obtida através do dito "aperfeiçoamento" do argumento ${ }^{130}$. De fato, não fosse a aplicação de (R1), essa conclusão não poderia ser obtida a partir desse par de premissas. Isso, por sua vez, representa uma falha no cumprimento da Cláusula Final da $D G S$, o que seria suficiente para considerar que AeC se segue logica mas não silogisticamente desse par de premissas $^{131}$.

129 Lembremos que essa noção de negação é proposicional e se define da seguinte maneira: (CaA) $\rightarrow \perp$. Vide capítulo 1, p.12.

130 A rigor, essa etapa adicional, após a obtenção da conclusão silogística, não pode ser denominada de aperfeiçoamento do argumento, pois não conta como etapa de inferência para se obter a mesma conclusão silogística, mas como etapa lógica adicional para obter uma outra conclusão, muito embora seja extensionalmente equivalente.

131 A partir do sistema semântico introduzido por Ferreira [2012], poder-se-ia entender o silogismo como um argumento análogo à regra de inferência do modus ponens. De acordo com esse sistema, o enunciado da 
Se nossa interpretação estiver correta, temos duas razões para defender o fato da Cláusula Final não ser cumprida por esse par de premissas, para a obtenção da conclusão AeC. A primeira razão se liga diretamente ao último trecho de $D G S, 24 \mathrm{~b} 21-2$, onde Aristóteles afirma que um critério pelo qual a Cláusula Final deve ser reconhecida é que "nenhum elemento externo ao argumento precisa ser adicionado para aquilo que é necessário ser engendrado". Ora, vimos na prova acima que a conclusão que pretendíamos obter só era possível mediante a adição de uma regra de conversão, aplicada diretamente sobre o enunciado da conclusão, uma vez que estávamos comprometidos com a ordenação das premissas.

A segunda razão se associa, justamente, à ordem das premissas, a qual deve ser preservada na sequência dos termos da conclusão, para o argumento valer como silogismo. Essa condição nos foi dada mediante a análise dos casos de argumentos válidos não-silogísticos e seus silogismos correspondentes, pelos quais são verificados. Naquela ocasião nos foi possível distinguir as noções de validade e consequência lógica para argumentos válidos em geral e para argumentos silogísticos, graças a essa hipótese de preservação da sequência, ao longo do argumento. Valendo-nos dessa análise, somos, então, forçados a considerar que um suposto Cesare com os termos invertidos na conclusão não satisfaz o critério "aquilo que é necessário" e, por isso, não pode satisfazer a própria Cláusula Final.

A única maneira pela qual essas premissas podem levar à conclusão, sem obter o resultado

premissa maior seria um caso geral que seria instanciado pela premissa menor. Em Ferreira [2012][2013], essa propriedade da silogística é apresentada como critério lógico que poderia justificar a dita "perfeição dos silogismos". Para o nosso presente fim, gostaríamos de adotar esse sistema semântico com intenção de estudar as propriedades lógicas dos silogismos. Sendo assim, gostaríamos de frisar que a relação introduzida pela semântica da pré-ordem tem as propriedades de reflexividade e de transitividade, mas não a de simetria. Isso é importante, pois se assumirmos um enunciado como $(\mathrm{XaA} \rightarrow \neg(\mathrm{XaB}))$, a relação do termo $\mathrm{X}$ não inverte sua posição com qualquer um de seus predicados. Isso fica evidente no caso de aplicação da contra-positiva $(\mathrm{XaB} \rightarrow \neg(\mathrm{XaA}))$. Como para a prova de Camestres é preciso pressupor a simetria da relação, essa semântica garantiria a exigência por uma etapa adicional que distinguiria Camestres de Cesare. 
indesejável de um modo silogístico acabar sendo redundante e eliminável, é considerá-las como um par invertido de premissas. Para sustentar as afirmações feitas a respeito do argumento anterior, cumpre verificar que o par invertido de premissas satisfaz a conclusão AeC como suposto e verificar se com esse novo par de premissas vale o mesmo que com o par anterior, isto é, se a conclusão em $\mathrm{C} e \mathrm{~A}$ depende da adição de novos itens, considerando-se essa sequência.

Feitas essas considerações, devemos provar um teorema e seu corolário: (teorema 3.2.2)

- $\mathrm{C} a \mathrm{~B}, \mathrm{~A} e \mathrm{~B} \square \|_{\Sigma} \mathrm{A} e \mathrm{C}$; (corolário 3.3) $\cdot \mathrm{C} a \mathrm{~B}, \mathrm{~A} e \mathrm{~B} \square$ - $\mathrm{Ce} \mathrm{A}$ :

Teorema 3.2.2: $\quad \cdot \mathrm{C} a \mathrm{~B}, \mathrm{~A} e \mathrm{~B} \square \|_{2} \mathrm{~A} e \mathrm{C}$

Prova: $\quad$ 1. $\cdot \mathrm{X}(\mathrm{X} a \mathrm{C} \Rightarrow \mathrm{X} a \mathrm{~B}) \quad$, premissa 1, dictum de omni;

2. $\mathrm{A} e \mathrm{~B} \stackrel{\text { def }}{=} \lambda \mathrm{A} \neg(\mathrm{A} a \mathrm{~B}) \quad$, premissa 2 ;

3. • $\mathrm{X}(\neg(\mathrm{X} a \mathrm{~B}) \Rightarrow \neg(\mathrm{X} a \mathrm{C}))$, contrapositiva de 1 ;

4. $\lambda \mathrm{A}(\neg(\mathrm{A} a \mathrm{~B}) \Rightarrow \neg(\mathrm{A} a \mathrm{C})) \quad$, instanciação de 2 sobre 3;

5. $\lambda \mathrm{A} \neg(\mathrm{A} a \mathrm{C}) \stackrel{\text { def }}{=} \mathrm{A} e \mathrm{C} \quad, \mathrm{LC}$ (modus ponens), 2, 3.

Comentário: Assuma as premissas $\mathrm{C} a \mathrm{~B}$ e $\mathrm{A} e \mathrm{~B}$. Pela regra do dictum de omni, podemos inferir que a premissa maior pode ser interpretada como $\mathrm{X} a \mathrm{C} \Rightarrow \mathrm{X} a \mathrm{~B}$. Entretanto, isso não pode ser satisfeito devido à segunda premissa $\mathrm{A} e \mathrm{~B}$, a qual determina a negação do consequente, isto é, ᄀ $(\mathrm{A} a \mathrm{~B})$. Por contra-positiva da hipótese do dictum, temos que $\neg(\mathrm{X} a \mathrm{~B}) \Rightarrow \neg(\mathrm{X} a \mathrm{C})$, e inferimos, por modus ponens ${ }^{132}$, ᄀ $(\mathrm{A} a \mathrm{C})$. Como a segunda premissa é uma predicação universal, somos permitidos a considerar a negação como se aplicando ao caso universal de modo que $\mathrm{A} e \mathrm{~B} \Rightarrow$ AeC. Disso podemos inferir que $\mathrm{A} e \mathrm{C}$.

132 Poderíamos diminuir a prova por um passo de inferência, considerando uma regra análoga ao modus ponens, a saber, o modus tollens. 


\section{Corolário 3.2.3: $\quad \cdot \mathrm{C} a \mathrm{~B}, \mathrm{~A} e \mathrm{~B} \square+\mathrm{C} e \mathrm{~A}$}

Prova: Assuma a prova do teorema 3.2. Dele obtemos a conclusão AeC, sobre a qual devemos aplicar a regra de conversão (R1).

A partir dessas provas, podemos verificar o argumento utilizado para defender o ponto que procuramos destacar, a saber, que a Cláusula Final não é cumprida quando assumimos um par ordenado de premissas e uma conclusão com a sequência invertida de termos.

Se nossa análise dos casos Cesare e Camestres estiver correta, temos uma instância de confirmação de nossa hipótese geral, segundo a qual a Cláusula Final é responsável não apenas para distinguir argumentos válidos em silogísticos e não-silogísticos, mas também para distinguir os modos silogísticos entre si. Uma prova disso poderia ser garantida se o mesmo tipo de prova pudesse ser aplicada ao segundo grupo de silogismos extensionalmente equivalentes, isto é, aos modos Datisi e Disamis. Entrementes, essa confirmação não é logicamente possível, limitando a nossa hipótese ${ }^{133}$. Não obstante, considerando que as Condições Inferenciais, ou qualquer outro critério lógico, não provam a diferença apresentada por Aristóteles, a Cláusula Final, por exclusão, seria o único critério da $D G S$ capaz de distinguir esses casos.

O papel da Cláusula Final parece ser fundamental para uma defesa da silogística como lógica relevante, uma vez que ela estabelece exigências mais rigorosas para a demonstração de seus resultados que uma lógica embasada sobre cálculo quantificado de indivíduos. A defesa de certos aspectos de relevância não seria o único resultado que se obteria em consequência dessas considerações. As consequências obtidas a partir da Cláusula Final parecem ser numerosas e dignas de menção, o que faremos na próxima seção.

133 As provas desse fato, a respeito desses modos silogísticos, foram deixadas para o Apêndice X. 


\subsection{Algumas consequências da aplicação da Cláusula Final}

\section{A falha do projeto reducionista para a $\boldsymbol{D G S}$ : Consideremos as seguintes descrições de}

validade lógica: (i) um argumento é válido se e somente se a conclusão se segue necessariamente das premissas; (ii) um argumento é válido se e somente se não for o caso da conclusão ser falsa e suas premissas serem verdadeiras. Essas formas intuitivas de se apresentar a validade de um argumento são, em geral, relacionadas de modo a revelar um projeto filosófico em que conceitos não-lógicos são interpretados por meio de um modelo com a pretensão de facilitar sua compreensão. Isto é, costuma-se reduzir (i) a (ii) com o objetivo de explicar a partir de (ii) um item em (i), que é de difícil compreensão. Neste caso, trata-se da expressão modal de necessidade que está presente na caracterização (i) da validade lógica de um argumento.

Um projeto semelhante tem sido atribuído à silogística aristotélica, na esperança de ter o sentido da expressão modal de necessidade revelado com precisão, uma vez que a $D G S$ se assemelha a (i). Uma consequência desse projeto reducionista é uma ampliação considerável da classe dos argumentos que a $D G S$ satisfaz. O objetivo do projeto reducionista é entender a relação do que é algo se seguir por necessidade, satisfeitas certas condições. Como as Condições Inferenciais da DGS estabelecem alguns critérios para se obter uma noção de consequência lógica, um tal projeto estaria, assim, justificado.

No entanto, a discussão apresentada por Aristóteles entre uma sequência de premissas que silogisticamente não seria concludente, mas admite uma conclusão válida, possibilitou uma distinção dos argumentos válidos em silogísticos e não-silogísticos. O ponto principal para a distinção entre essas classes de argumentos foi a aplicação da Cláusula Final como razão para se obter aquilo que é necessário, funcionando como mediador entre o fato de um argumento obter 
uma conclusão silogística ou não.

O fato de Aristóteles reconhecer, com a apresentação dos trechos de $A P r$ I.4 e I.7, uma classe de argumentos válidos que não são silogismos, por não satisfazerem as exigências ditadas pela Cláusula Final, é suficiente para frustrar o projeto reducionista da interpretação da silogística. Se nossa interpretação dos problemas relacionados à Cláusula Final estiver correta, poderemos considerar que Aristóteles não tinha em vista reduzir os silogismos à validade lógica quando expôs a DGS. Mais ainda, segue-se de nossa interpretação que Aristóteles tampouco estava considerando uma noção geral de consequência lógica em geral. Parece, antes, que seu foco se ligaria a noções bem mais restritas de consequência ${ }^{134}$.

Podemos considerar, então, que a Cláusula Final da $D G S$ não é apenas um elemento adicional à Definição Geral, mas é um critério pelo qual se determina argumentos propriamente silogísticos. Ademais, como vimos na seção anterior, esse argumento serve para determinar modos distintos entre os argumentos silogísticos.

Uma restrição tão rigorosa aplicada a argumentos válidos, graças à silogística, tem como consequência a inadequação da $D G S$ para determinar a noção da validade lógica de um argumento qualquer. Nesse sentido a interpretação do projeto reducionista da lógica parece apresentar algumas vantagens, uma vez que a sua definição de consequência lógica depende da própria noção de validade lógica. Exemplos dessa estratégia são encontrados em praticamente todas as interpretações da silogística como sistema lógico. Em decorrência disso, poder-se-ia questionar se, apesar do projeto reducionista perder sua validade em interpretar toda a $D G S$, esse procedimento de análise não teria algum valor para a interpretação da noção da validade lógica na

134 Essa classe de argumentos, inclusive, pode se apresentar como sendo mais restrita à classe imaginada por Smith [1989], p.110. 
obra de Aristóteles. A única observação que nos é lícita, a partir das análises apresentadas, é que esse projeto não poderia ser aplicado com sucesso na parte que tange à definição daquilo que é um silogismo.

Aspectos de lógicas relevantes e intuicionistas: Apontamos para o fato de Smith [2012] ter defendido uma interpretação da Cláusula Final como critério para a relevância lógica. Tentamos mostrar no capítulo primeiro deste nosso trabalho, que a mera consideração da Cláusula Final como um critério de relevância não era suficiente para decidir se a Cláusula Final servia como uma exigência adicional, distinta das exigências já apresentadas na parte das Condições Inferenciais. Afinal, a própria exigência de que a conclusão não poderia repetir uma das premissas determina que não pode haver premissas supérfluas em um argumento.

Com nossa análise do exemplo apresentado por Aristóteles, tanto em APr I.4 como em APr I.7, chegamos ao resultado que a Cláusula Final, de fato, restringe a noção daquilo que é seguir por necessidade e o faz mediante uma sequência que os termos da conclusão devem respeitar. Essa sequência específica dos termos se mostra como reflexo da ordem dos mesmos no par ordenado das premissas que obtêm esse resultado. A introdução de uma disposição pela qual podemos decidir se um argumento se afigura como silogismo ou não, condicionado pela Cláusula Final, permite assumir que essa mesma seja uma exigência adicional à $D G S$ e que, de fato, exibe traços de exigências relevantistas.

Para a satisfação da Cláusula Final, não basta que um argumento obtenha uma conclusão válida, mas essa conclusão deve ser consequência precisamente desse par de premissas. A descrição de como um argumento silogístico deve proceder, respeitadas as condições estipuladas pela Cláusula Final, preserva um caráter de relevância lógica de um argumento. Esse caráter de 
relevância é especialmente evidente quando as exigências da Cláusula Final determinam dois modos silogísticos distintos para justificar a inversão dos termos de uma conclusão, mesmo que esses enunciados sejam extensionalmente idênticos.

Os resultados do último caso, a saber, da distinção entre modos silogísticos extensionalmente equivalentes, no entanto, são muito curiosos por outra razão. Não se trata apenas do fato de um par de premissas ser distinguido a partir da disposição dos termos no enunciado da conclusão, mas de uma preocupação pela demonstração de cada conclusão. Nesse caso, não seria estranho asseverar que para cada conclusão, se ela deve ser silogisticamente obtida, ela deve ser provada diretamente por um silogismo. Isso revela um aspecto curioso da silogística que poderia ser comparado a um tratamento intuicionista dos argumentos silogísticos ${ }^{135}$.

Lear [1980] se aproximou muito de interpretações intuicionistas para fundar sua própria interpretação da silogística. De fato, em uma nota Lear remete ao tratamento apresentado pela lógica intuicionista para justificar a noção de validade que ele atribui à silogística, a saber, a noção de "validade por substituição ${ }^{136 "}$. Visto que a DGS não se compromete com uma definição de validade lógica de um argumento, nos reservamos o direito de não assumir uma posição a respeito de qual interpretação seria melhor para essa noção, no contexto da lógica aristotélica. Nossa pretensão, no entanto, é apontar para o fato de que cada conclusão, caso se deseja assumila como silogística, deve ter uma prova silogística exclusiva dela. Não se trata de uma simples consideração extensional, mas de uma exigência específica para a mesma conclusão satisfazer as

135 Considerando-se a notação da silogística poderemos interpretá-la não mais como apenas consequência, mas como uma prova silogística.

136 Lear [1980], p.8, n.12: Valid under replacement. A referência que ele apresente está no livro de Michael Dummett "Elements of Intuitionism". 
condições estipuladas pela Cláusula Final.

O sentido das expressões modais de necessidade na DGS: Retornemos à Definição Geral do Silogismo. Um problema muito comum se liga ao uso aristotélico da expressão modal de necessidade, a qual tem duas ocorrências em DGS. A primeira dessas ocorrências se liga à noção de inferência lógica de um silogismo; a segunda ocorre ao final da descrição da Cláusula Final.

O silogismo é um argumento em que, [i] certas coisas tendo sido estabelecidas, algo distinto se segue por necessidade, [ii] em virtude de serem tais coisas. Digo por 'em virtude de serem tais coisas' 'por causa dessas mesmas coisas' que a conclusão decorre, e 'por causa dessas mesmas coisas que a conclusão decorre' entendo não ser preciso adicionar outro termo para o necessário ser engendrado.

Como vimos no primeiro capítulo, a noção daquilo que se segue por necessidade originou a principal preocupação das interpretações tradicionais, uma vez que a descrição na qual a expressão está inserida é muito semelhante à descrição intuitiva de consequência lógica ainda atualmente em voga.

A despeito da semelhança com a descrição intuitiva, uma distinção clara entre esse uso da expressão modal de necessidade e o uso predicativo da modalidade é apresentada por Aristóteles em $A P r$ I.10, 30b32-3, 38-40. Naquele contexto, Aristóteles procura mostrar como argumentos silogísticos com premissas que são contingentes, no sentido modal, obtêm conclusão silogística, a qual também é descrita através da expressão modal de necessidade. Como não se trata de uma noção similar à noção da lógica modal, esse uso de necessidade seria referente a outro aspecto da argumentação lógica.

No que diz respeito aos dois usos empregados na $D G S$, no entanto, não há consenso quanto ao sentido de ambos os usos da expressão modal de necessidade. Enquanto o uso da 
primeira ocorrência, ainda na parte das Condições Inferenciais, é claramente interpretado como se tratando de uma descrição de inferência lógica, em geral, o segundo uso parece ser outro. Uma das possibilidades sugeridas era de compreender o segundo uso da expressão modal de necessidade como requisito sobre as próprias premissas, sendo que as premissas, não outros requisitos, determinassem a conclusão ${ }^{137}$. O uso da expressão modal de necessidade, tal como vemos em APr I.1, 24b22 (to anankaion), é distinguido do uso que se faz em 24b20 (ex anankēs symbainei) em função de um forte paralelismo de sua descrição com o mesmo emprego no contexto da perfeição do silogismo. Como um argumento válido satisfaz a expressão ex anankēs symbainei, e não dependeria de seu aperfeiçoamento para garantir sua validade, o emprego de to anankaion no contexto de silogismos perfeitos não poderia estar ligado à expressão de 24b20. Por sua vez, como há um forte paralelismo na descrição dos silogismos perfeitos com a explicação feita a respeito da Cláusula Final, acredita-se que o to anankaion de 24 b22 tampouco se ligasse ao emprego em 24b20. Se, no caso desse contexto, a expressão modal tivesse o mesmo sentido, a saber, de inferência lógica, ter-se-ia como consequência que todos argumentos silogísticos que não fossem da primeira figura seriam inválidos, a menos que fosse demonstrado o contrário.

Devemos observar, por conta desses resultados, que a noção apresentada em relação com a Cláusula Final se refere exclusivamente aos argumentos silogísticos. Como foi visto em nossa discussão a respeito do argumento de Aristóteles em $A P r$ I.4, a Cláusula Final serviu de mediador na primeira etapa argumentativa da prova pretendida. Conforme se sucedeu na reconstituição

137 Essa interpretação é de Lucas Angioni [2014]. Ela foi concebida, sobretudo, em um estudo acerca da noção aristotélica de perfeição do silogismo, com respeito à qual Angioni apresenta uma interpretação muito elegante. Como na descrição da perfeição do silogismos, em $A \operatorname{Pr}$ I.1, 24b22-6, ocorre exatamente o mesmo uso da expressão modal de necessidade, com a diferença de que para a noção de perfeição o requisito é um esclarecimento a respeito daquilo que é necessário, enquanto na Cláusula Final se trata de uma descrição de como vem a ser. Em se tratando do mesmo uso da expressão, ela não poderia ser assumida como se tratando da validade lógica, dando a abertura para a noção de requisitação das premissas. 
desse argumento, é possível provar a relação co-extensiva de argumentos silogísticos com a satisfação da Cláusula Final, tendo-se como termo mediador a expressão modal de necessidade, tal como ocorre na segunda parte da DGS. Como o segundo uso da expressão modal de necessidade é o termo mediador, se esse uso provar a co-extensão entre Condições Inferenciais e a Cláusula Final, ele inexoravelmente há de ser co-extensivo tanto com a classe dos silogismos como com a própria cláusula.

A princípio, parece que a Cláusula Final serve como critério de restrição dos argumentos válidos apenas aos casos de silogismos categóricos. No entanto, deve-se observar que a própria $D G S$ permite uma definição relevante do argumento, em que ambos os usos da expressão modal de necessidade não apenas são compatíveis, como resultam no mesmo uso ${ }^{138}$. De fato, a discussão que apresentamos no que diz respeito à Cláusula Final não impede que a noção descrita por essa expressão seja uma única. A única exigência é que o primeiro uso da expressão modal não se refira apenas à noção geral de validade ou de consequência lógica. Caso as duas ocorrências da expressão modal de necessidade tenham o mesmo sentido, então a primeira ocorrência será co-extensiva com os argumentos propriamente silogísticos e com a Cláusula Final. Sendo assim, independente da interpretação que se busca para compreender as ocorrências da expressão modal de necessidade, o resultado final sempre será que a $D G S$ é uma definição que se restringe a argumentos reconhecidos como silogísticos.

Tal como se pôde constatar, a decisão a respeito da interpretação se ambos os usos da expressão modal de necessidade são distintos ou equivalentes, depende somente da decisão que se faz do primeiro uso. Se o primeiro uso for assumido como inferência lógica válida, em geral, o segundo uso apresentará critérios adicionais que limitam seu sentido a uma inferência silogística,

138 Agradecemos a Marcelo E. Coniglio por essa sugestão. 
a qual deve satisfazer certas condições, as quais não poderiam ser obtidas através da primeira parte. Já no caso de se considerar diretamente a noção de inferência silogística, no primeiro uso, a Cláusula Final serviria como a razão que justifica o uso da expressão modal de necessidade.

Seja como for, em ambas as interpretações fica claro que o papel da Cláusula Final é o de restringir argumentos válidos a uma classe de inferências que satisfazem certas condições, entre as quais constam uma sequência precisa dos termos extremos. Se uma tal disposição obter um resultado único, conforme o argumento de $A P r$ I.4, e preservar a sequência dos termos determinada pelas premissas, então o argumento, respeitando a Cláusula Final, será silogístico. Ou seja, se um argumento válido satisfaz todas as exigências estipuladas pela Cláusula Final, ele será um silogismo. Caso contrário, se o argumento não for um silogismo, ele deverá ser provado indiretamente mediante um silogismo. Como argumentos silogísticos foram apresentados como co-extensivos com a Cláusula Final, o outro lado da relação também se aplica: se a Cláusula Final restringe um argumento, esse argumento será um silogismo.

Definição parcial da Cláusula Final: Tal como tentamos apresentar a Cláusula Final, até o presente momento, conseguimos chegar ao resultado de uma certa correspondência entre sua aplicação e argumentos propriamente silogísticos. A partir disso, podemos afirmar que a $D G S$ é uma definição própria de argumentos silogísticos e não de argumentos válidos, em geral.

A Cláusula Final, tal como apresentamos ao longo deste capítulo, se apresentou inicialmente como um critério que exigia para os argumentos uma conclusão única e com sequência determinada dos termos da conclusão. $\mathrm{O}$ desdobramento dessa análise apontou para a possibilidade da Cláusula Final servir como exigência para uma restrição mais rigorosa a argumentos válidos que aquela inicialmente suposta. Isso se deve à consideração de que a 
exigência se concentrava não apenas na sequência dos termos da conclusão, mas também na disposição das próprias premissas. Dado que a disposição das premissas deve determinar a disposição dos termos na conclusão, pode-se inferir que há uma exigência de preservação da ordem entre premissas e a conclusão correspondente. Com isso, abriu-se a possibilidade para estabelecer um critério, mediante o qual foi possível distinguir modos silogísticos, embora os argumentos sejam extensionalmente equivalentes.

Apresentada uma tal interpretação da Cláusula Final, podemos combinar os resultados obtidos em nossa investigação com a descrição apresentada em $\operatorname{APr}$ I.1, 24b20-2. Naquele contexto, a Cláusula Final se identificava com duas descrições: que algo se segue por necessidade (a) graças ao fato de serem essas as premissas e (b) como sendo um critério que não requer adição de outro item para garantir aquilo que é necessário. Com base nos resultados obtidos neste capítulo, podemos aventar algumas hipóteses interpretativas para a definição da Cláusula Final.

No que diz respeito à interpretação da descrição (a), poder-se-ia imaginar, de início, que a referência era simplesmente às premissas que compunham um argumento silogístico. Isso, no entanto, se provou errado com a apresentação do caso em $A \operatorname{Pr}$ I.4. A mera apresentação de premissas que, em uma outra configuração qualquer, podem formar um argumento silogístico, não é suficiente para o argumento ser, ele mesmo, um silogismo. Como se viu, uma certa sequência de premissas é exigida a fim de se obter um silogismo. Com isso, podemos reinterpretar (a) não como exigindo certas premissas, mas como exigindo essas premissas em uma determinada ordem.

Do mesmo modo, a interpretação (b) parece ser fraca demais, a princípio. À primeira vista, a condição apresentada por (b) parece exigir apenas a satisfação das condições mínimas para um argumento obter uma conclusão silogística. Denominemos essa leitura de "leitura fraca". 
A leitura fraca de (b) parece, inicialmente, ser mais ampla que as próprias restrições estabelecidas na parte das Condições Inferenciais da DGS. Entretanto, em conjunto com a exigência da sequência de premissas e do uso diferenciado de sua ocorrência da expressão modal de necessidade, vimos que essa mesma condição foi aplicada para demonstrar que seria preciso uma distinção entre dois modos silogísticos, os quais, a princípio, seriam equivalentes. Vale ressaltar que a noção dada pelo segundo uso da expressão modal de necessidade, o qual é repetido em $A P r$ I.4, é determinante tanto para compreender o argumento aristotélico naquele trecho, como no final da $D G S$, permitindo-nos respaldar a interpretação forte, sugerida por Angioni.

Com os resultados obtidos nesta investigação, somos levados a alterar o peso das descrições (a) e (b), apontando para uma exigência mais pesada sobre argumentos lógicos que aquele inicialmente concebida pela tradição interpretativa. Com isso, podemos afirmar que a Cláusula Final é um item relevante à descrição do silogismo e que seu caráter é mais pesada do que tradicionalmente exigida. Por outro lado, o papel da Cláusula Final é precisamente limitado como exigência de determinadas características para um argumento ser silogístico. 
117 


\section{Primeiros Analíticos I: dois tratados distintos ou uma investigacão}

\section{coesa?}

Ao contrário do que tem sido afirmado pelas interpretações tradicionais, a nossa análise da Definição Geral do Silogismo $(D G S)$ propõe razões pelas quais asseveramos que não se trata de uma definição ampla, mas de uma noção bem restrita de argumento lógico. Chegamos a essa conclusão através da análise feita a respeito da Cláusula Final, a qual se apresenta não apenas como critério de relevância, mas como o critério pelo qual argumentos lógicos em geral são restritos às figuras silogísticas ${ }^{139}$.

Vimos que o fator inicial para esse tipo de restrição foi obtido na observação que argumentos silogísticos obtêm uma conclusão satisfazendo uma sequência previamente determinada entre os termos extremos. Apesar de uma conclusão ser possível, em casos de supostos argumentos como aqueles apresentados em $A P r$ I.4 e I.7, o fato desse resultado não se conformar à estrutura estabelecida basta para descartar o caso como silogístico. Consequentemente, essa exigência, atribuída à Clausula Final da $D G S^{140}$, deve ser capaz de distinguir argumentos silogísticos de argumentos não-silogísticos.

Uma tal interpretação está sujeita a ser duramente criticada. Como vimos no capítulo anterior, um alvo de crítica poderia ser a própria concepção da sequência dos termos na conclusão

Vale frisar que não temos a pretensão de comentar se Aristóteles não observou a quarta figura ou se essa foi por ele recusada. Por conveniência, adotamos, para este capítulo, as afirmações aristotélicas a respeito de haver apenas três figuras. Acreditamos que a adição da suposta quarta figura silogística não influencia os resultados que obtemos em nossa análise, dando-nos essa liberdade de não entrar nos méritos da questão.

140 Cf. $A \operatorname{Pr}$ I.4, 26a4-5. 
ser um reflexo de uma ordenação das premissas. Para um linha de interpretação, a nossa concepção seria errada pois possibilita a introdução de argumentos como silogísticos, os quais não o são. Para uma segunda linha, a nossa interpretação seria inadequada, pois reconhecemos como argumentos não-silogísticos, aqueles que pertenceriam à suposta quarta figura silogística.

Afinal, qual é o fator que garante esse tipo de distinção? Trata-se de um critério lógico ou de outra natureza? Quais são as vantagens de adotar uma interpretação tão restrita para a lógica? Essa amostra de questões que surgiram em nosso capítulo anterior vexam, de certo modo, o estudioso, pois no conjunto de capítulos de $A \operatorname{Pr}$ I.1 a I.7 não encontramos evidências para darlhes uma resposta satisfatória, dependendo de uma análise posterior para jogar alguma luz sobre esse problema. Chegamos a sugerir, em linhas gerais, algumas etapas que poderiam fazer parte de uma solução para esse ponto.

No capítulo anterior, quando comparamos argumentos silogísticos com não-silogísticos, esboçamos uma prova na semântica dos dicta, que apresentava um resultado interessante. Sabe-se que a recusa desses argumentos se deve ao fato de violarem a Cláusula Final. No entanto, qual seria o fator da Cláusula Final que poderia estabelecer uma tal diferença? Naquele contexto, estabelecemos uma hipótese de trabalho que responsabilizaria o termo comum a ambas as premissas por satisfazer ou não aquilo que chamamos de mediação. Entrementes, atribuir ao termo comum a responsabilidade de uma tal distinção não poderia ser feito sem evidências e razões convincentes.

Vimos, também, no segundo capítulo deste nosso trabalho, que esse conjunto de capítulos de $A \operatorname{Pr}$ I.1 a I.7, denominados de Capítulos de Apresentação Geral (CAG), é muito disputado, não apenas no que diz respeito a seu conteúdo, com numerosas propostas que visam melhor interpretar a silogística, mas também no que diz respeito a sua relação com o conjunto de 
capítulos que tem início em $A P r$ I.23, denominados de Capítulos de Apresentação Específica $(C A E)$. Parte da razão para essa situação está associada a problemas análogos aos que foram levantados em nossa análise e se aprofundaram com as investigações, como o suposto contexto da completude do sistema silogístico, entre outros.

O problema principal desse tipo de análise era a expectativa de se encontrar em $A P r$ I um tratado lógico coeso e, em sua maior extensão, consistente. Devemos enfatizar o aspecto lógico pretendido por essa análise. De acordo com essa tradição, $C A E$ continuaria com um tratamento propriamente lógico, apesar dos problemas que se apresentam nesse conjunto de capítulos. Essa visão a respeito da obra perdurou por muito tempo até Striker [1997] formular um forte ataque contra essa interpretação não só da obra, mas da silogística como um todo. Sua radical defesa de uma interpretação que se estende desde os comentários antigos à obra de Aristóteles ${ }^{141}$, classificando a silogística como ferramenta da filosofia, teve a consequência de representar Aristóteles não como um lógico no sentido atual.

Consideramos esse resultado como positivo, por diversas razões, as quais tentaremos apresentar mais adiante. Entretanto, consideramos, também, que essa crítica que Striker apresentou teve uma consequência negativa no que tange à exposição do texto de $A \operatorname{Pr}$ I. Sua defesa da interpretação que a silogística deveria ser reconhecida como uma mera ferramenta para a lógica sofreu, como consequência, uma radical distinção entre $C A G$ e $C A E$. De fato, o reconhecimento de $C A E$ como profundamente conectado a problemas abordados nos Tópicos, fez com que se cogitasse em $A P r$ I como consistindo de dois tratados diferentes: em $C A G$, um tratado

141 Cf. Alexandre [1883], p.1.7-9. Após uma breve introdução da lógica, ele passa a comentar que "dado que a lógica é uma prática da filosofia, há aqueles que a consideram como parte da filosofia, como há aqueles que a

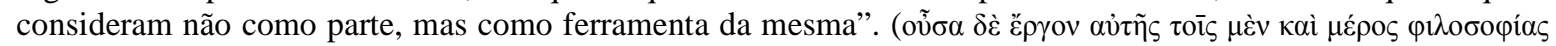

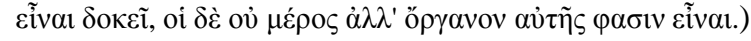


propriamente lógico $^{142}$, e em $C A E$, um tratado de argumentação geral.

Neste presente capítulo tentaremos amenizar os resultados apresentados por Striker [1997]. Concordamos com Striker no que diz respeito à interpretação de Aristóteles como lógico, no sentido atual, e especialmente com a crítica que originou esse tipo de consideração, a saber, o suposto contexto da completude do sistema silogístico, apresentado em $A P r$ I.23. Entretanto, tentaremos mostrar que o interesse de Aristóteles não era o de apresentar, pela segunda vez, um tratado de argumentação geral. Acreditamos que a investigação que Aristóteles introduz com seu complexo argumento em $A P r$ I.23 é uma investigação filosófica sobre a natureza da prova. Se nossa hipótese de leitura for confirmada, seremos capazes de afirmar que, efetivamente, há uma mudança de foco entre $C A G$ e $C A E$, mas que essa mudança se segue do tratamento que se dá à silogística que envolvem questões como aquelas que levantamos em nosso capítulo terceiro.

Sendo assim, nosso foco, neste presente capítulo, será apresentar como Aristóteles constrói a silogística e se volta a certos aspectos que estão ligados aos problemas aos quais tentamos chamar a atenção até o presente momento. Iniciaremos a nossa discussão com a análise do difícil argumento que Aristóteles desenvolve em $A P r$ I.23 e que ficou marcado nas interpretações recentes como se tratando de seu argumento em favor da completude da silogística. Nosso objetivo não será provar que a silogística é completa. Sabe-se que, com essa interpretação, Aristóteles não tem sucesso em sua empreitada ${ }^{143}$, pois não consegue representar silogisticamente argumentos tidos como indiretos ${ }^{144}$. Nossa intenção, com esta análise, será comparar a argumentação aristotélica às exigências estabelecidas por $D G S$ e verificar em que

142 No sentido clássico, inclusive.

143 Cf. APr I.35, 44.

144 Em geral, considera-se argumentos como indiretos quando são provados ou por redução ao absurdo ou por um método que ficou conhecido como "argumento a partir de uma hipótese" (syllogismos ex hypotheseōs). 
sentido elas poderiam ser correlacionadas.

Razão para isso é que $C A E$ inicia seus primeiros capítulos com uma preocupação que se liga à noção de mediação. Essa noção de mediação é um dos aspectos mais interessantes na parte inicial de $C A E$, pois está praticamente ausente em $C A G$. A mediação deve ser desempenhada pelo termo comum a ambas as premissas, a que demos o nome de mediador ${ }^{145}$. Nesse contexto, Aristóteles introduz uma distinção muito peculiar de como o tipo de argumento corresponde ao tipo de premissas estabelecidas nesse argumento. Essa qualificação das premissas, correspondente à qualificação do tipo de argumento é obtida através do termo mediador, o qual relaciona os dois termos extremos, mas pode fazê-lo, como vimos em $C A G$, de diversas maneiras.

Se nossa leitura estiver correta, poderemos, então, considerar que Aristóteles está investigando certas propriedades que não são mais propriamente lógicas, mas fazem parte de uma interpretação filosófica da noção de prova, relacionada proximamente às exigências estabelecidas pela Cláusula Final. Entretanto, a nossa análise de $A \operatorname{Pr}$ I.23 não garante evidências suficientes para correlacionar a Cláusula Final com o objeto da investigação. Apesar das semelhanças, julgamos que só temos uma evidência clara que esse contexto é compatível com a Cláusula Final, quando avançamos nossa análise para $A \operatorname{Pr}$ I.25. Confirmada a correlação entre a Cláusula Final e a noção de mediação, estaremos aptos não só a lançar alguma luz sobre o problema da sequência de $C A G$ para $C A E$, mas também aptos a especificar melhor a própria Cláusula Final e, com isso, a

$145 \mathrm{O}$ termo mediador consta como um dos conceitos mais sensíveis em toda análise da silogística e da história de sua interpretação. Por muito tempo, quando as interpretações da silogística não tinham à sua disposição as ferramentas da lógica clássica, intérpretes atribuíram ao mediador um papel preponderante na obtenção da conclusão, o qual não poderia ser justificado de um ponto de vista lógico. De acordo com essas interpretações, o mediador não só seria um elemento de conexão entre dois extremos, como seria, também, a causa dessa conexão e a razão, pela qual, haveria "uma força que impele a enunciação da conclusão" (cf. Maier cit. In Łukasiewicz [1957], p.11).

Esse tipo de interpretação foi, com razão, duramente criticada, pois atribuía à silogística características que não poderiam ser compreendidas por nenhum raciocínio válido, apresentando um caráter "de poderes mágicos" (cf. Striker [1997], p.209). 
própria $D G S$.

Em $A P r$ I. 25, Aristóteles está proximamente ligado à discussão da primeira parte de I.23, o que nos permite fazer a conexão desse capítulo com a Cláusula Final. Aristóteles discute nesse capítulo os critérios e as diferenças obtidas por vários argumentos distintos, os quais apresentam a mesma conclusão. A conclusão a que Aristóteles chega nesse capítulo é o reconhecimento que vários argumentos são possíveis e que há uma distinção entre eles. O resultado principal dele é a afirmação de que todo argumento consiste não mais de pelo menos duas premissas, mas de no máximo duas premissas. Em nossa análise, tentaremos aproximar esse resultado à Cláusula Final, na tentativa de apontar como essa descrição é compatível com a $D G S$, mas como sua preocupação é apresentar as propriedades específicas que fazem com que os argumentos silogísticos sejam tão restritos e tão importantes.

Se nossa leitura estiver correta, a investigação aristotélica, em $C A E$, é um estudo a respeito das características da prova. Na contramão da interpretação que tende compreender essa discussão como parte do contexto dialético, Aristóteles tenta chegar aos fundamentos daquilo que torna uma prova segura. $\mathrm{O}$ método que ele usa para tal está proximamente ligado à Cláusula Final, a qual, embora não apareça, pode ser compreendida a partir de diversos comentários que remetem a ela. Se conseguirmos fundar essa leitura com evidências, teremos encontrado um forte indício para considerar a Cláusula Final, bem como os problemas que ela levantou em $C A G$, como o critério que liga as duas parte da obra em um tratado coeso, muito embora haja a mencionada mudança de foco.

\subsection{A silogística e critérios de prova. $O$ argumento em $\operatorname{APr}$ I.23}

Uma longa disputa tem sido travada ao redor das afirmações que Aristóteles faz no início 
de $A P r$ I.23. Logo no início, em 40b20-2, Aristóteles é interpretado como estabelecendo a alegação que toda inferência lógica será representada através de uma das três figuras silogísticas reconhecidas $^{146}$. A rigor, uma tal alegação é falsa, pois as regras de conversão, reconhecidas por Aristóteles, seriam contra-exemplos claros a esse tipo de interpretação. Por sua vez, caso se tomasse o termo empregado por Aristóteles como se referindo a silogismos, stricto sensu, além de estranha, essa alegação nada mais seria que mera reiteração dos resultados obtidos por Aristóteles ao longo do argumento desenvolvido em $\operatorname{APr}$ I. $7^{147}$.

Visto que a classe dos silogismos é bem mais restrita que a de outros argumentos que poderiam respeitar as Condições Inferenciais da $D G S$, tem-se duas alternativas adicionais: ou consideramos argumentos não-silogísticos, os quais podem ser representados como silogismos, ou devemos considerar que não se trata mais da noção de argumento, mas de algo bem diferente. A resposta a essa questão é bastante simples e não requer um exame detalhado do próprio capítulo. Não se trata da noção de argumentação ou de suas consequências; Aristóteles está interessado em mostrar que há elementos em comum a todo método de prova. Sabe-se pelos resultados obtidos em $A P r$ I.44 que argumentos de redução ao absurdo têm uma etapa inferencial que não pode ser justificada silogisticamente ${ }^{148}$. Isso contraria a possível leitura na qual se considera uma classe maior de argumentos válidos e estabelece o interesse aristotélico na fundação da prova.

146 Tratando-se de uma generalização do argumento anterior, dado em $\operatorname{APr}$ I.7, todos os argumentos serão, de acordo com essa interpretação, redutíveis aos modos silogísticos universais da primeira figura. Cf. $A P r$ I.7, 29b1-2.

147 Uma possibilidade de se interpretar essa alegação de Aristóteles é considerar argumentos como aqueles apresentados no início de $A \operatorname{Pr}$ I.7, onde ele reconhece que é possível obter um silogismo, feitas as devidas alterações ao argumento. Entretanto, esse ponto não parece ser relevante ao longo de toda discussão avançada em $A P r$ I.23, sugerindo que Aristóteles teria algo completamente distinto em mente.

148 Trata-se da última etapa, após a obtenção da contradição, a qual corresponde apenas à consideração do oposto, para concluir-se a prova. Essa última etapa se apresenta apenas como a dissolução da hipótese (no sentido moderno) da contraditória e não pode ser estabelecida por um silogismo. 
$\mathrm{O}$ fato de mostrar um interesse naquilo que determina uma prova lógica apresenta algumas consequências: Aristóteles não precisa apresentar uma nova definição do que é um argumento e deve assumir uma noção de consequência lógica, isto é, a silogística, como dada. De fato, não faria sentido Aristóteles avaliar critérios que definam uma consequência lógica, como se poderia imaginar $^{149}$, visto que uma definição foi dada em diversos textos ${ }^{150}$. Mesmo assim, não fica certo o que Aristóteles entende por essa noção de prova e abre-se a questão se o critério que ele está buscando é um critério propriamente lógico ou de outra natureza.

A generalização da silogística ou prova?: Aristóteles inicia $\operatorname{APr}$ I.23 estabelecendo uma referência direta com $A P r$ I.7, ao assumir a demonstração de como todos os silogismos são aperfeiçoados e podem ser reduzido aos modos universais da primeira figura silogística ${ }^{151}$. Em seguida, Aristóteles muda o foco a apresenta sua meta, a qual foi comumente interpretada como se tratando da enunciação de um meta-teorema de completude do sistema silogístico. Assim sendo, de acordo com a tradição, ele retomaria a tese de $A \operatorname{Pr}$ I.7, tendo em vista, supostamente, a generalização da mesma. Aristóteles introduz o suposto meta-teorema da completude da seguinte maneira:

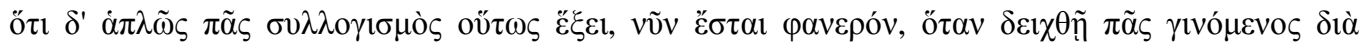

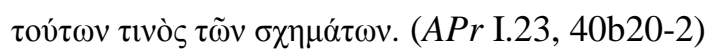

149 Ebert assume a pretensão aristotélica de provar que toda inferência lógica seja silogística: cf. Ebert \& Nortmann [2007], p.740.

150 Cf. $A P r$ I.1, 24b18-22; Top I.1, 100b25-7; RS 1, 165b5; Rhet. I.2, 12xxcyy-zz.

151 Essa remissão é tratada como forte indício da introdução tardia dos capítulos referentes à lógica modal de Aristóteles em $A \operatorname{Pr} \mathrm{I}$.

Devemos ressaltar que nas interpretações da silogística como um sistema de dedução natural, tendem a assumir a completude da silogística a partir da consideração que todos os silogismos podem ser provados mediante um silogismo perfeito (cf. Corcoran [1972][1974]). Nesse sentido, todas as interpretações da completude que adotam a linguagem estabelecida por Corcoran, embora atribuam a enunciação do meta-teorema ao capítulo $A P r$ I.23, assumem como critério as demonstrações de $A P r$ I.7. Para outras interpretações da silogística como sistema lógico: Martin [2004]; Andrade-Lotero [2007]; Malink [2013]; Ferreira [2012]. 
Ficará claro, agora, que, em geral, toda prova será dará da mesma maneira, quando toda prova que se apresentar for demonstrada a partir de uma dessas figuras ${ }^{152}$.

Não é difícil perceber como esse enunciado geral poderia ter sido assumido como apresentação do meta-teorema da completude lógica do sistema silogístico. Aristóteles não parece ser consistente em seu uso do vocabulário técnico, como é o caso do termo syllogismos. Se esse termo for assumido no sentido de argumentação, não se poderá negar que há uma forte semelhança com a noção de completude. Entretanto, como mencionamos antes, esse argumento lida com algumas dificuldades no que tange ao escopo desse suposto meta-teorema.

A começar com a noção do termo dado pelo grego syllogismos. Como mencionamos acima, esse termo não poderia ser considerado em seu uso técnico corrente, referindo-se a inferências lógicas. Como vimos, nesse sentido há duas maneiras de compreender o termo: como argumento silogístico e como inferência lógica, em geral. Caso se considerasse o termo no sentido técnico de silogismo, tal como descrito em $D G S$, a própria enunciação seria um contrassenso, pois a pretensão seria nada mais que repetir a prova avançada em $A P r$ I.7 e considerada como encerrada em I.23 ${ }^{153}$. Caso se considerasse o termo como inferência lógica, em geral, ter-se-ia um contra-exemplo óbvio, a saber: as regras de conversão, apresentadas em $A P r$ I.2.

Nenhum desses resultados é desejável, pois indica que o sentido do termo grego

152 Entendemos, pela razões dadas acima, que Aristóteles não poderia trabalhar com uma noção de argumento intermediária entre argumentos silogísticos e argumentos válidos, em geral, incluindo argumentos com reiteração de premissas na conclusão etc.

Adotar uma tal tradução não é fácil, pois Aristóteles apresenta desde o início da obra um termo que é melhor adequado para a adoção desse sentido: a apodeixis. No entanto, a neutralidade com que Aristóteles opera ao longo desse capítulo indetermina o tipo de inferência que está em jogo, desde que se encontre um elemento que dê a garantia da conclusão. Nesse sentido, apesar da presença do termo syllogismos, entendemos que se trataria, preferencialmente, da noção de prova ou de método inferencial.

153 Cf. 40b17-20. 
syllogismos não pode ser aquele de uma noção inferencial. A consequência de se assumi-lo assim seria o fato de algumas etapas propriamente inferenciais não poderem ser computadas como sendo silogísticas. A exemplo disso, temos as provas por redução ao absurdo, cuja última etapa inferencial é feita após a prova da contradição da hipótese da reductio. Demonstrada a contradição da hipótese, obtém-se a solução desfazendo-se dessa hipótese, assumindo sua contraditória. Essa etapa, como Aristóteles apresenta em $A P r$ I.44, não é silogística, mas é justificada pela etapa anterior, a qual é representada, no sistema aristotélico, por um silogismo.

Levando-se em consideração as afirmações de Aristóteles tanto em $A P r$ I.23 como em I.44, podemos dizer apenas que argumentos por redução ao absurdo consistem em duas etapas lógicas, uma das quais é um silogismo e a outra é uma inferência adicional que não pode ser traduzida silogisticamente. Ora, mas isso conflita diretamente com a meta estabelecida por Aristóteles no início do capítulo, caso assumimos o sentido de inferência lógica. Como, de fato, não é possível demonstrar todas as etapas inferenciais como silogísticas, então, de acordo com a tradição interpretativa, Aristóteles teria cometido um engano ao assumir algo que não poderia provar.

Entretanto, é possível que Aristóteles não tivera interesse em apresentar uma prova de como os argumentos se apresentam, desde o início. Em seu tratamento acerca dos argumentos de redução ao impossível, ele não está interessado no argumento como todo, mas julga que aquilo que prova através do impossível é composto de duas etapas, das quais uma é "inferir silogisticamente o falso" (to men pseudos syllogizontai ${ }^{154}$ ). Ele se refere à etapa do argumento que infere o enunciado contraditório, a qual deve ser descrito por intermédio de um silogismo ${ }^{155}$.

154 Cf. $A P r$ I.23, $41 \mathrm{a} 24$.

155 Cf. Striker [2009], pp. 174-5; Smith [1989], pp.139-40; Mignucci [1969], p.141. Ebert não adota uma posição a 
Nessa ocasião, Aristóteles toma um certo cuidado na escolha de seu vocabulário, denominando aquilo que no início de $A \operatorname{Pr}$ I.23 foi descrito, de acordo com a tradição, pelo termo syllogismos como sendo "aqueles itens concluídos” (perainontes) através do impossível ${ }^{156}$.

Com essa análise inicial, poder-se-ia supor que, aparentemente, Aristóteles não estaria tratando de silogismos, de acordo com a $D G S$, mas de algo mais próximo à noção de prova que à noção de cálculo. Essa distinção leva à tona uma óbvia questão, a saber: qual seria a relação entre silogismos e provas? Não há uma resposta, de imediato, para essa questão. Ao contrário disso, Aristóteles apresenta alguns fatos, os quais levam à estratégia pela qual ele pretende provar o suposto teorema da completude:

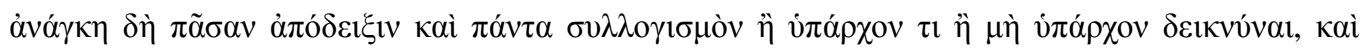

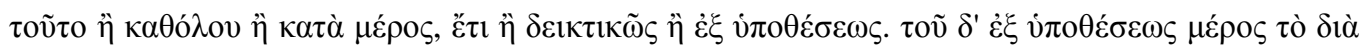

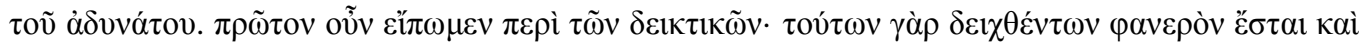

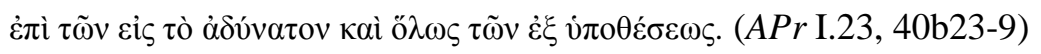

De fato, é preciso que toda demonstração científica e todo silogismo provem algo como pertencendo ou não. Isso será feito universalmente ou particularmente, ou ainda de modo ostensivo ou a partir de uma hipótese. A redução ao impossível é uma parte dos argumentos a partir de uma hipótese. Falemos primeiro, então, a respeito das provas ostensivas, porque, uma vez essas tendo sido demonstradas, estará claro também acerca das provas por absurdo e, em geral, das provas a partir de uma hipótese.

O primeiro fato que Aristóteles enuncia apresenta dois aspectos muito curiosos a respeito do método de prova: (i) uma descrição daquilo que deve ser provado por uma demonstração científica (apodeixis) ou um silogismo, a saber, uma predicação; (ii) os métodos pelos quais essas

esse respeito e se contentam apenas com a descrição da utilidade desse tipo de prova para alguns modos silogísticos, como é o caso de Baroco ou Bocardo (cf. Ebert \& Nortmann [2007], pp.744-5).

156 Striker [2009] entende que a escolha dos termos no contexto de 41a23-5 não teria sido a mais feliz, em função de ter apresentado a noção de silogismo no início de I.23 como argumentação em sentido mais amplo possível. Smith [1989], por outro lado, afirma que, a rigor, uma redução ao absurdo não é um silogismo (deduction), mas argumentos ou provas (arguments or proofs). $\mathrm{O}$ fato de Aristóteles se referir a essas provas por meio do termo syllogismoi seria sinal da recepção do vocabulário técnico que era utilizado na época (cf. Smith [1989], pp. 1412). 
provas podem ser obtidas são o método direto (deicticōs) ou "a partir de uma hipótese" (ex hypotheseōs). Já o segundo fato parece ser mais simples, uma vez que subordina provas por redução ao impossível a provas "a partir de uma hipótese”. Isto é, argumentos que atestam algo através do impossível são subconjunto da estratégia reconhecida como "prova a partir de uma hipótese" (syllogismos ex hypotheseōs).

Os problemas que podem ser apresentados apenas com a menção desses dois fatos são numerosos e de difícil solução. Tradicionalmente, a descrição de uma prova "a partir de uma hipótese" está entre os itens de maior dificuldade, não sendo propriamente definida, mas recebendo várias descrições possíveis ${ }^{157}$. As tentativas de determinar o critério exato, pelo qual uma prova se torna hipotética ${ }^{158}$ são numerosas e não há um consenso a seu respeito ${ }^{159}$. Tudo que podemos afirmar com certeza a respeito de uma tal prova é que ela opera em duas etapas, ao contrário das provas ditas diretas. Uma etapa será apresentada por um silogismo e outra etapa é uma consequência assumida.

Apesar da evidente dificuldade que a descrição dos argumentos hipotéticos apresenta, desde a antiguidade, há um outro problema no início dessa descrição, a saber: Aristóteles introduz os métodos de prova como aspectos das demonstrações científicas ou de silogismos? Caso Aristóteles tivesse mencionado apenas que se tratava de syllogismōn, a dificuldade estaria presente, mas poderia ser contornada pelas razões estabelecidas acima. No entanto, com a menção feita a demonstrações científicas (apodeixeis), deveríamos pressupor que o escopo de argumentos é mais restrito que a classe de silogismos, dada a alegação de Aristóteles em APr I.4,

157 Cf. $A P r$ I.29, 45b15-20; I.44; Top I.18, 108b12-9.

158 Ao longo desse trabalho temos utilizado o termo "hipotético" ou "hipótese" no sentido corrente em nossa linguagem natural. Como o uso de hipótese, em Aristóteles, é bastante distinto do uso nosso, italizamos todos os termos relacionados à hipótese, quando essa se referir à noção aristotélica.

159 Cf. Striker [1979]; [2009], p.176-7. 
em um contexto mais técnico. Seria, então, o caso de Aristóteles, efetivamente, ter levantado a possibilidade desses dois usos do termo syllogismos serem o mesmo conceito? De outro modo, esse sentido satisfaria as exigências de $D G S$ ? Por ora, não temos uma resposta a essa questão.

Apesar de não termos, ainda, uma boa compreensão do sentido apresentado pelo termo syllogismos, tentaremos prosseguir para a estratégia que Aristóteles avança para a prova do suposto meta-teorema de completude. A estratégia parece ser bem simples: ela pretende fazer uma prova primeiro do método direto e, a partir disso, poderá expandir seus resultados tanto para argumentos por redução ao impossível como, em geral, a argumentos hipotéticos. De acordo com a interpretação tradicional, a prova do primeiro método implicaria a prova do segundo método ${ }^{160}$. No entanto, a própria afirmação de Aristóteles em $A P r$ I.44 arruína essa mesma interpretação, pois nega que os argumentos hipotéticos sejam provados através dos resultados da prova dos argumentos dêicticos.

Como devemos interpretar a estratégia que Aristóteles apresenta, então? A afirmação que ele apresenta em 40b26-9 diz que uma vez demonstrado o caso das provas diretas, tornará mais clara sua pretensão acerca dos demais métodos de prova. Ora, vimos que uma prova como aquela atribuída pela tradição não cabe nessa afirmação aristotélica. Isso implicaria que a prova do caso dêictico seria suficiente apenas para se referir a uma parte do caso hipotético, como pudemos ver em $A P r$ I.44, e não a todo caso. Sendo assim, o dito contexto de completude sequer poderia formular um argumento, o que teria como consequência a falha na compreensão da suposta generalização que Aristóteles estava pressupondo ${ }^{161}$.

160 A estratégia da interpretação que assume essa afirmação como prova de completude seria assumir o teorema como se tratando do seguinte enunciado: $\mathbb{F}_{2} \mathrm{~A} \rightarrow \mathbb{V}_{2}(\mathrm{~B} \rightarrow \mathrm{C})$, onde $\mathrm{A}$ está para prova dêitica, $\mathrm{B}$ para redução ao absurdo e $\mathrm{C}$ para argumento hipotético.

161 Cf. Striker [1979]. 
Se essa estratégia não pode ser representada como uma fórmula lógica, então o objetivo aristotélico deve ser que a demonstração a respeito da prova dêitica revela algo que seja fundamental para os demais tipos de prova. De certo modo, dada a força de sua afirmação, no início de $A \operatorname{Pr}$ I.23, pode-se supor que Aristóteles tinha pretensão de encontrar o elemento de um argumento que poderia dar a garantia para a prova pretendida. Esse é um ponto delicado, pois em argumentos ditos indiretos, esse elemento teria que ser suficiente para garantir a prova de todo argumento, mesmo que seja constituída em duas etapas distintas. De outro modo, suponhamos que uma prova indireta seja constituída de uma prova direta de algum fato e mais uma inferência. A prova direta que é um elemento dessa prova indireta deve ser razão suficiente para a garantia da conclusão indireta.

Uma tal descrição parece bastante intuitiva e válida, mas apresenta um problema, em particular, com relação à redução ao impossível. A dificuldade que o caso dos argumentos por redução ao impossível representa está na última etapa que equivale à transição da parte silogística dos argumentos para a confirmação da hipótese. Em casos gerais, como aquele concebido em Top I.18, poder-se-ia entender aquilo que Aristóteles pretende com o estabelecimento de sua regra, pois parece que a necessidade da conclusão da etapa silogística é suficiente para conceder a necessidade para toda prova. Entretanto, isso não é o caso em argumentos de reductio. Nesse caso, a última etapa depende de uma consideração adicional, a saber, assumir que a contraditória que originou a etapa silogística seja falsa e, por conseguinte, sua contra-parte, verdadeira. Ora, de acordo com $A \operatorname{Pr}$ I.23, 40b25-6, as provas por redução ao absurdo seriam um sub-caso de argumentos hipotéticos. Sendo assim, a tentativa de encontrar uma tal garantia da prova seria colocada em risco.

Mas qual seria esse critério que Aristóteles pretende obter? Ao longo do argumento que 
Aristóteles desenvolve a partir de $A \operatorname{Pr}$ I.23, 40b30, ele tenta estabelecer o termo mediador como a razão pela qual uma prova pode ser determinada. Consideramos esse ponto como sendo de muito interesse, pois ele se aproxima à questão que não fomos capazes de responder em nossa análise de $A \operatorname{Pr}$ I.7, no capítulo anterior: qual é o item que tornaria um argumento silogístico capaz de satisfazer as exigências apresentadas pela Cláusula Final? Seria o termo mediador que em $A P r$ I.23 é apresentado como parte relevante para uma prova o item a cumprir e satisfazer a Cláusula Final? Para dar uma resposta a essa questão, devemos fazer uma breve análise da primeira parte da prova que Aristóteles apresenta em $A P r$ I.23.

Silogismos e provas. O argumento em $A P r$ I.23, 40b30-41a20: Aristóteles inicia seu argumento estabelecendo um determinado objetivo, a saber, uma predicação entre os termos B e A. A partir disso, ele apresenta uma longa análise de casos negativos que não resultam em um silogismo, muito menos em uma prova, após a qual ele introduz o termo mediador como solução para o problema apresentado. $\mathrm{O}$ critério de avaliação que Aristóteles assume para chegar a seu resultado, curiosamente, é oriundo de sua teoria da predicação, com exceção de que o enunciado da prova silogística é obtido silogisticamente ${ }^{162}$.

A diferença mencionada acima, de obter a mesma descrição, originalmente de sua teoria da predicação, através de um syllogismos não quer dizer que a pretensão de Aristóteles seja construir um silogismo. Essa parte já foi feita mediante a $D G S$ e a discussão apresentada em $C A G$. Por essa mesma razão, não podemos interpretar esta análise como tentativa de confirmação da noção de inferência lógica, mas como uma investigação a respeito dos critérios que

162 Devemos frisar que, dado o contexto anterior em que o termo syllogismos pode não se referir diretamente a argumentos propriamente silogísticos, é preciso certo cuidado ao interpretar as próximas etapas. 
determinam o elemento que garante essa mesma inferência. Sendo assim, assumimos que uma noção de consequência lógica já esteja dada e que essa corresponda, fundamentalmente, à $D G S$. Com isso, nossa investigação irá focar de que modo a Cláusula Final poderá ser justificada.

Aproveitando-se do vocabulário predicativo, Aristóteles faz uso de um lema que já empregara em sua análise a respeito de asserções predicativas: para um enunciado ser assertivo, ele precisa assumir um item em relação ao outro. Com efeito, esse lema abre uma questão a respeito de como um item deve ser assumido com relação a outro. Isto é, qual a justificativa pela qual um termo pode ser relacionado com outro? Rapidamente, pode-se notar que surgem várias possibilidades para responder a essa questão e que Aristóteles inicia sua prova tomando esse lema como critério. A seguir, analisaremos os diversos casos introduzidos por Aristóteles, separadamente.

O primeiro caso prova a relação entre B e A, seja qual for, a partir do mesmo enunciado. Suponhamos, pois, que se queira provar que todo $\mathrm{B}$ é $\mathrm{A}$, isto é, $\mathrm{B} a \mathrm{~A}$. Um argumento lógico poderia ser que $\mathrm{B} a \mathrm{~A}$ é consequência lógica de $\mathrm{B} a \mathrm{~A}$, o que constaria como uma verdade lógica. Entretanto, essa verdade lógica não se estabelece como argumento interessante e, além disso, não serve como uma prova da conclusão, muito menos como prova silogística ${ }^{163}$. Sendo assim, Aristóteles rejeita o primeiro caso com base em que esse suposto argumento cairia em uma petição de princípio (to ex archēs estai eilēmenon ${ }^{164}$ ). Esse caso é desconsiderado como

163 De fato, como pretendemos discutir mais adiante, nesta seção, o argumento de Aristóteles procede muito proximamente às exigências estabelecidas pela $D G S$. No presente caso, temos um caso que lesa a exigência de $D G S$ em obter uma conclusão distinta do conjunto de premissas.

164 Striker [2009] afirma que a expressão ex archēs é de uso comum para Aristóteles se referir ao que posteriormente ficou conhecido como petição de princípio. A descrição dessa recusa de Aristóteles como petição de princípio, no entanto, requer alguns esclarecimentos. No caso de ter uma inferência do gênero que poderia ser representado por $\mathrm{p} F \mathrm{p}$, esse tipo de procedimento lógico, embora válido, não faria sentido se apresentado como argumento ou como prova para algo. $O$ fato que se chama de petição de princípio é a tentativa de provar um enunciado a partir dele mesmo, o que é um absurdo. 
candidato para uma prova, porque, apesar de ser um raciocínio necessário, não fornece qualquer critério pelo qual a conclusão possa ser justificada.

Essa caso que foi rejeitado é uma de duas possibilidades que podem formar o que se conceberia como argumento com apenas uma premissa. O primeiro caso foi a possibilidade de se obter uma prova ao re-instanciar uma premissa. Por sua vez, o segundo caso é a tentativa de formar um argumento a partir de uma única premissa que seja distinta do enunciado da conclusão. Ou seja, dada a relação entre B e A como termos do enunciado conclusivo, a premissa única deveria ter ao menos um termo adicional que substitui um desses dois termos. Aristóteles introduz sua consideração à seguinte maneira:

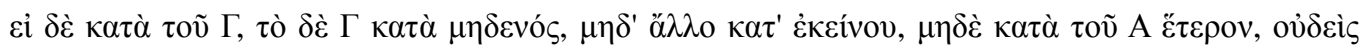

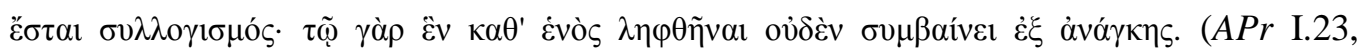
40b33-6)

Se A é C, mas o C não se predica de nada, nem outro se predica dele, nem um segundo em relação a $\mathrm{A}$, então não haverá silogismo. Pois, em virtude de se assumir um item em relação ao outro, nada resulta por necessidade.

Essa descrição é um tanto surpreendente, pois assume exclusivamente a predicação entre os termos $\mathrm{C}$ e A, e nenhuma outra relação possível nem em relação ao termo $\mathrm{C}$ nem ao termo A. De outro modo, devemos supor, por essa descrição, que a única premissa desse suposto argumento seja uma asserção cujos termos não estabelecem qualquer relação com os demais termos ${ }^{165}$.

Assumir uma leitura de ex archēs como petição de princípio tampouco é consistente, pois no mesmo capítulo, em 41a24-5, Aristóteles afirma que uma prova por redução ao absurdo consiste em duas etapas, uma propriamente silogística e uma segunda que é assumida ex archēs. É evidente que, nesse caso, não se trata de uma petição de princípio.

165 Essa descrição aristotélica, embora sirva muito bem ao argumento que ele pretende desenvolver, é contraintuitiva e, em última análise, não satisfaria todas as possibilidades dadas pela teoria da predicação, onde os

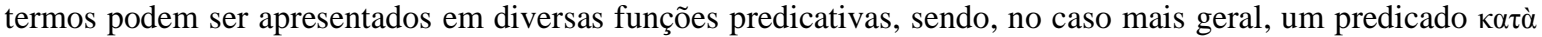
$\sigma u \mu \beta \varepsilon \beta \eta \kappa o ́ \varsigma$ (isso se aplica a nomes próprios, inclusive). Nesse caso, o termo $\mathrm{C}$ e o termo A teriam diversas sequências de termos, cuja relação seria sempre de total privação. Consideramos o segundo caso como hipótese para a presente análise. 
Sendo assim, não é possível assumir o termo C como termo mediador do argumento. Tampouco é o caso de haver um termo que possa se ligar ao termo A e funcionar com o mediador do argumento.

Na medida em que não se introduz um termo que sirva de mediador ao argumento, devemos supor que a inferência pretendida de $\mathrm{C} a \mathrm{~A}$ para $\mathrm{B} x \mathrm{~A}$, onde $x \in\{a, e, i, o\}$, seja imediata, o que é um absurdo. Pela descrição dada nesse caso, não se pressupõe um termo $X$ tal que todo ou algum X seja C, de modo a obter uma conclusão em Barbara ou Darii. Nem se assume um Y tal que $\mathrm{C} x \mathrm{Y}$, obtendo através da terceira figura conclusões em YiA ou AiY e AoY. Tampouco se apresenta um termo $\mathrm{Z}$, tal que $\mathrm{Z}$ se predique de $\mathrm{A}$, formando argumentos na primeira ou na segunda figura silogística. Se as relações entre os termos apresentados forem assumidas como acima descrito, não será possível obter um argumento silogístico ${ }^{166}$, nem qualquer outra inferência lógica considerando-se, a rigor, o termo C como distinto do termo B e incompatível com ele ${ }^{167}$

A conclusão a que Aristóteles chega é que não há possibilidade para se obter um argumento silogístico, dadas as condições estabelecidas anteriormente. Essa conclusão seria óbvia se ele invocasse uma das condições estabelecidas nas Condições Inferenciais da DGS, segundo a qual um silogismo deve conter mais de uma premissa para obter sua conclusão. Entretanto, Aristóteles utiliza como justificativa uma descrição bastante incomum. Ele defende o fato de nenhum silogismo seguir dessa premissa, "pois, em virtude de se assumir um item em

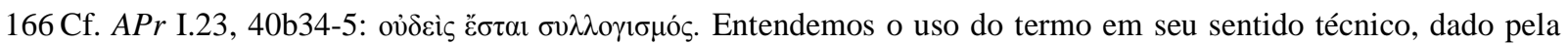
DGS, em APr I.1, 24b18-22.

167 Nos referimos às regras de conversão apresentadas em $A P r$ I.2. A rigor, essas regras são inferências lógicas em que dois termos invertem suas posições, podendo mudar de relação lógica ou não. Ou seja, o caso das conversões não pode ser levado em consideração nesse exemplo de 40b33-6, pois, embora se tenha proposto um argumento com uma só premissa, esse mesmo argumento é formado por três termos, excluíndo a possibilidade de inserir as conversões na discussão. 
relação ao outro, nada resulta por necessidade". Essa justificativa, a rigor, não poderia ser assumida sem alguma qualificação, como toda a tradição entende ${ }^{168}$, pois se assume que as regras de conversões sejam inferências lógicas, embora Aristóteles não tenha se expressado a esse respeito.

A solução que Alexandre apresenta é considerar que o texto omite um advérbio de modo como "silogisticamente", remetendo diretamente à segunda Condição Inferencial da DGS. De acordo com a leitura de Alexandre, Aristóteles estaria, efetivamente, expressando que o caso em questão não pode representar um silogismo, uma vez que viola a condição de ter mais de uma premissa. Ora, por um lado, a suposta omissão do advérbio modal é totalmente justificada, com base já no dado inicial que motivou a investigação, a saber, que o enunciado em que A se predica de B fosse obtido silogisticamente. Nessa prova, Aristóteles está constantemente lidando com a noção técnica do silogismo, apontando para o uso técnico do termo em 40b35, imediatamente antes dessa explicação.

Por outro lado, a solução apresentada por Alexandre, embora ele tenha observado a relação dessa descrição com a $D G S$, não nos parece ser ideal. A descrição "assumir um item em relação a outro", parece nos remeter à descrição semelhante feita em 40b31, a qual é típica do contexto da teoria aristotélica da predicação. Se, no presente caso, a descrição efetivamente se ligar à noção de relação de termos, então podemos admitir dois casos, em princípio: (a) ou os termos da conclusão são assumidos ou (b) os termos da premissa são assumidos. Como o caso (a) é idêntico ao primeiro caso desse argumento, podemos desconsiderá-lo. Então, trata-se da hipótese de que dos termos da premissa se segue a conclusão desejada e já anunciada, desde o início. Se essa interpretação estiver correta, Aristóteles não estava enunciando uma regra geral 168 Cf. Alexandre [1883], ; Smith [1989], p.140; Striker [2009], p.172. 
que justificasse o caso mencionado, mas estava fazendo observações pontuais a respeito do fato que impedia a formação do argumento silogístico.

Aristóteles conclui sua breve análise desse segundo comentário com a observação que há necessidade de se adicionar novas premissas para possibilitar a obtenção de uma conclusão silogística. Para o caso da adição de novas premissas, Aristóteles apresenta dois casos: (c) adição de uma premissa (argumento com duas premissas, apenas) e (d) adição de mais de uma premissa (caso geral). Quanto ao ponto (c), poder-se-ia cogitar que bastasse retirar as restrições apresentadas ao caso anterior. Vimos, no segundo caso, que a relação entre $\mathrm{C}$ e $\mathrm{A}$ era tal que os termos não apresentavam outra relação com demais termos e eram, portanto, isolados. A única relação predicativa que lhes era possível era entre si, não mais tendo qualquer outra relação com outros termos.

Uma vez descartada qualquer possibilidade de provas com base em uma só premissa, Aristóteles passa a considerar alguns pontos a respeito de supostos argumentos com mais de uma premissa. Esse estudo é apresentado por duas situações: argumentos com duas premissas e argumentos com mais de duas premissas. No entanto, esses exemplos têm um ponto em comum, a saber, eles suspendem as restrições impostas no segundo caso de análise. Com isso, a princípio, seria possível formar silogismos em todas as figuras. Entretanto, o fato de poder formar um silogismo não significa que o resulta obtido seja uma prova. No caso, Aristóteles está levando em consideração a total ausência do termo B, o qual deve figurar como termo-sujeito na conclusão da prova, do próprio argumento. Esse caso poderá ser estendido para exemplo de argumentos com infinitas premissas, assumindo-se um termo $\mathrm{W}_{n}$, para $n \square\{1,2,3, \ldots, n\}$, que se liga a um dos dois termos apresentados no caso anterior. Com isso, poder-se-ia formular quaisquer argumentos, 
a partir dos quais obtemos inúmeras conclusões, mas nenhuma conclusão, na qual o termo B aparece.

A justificativa que Aristóteles utiliza para explicar porque nenhuma conclusão se segue, ostentando B como termo-sujeito e A como termo-predicado da prova, depende da consideração que não há qualquer conexão entre um dos termos escolhidos, que não o próprio A, na conclusão. Visto que não há qualquer elemento que sirva de garantia para obter a conclusão desejada entre B e A, esse exemplo não funciona como prova. Não importa quantos termos e, consequentemente, quantas premissas sejam adicionadas, ou qualquer outra consideração que se faça a respeito desse argumento, ele não sucederá em sua pretensão inicial. É preciso, pois, que haja alguma conexão entre esses termos para que toda sequência de premissas possa ser combinada para formar uma prova que conecte, com sucesso, o termo A ao termo B.

Dados esses prospectos, Aristóteles afirma que jamais haverá uma prova de um item em relação a outro sem haver um tal elemento conector. Sua observação é apresentada da seguinte maneira:

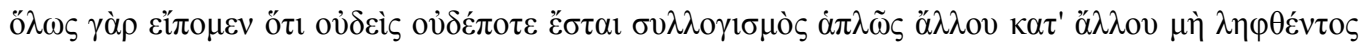

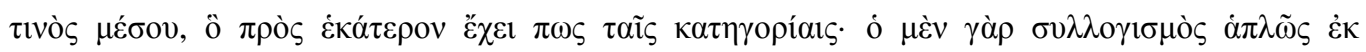

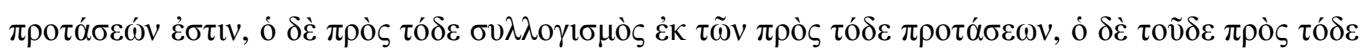

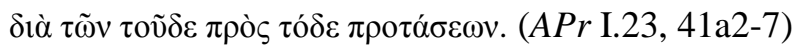

Em virtude disso, dizemos, em geral, que jamais será possível uma prova de um item com relação a outro, sem assumir algum mediador, o qual se relaciona com cada termo de acordo com as predicações. Afinal, por um lado, uma prova simples se dá a partir de premissas, por outro lado, uma prova com vista a algo será obtida a partir de premissas com vista a algo e uma prova disso em relação a algo é obtida disso em relação a algo.

Essa descrição é muito curiosa. Está claro que jamais haverá uma prova se não tiver um mediador. Entretanto, essa solução de Aristóteles é qualificada pela descrição que o termo 
mediador deve estar relacionado a cada um dos termos através das predicações. Uma tal qualificação pode parecer trivial, mas ela nos permite inferir que a mera existência de um termo comum a ambas as premissas não é suficiente para obter uma prova. Esse termo comum deve estar relacionado de modo que obtenha um resultado efetivo. Um termo deve estar relacionado por uma de quatro formas categóricas com cada termo com o qual ele se relaciona. Ademais, a combinação entre essas formas categóricas tinha que ser de tal modo que esse termo poderia desempenhar, de fato, o papel de mediador.

A justificativa que Aristóteles apresenta para a qualificação do termo mediador causa um certo estranhamento pelo seu aparente conteúdo tautológico. Não só parece intuitivo como também parece ser extremamente óbvio que, dado que uma prova resulta de premissas, que uma prova qualificada de tal e tal modo, seja resultado de premissas qualificadas de tal e tal modo. $\mathrm{O}$ problema, no entanto, é o seguinte: a que se refere essa qualificação e há, se for o caso, uma diferença entre argumentos serem em vista de algo ou serem em vista de algo, mas a partir de outros itens?

Aristóteles apresenta essa sua descrição como justificativa para o caso de provas em que o termo mediador deve ser qualificado. Mas como essa qualificação altera o próprio argumento? Sabemos que essas provas precisam ser silogísticas, uma vez que a análise anterior de casos apresenta uma clara conexão com a DGS. Os argumentos devem conter mais de uma premissa e não pode haver exclusão de termos no cálculo silogístico a ser apresentado. O fato de um termo ser excluído do cômputo não impede que haja uma prova silogística, muito embora falhe em estabelecer uma prova a respeito dos termos pressupostos, como ocorre no argumento de $\mathrm{APr}$ I.23, 40b30. Se a pretensão de uma prova é atestar que um termo esteja relacionado a outro, sua prova deve satisfazer uma tal disposição. De outro modo, ela deve ser tal que a relação exigida 
seja preservada.

Se nossa análise estiver correta, obtivemos um número considerável de condições para a satisfação de uma prova silogística. A primeira condição é que as premissas devem ser formadas de modo a obter um termo mediador. Esse mesmo é um termo comum a duas premissas, mas que está de tal modo relacionado, através de functores, aos demais termos, que essas premissas formam uma conclusão silogística. Por fim, uma prova só será obtida se e somente se ela equaciona, através de combinações específicas de functores e termos mediadores, os termos que devem constar na conclusão. Afinal, seria impossível assumir uma prova com relação a um dos termos se esse não fizer parte das premissas ou se não houver nada em comum aos termos $\operatorname{extremos}^{169}$.

Aristóteles conclui a partir desse raciocínio que se iniciou com sua estranha observação, que uma prova depende de um mediador, o qual conecta as predicações se, de fato, houver uma prova de um item com relação a outro. Isso, por sua vez, seria feito apenas em uma das três figuras apresentadas previamente, em $C A G$. Ao longo dessa primeira parte do argumento, Aristóteles parece insistir em uma relação entre as exigências das provas e a $D G S$.

Vimos, na análise dos primeiros dois casos, a satisfação de todos os critérios exigidos pelas Condições Inferenciais da DGS. O terceiro caso de análise, no entanto, apresenta dificuldade maior, pelas seguintes razões: por um lado, Aristóteles já estava operando com uma noção inferencial clara ao apresentar o argumento; por outro lado, ele reconhece que certa concatenação de premissas pode resultar em silogismos, mas que nenhum desses casos será a prova desejada.

O primeiro ponto rejeita a suposição que Aristóteles estaria comprometido em apresentar 169 Cf. $A \operatorname{Pr}$ I.23, 41a7-11. 
uma simples noção de inferência lógica qualquer, enunciando, com isso, a descrição de consequência lógica que conhecemos das Condições Inferenciais da DGS. Esse compromisso de satisfazer uma determinada inferência e não de descobrir qual seria, se apresenta como ponto central na discussão de como satisfazer uma determinada prova. Ou seja, a satisfação das Condições Inferenciais não é suficiente para garantir a prova pretendida. De fato, nem a obtenção de um silogismo seria suficiente, se esse não for um silogismo se focando especificamente sobre os termos relacionados.

O segundo ponto, por sua vez, dá relevância à obtenção de um simples silogismo não ser suficiente para garantir a prova de um determinado enunciado. Aristóteles reconhece a possibilidade de formular diversos argumentos em todas as figuras silogísticas, mas os descarta por não servirem como prova da conclusão que se pretendia obter. Uma prova deve ter como objetivo a demonstração da conclusão e sua garantia, focando-se sobre os termos a serem relacionados. Ora, esse último ponto se conforma com a Cláusula Final de DGS. Essa não só envolve os atributos que o caracterizam em sua relevância, mas também restringe o número de argumentos válidos que poderiam ocorrer em uma prova.

Embora pareça não agregar novas características à Cláusula Final, o papel a ser desempenhado pelo termo mediador apresenta detalhes que apenas poderiam ser conjecturados, anteriormente. Confirmamos, com isso, a nossa hipótese de trabalho que formulamos antes, em nosso terceiro capítulo. Naquele contexto estávamos preocupados em encontrar um critério que poderia distinguir argumentos silogísticos de não-silogísticos e propuséramos que essa diferença poderia estar relacionada com a função de mediação. Com o resultado obtido em $A \operatorname{Pr}$ I.23, podemos confirmar que se trata de uma tal diferença. Entrementes, a análise de I.23 sugere algo mais forte, a saber: a diferença entre esses dois tipos de argumentos, o silogístico e não- 
silogístico, não se dá por sua capacidade de obter resultados, mas por seu potencial de prová-los. Sendo assim, observamos que a Cláusula Final, além de todas as exigências que estabelece a respeito de argumentos silogísticos, se propõe como exigência de prova.

Se nossa interpretação estiver correta, podemos afirmar que a Cláusula Final estabelece uma exigência de prova, tendo em vista um resultado específico. $\mathrm{O}$ argumento silogístico cumpre essa exigência através de um termo mediador de X para Y (dia toude pros tode protaseōn). Essa descrição das provas, no entanto, apresenta forte semelhança com uma outra descrição aristotélica, o qual poderia introduzir uma nova perspectiva a respeito da Cláusula Final e seu papel em DGS. Trata-se de uma cláusula utilizada em outros contextos, como em Tópicos, determinando que o argumento seja estabelecido em vista de uma conclusão específica (pros tēn thesin ${ }^{170}$. Haveria, por acaso, uma correlação entre essas descrições? Embora o tratamento em APr I.23 seja compatível com ambas as descrições, ele não apresenta evidências suficientes para considerar sua correlação ou uma preferência para algumas dessas cláusulas. Cumpre, então, buscar uma evidência textual que possa fundamentar essa possibilidade ou descartá-la. Por enquanto, devemos continuar a nossa análise de $A \operatorname{Pr}$ I.23.

Como em nossa discussão preliminar, chegamos à consideração que o assunto apresentado nesse capítulo não estabelece um contexto de completude lógica. Em virtude disso, fomos levados a avaliar se Aristóteles pretendia revelar um elemento que garantisse a prova em caso de argumentos diretos, bem como em argumentos indiretos. Na primeira parte do argumento, obtivemos o resultado que estabelecia o termo mediador como elemento crítico na garantia da prova de argumentos diretos. Se a estratégia de Aristóteles for consistente, devemos supor que ele concebia o termo mediador como o elemento responsável para garantia dos resultados em 170 Cf. Top II.2, 110a11; VIII.11, 161b24-6; APr I.25, 42a39-40. 
argumentos indiretos.

Provas indiretas e silogismos: Um dos pontos mais delicados na discussão acerca de provas indiretas é sua relação com os silogismos. A princípio, parece que o simples fato de se ter um mediador seria suficiente para garantir a prova da etapa não-silogística ${ }^{171}$. Em caso de argumentos que são indiretos, mas não se apresentam como reduções ao impossível, tem-se a hipótese que a prova da etapa silogística seria suficiente para garantir a prova do caso final. Esse cenário estaria de acordo com a visão geral em que o mediador seria o núcleo da prova. Entretanto, vimos que o argumento por redução ao impossível não poderia obter o mesmo resultado, tendo em vista que a prova da conclusão final é dependente não do resultado silogístico mas da contradição que dele resulta.

Esse fato parece ser forte o bastante para questionar o projeto de Aristóteles em $\operatorname{APr}$ I.23 e, em geral, de $C A E$, uma vez que teria apresentado um contra-argumento à proposta aristotélica. Apesar de se apresentar como problema sério, esse tipo de argumento poderia ser contornado por afirmações que Aristóteles faz a respeito desse tipo de argumento. Aristóteles comenta que a etapa silogística prova algo falso, o que prova por vacuidade a tese desejada ${ }^{172}$. Esse procedimento segue as seguintes etapas: primeiro se assume a contraditória da tese a ser provada; em seguida, se a contraditória provar algo falso e as demais premissas forem verdadeiras, então ela é falsa, implicando na verdade da tese original. Como desde o início se assume um par de enunciados contraditórios ${ }^{173}$, pode-se dizer que a mediação é suficiente para desencadear uma sequência de considerações, as quais culminam na prova por vacuidade.

171 Cf. APr I. 44

172 Cf. $A P r$ I.23, 41a23-6.

173 Cf. Whitaker [1997]. 
A mencionada sequência se inicia com o estabelecimento de uma prova silogística cuja conclusão é verificada como sendo falsa, seja por ser internamente incompatível ${ }^{174}$. Uma conclusão falsa em uma prova silogística implica um elemento falso no par de premissas. Se a segunda premissa, a qual não é o enunciado contraditório do enunciado a ser provado, for verdadeira, esse fato torna o outro enunciado falso, o qual é contraditório com a outra premissa, o que, por sua vez, assevera a verdade do enunciado pretendido. Devido às regras que regem as relações entre enunciados, como pares contraditórios, pode-se afirmar que a prova do falso seria suficiente para assumir a verdade do outro elemento do par de contradições.

Com esse raciocínio, pode-se dizer que, muito embora os casos de redução ao impossível dependam, de fato, de um critério adicional para obter a conclusão desejada, a etapa silogística se mostra como suficiente para garantir a prova dessa cadeia de demonstrações. Sendo assim, ela cumpre o seu papel e o termo mediador garantiria sua função. O problema principal, no entanto, está na decisão de qual seria o termo mediador relevante para garantir a prova pretendida. No caso de provas de silogismos, como os modos Baroco e Bocardo, o mediador que irá provar o falso será um dos termos da conclusão ${ }^{175}$.

Essa questão é um obstáculo considerável para a análise do papel da mediação, bem como sua possível relação para a Cláusula Final. Esse papel do mediador não se afigura como um terceiro elemento para a prova pretendida, mas é razão suficiente para provar uma outra informação, a qual, por fim, servirá como condição para a prova pretendida. Também nos casos apresentados em $A P r$ I.23, a parte silogística desse tipo de prova assume o enunciado

174 Há vários modos pelos quais se obtém um enunciados dito internamente incompatível: esses enunciados podem ser negações reflexivas, como AeA ou AoA, ou podem apresentar predicados que se excluem mutuamente, como "círculo ser quadrado", "par ser igual a ímpar" etc.

175 No caso de Baroco, o mediador é o extremo maior; no caso de Bocardo, o extremo menor. 
contraditório como elemento para sua prova, o que implica que esse enunciado, ou um elemento dele, sirva como mediador.

O exemplo a que nos referimos é extraído do contexto da matemática grega, a saber: a prova da incomensurabilidade da diagonal de um quadrado com seus lados ${ }^{176}$. Aristóteles afirma que esse enunciado é provado por redução ao impossível, onde se chega à conclusão que número par é igual a ímpar. Essa conclusão seria a razão pela qual o enunciado que toda diagonal de uma quadrado é comensurável com seus lados seja falso, provando sua contraditória. A prova matemática não é difícil e, de fato, pode-se chegar a esse resultado ${ }^{177}$. O problema, no entanto, é adequar a prova matemática ao projeto aristotélico de justificação silogística. Por sua vez, isso se resume a identificar o termo mediador dessa etapa silogística. Ou seja, qual seria o mediador desse exemplo que Aristóteles apresenta?

Se considerarmos que a razão para a diagonal não ser comensurável com os lados é o resultado internamente inconsistente que afirma que par é ímpar, então, devemos assumi-lo como conclusão da etapa silogística. Isso, por sua vez, implica no fato que a contraditória do enunciado a ser provado não pode se apresentar como premissa do silogismo em questão, mas, ao que tudo indica, como sendo, ele mesmo, o mediador da prova. Isso é altamente conjectural e não queremos afirmar que Aristóteles teria concebido as provas matemáticas desse modo. De fato, Aristóteles não apresenta uma prova a respeito de como a etapa da reductio poderia ser traduzida silogisticamente. Interpretações tradicionais assumem que, se estiver embasada sobre a prova matemática, o argumento há de conter um número elevado de premissas, consequentemente de mediadores, para conseguir obter a conclusão já mencionada. Isso gera um problema de

176 Cf. APr I.23, 41a26-32.

177 Cf. Euclides Elementos, X.117; Alexandre [1883], 260.9-261.28; Vide, também, Ebert \& Nortmann [2007], pp.745-7. 
identificação de quais seriam os mediadores apropriados para cada caso. Nos satisfazemos, porém, com o fato de um elemento do enunciado a ser provado ter de fazer parte da etapa silogística, possibilitando, assim, a prova.

Apesar dos problemas levantados para o caso das provas por redução ao impossível, tivemos alguns resultados positivos, especialmente nos casos dêicticos. Nesses casos, a prova se confunde com a própria silogística, atribuindo à última a maior relevância, já que ela não só serve como argumento lógico, mas como prova efetiva de algo. A noção de prova, como tentamos indicar, se deve sobretudo ao papel desempenhado pelo termo mediador, o qual garante a relação que se apresenta entre os termos extremos.

O ponto mais relevante, no entanto, que parece permear essa discussão é a hipótese da relação entre a função de mediação e a Cláusula Final da DGS. Como mencionamos antes, no entanto, essa mesma descrição se aproxima muito de uma outra descrição apresentada por Aristóteles em outras obras. Deixamos em suspenso a questão se essas duas descrições, a Cláusula Final da $D G S$ e a descrição pros tēn thesin, são descrições correspondentes ou se uma estaria subordinada à outra. Caso for atestada uma correspondência entre essas cláusulas, poderíamos inferir que a Cláusula Final é responsável não apenas para a obtenção de um argumento restrito a certos esquemas estabelecidos, mas é uma exigência da adequação do termo mediador com relação aos extremos ${ }^{178}$.

Como foi mencionado antes, acreditamos que uma evidência para decidir com qual das cláusulas $A P r$ I.23 se relaciona está localizada em $A P r$ I.25, onde Aristóteles menciona

178 Devemos frisar que o uso que fazemos por ora da noção de adequação é mais amplo e não tem o mesmo peso que a noção de adequação no contexto da investigação científica, onde o termo mediador pode ser adequado no sentido que lhe aferimos, mas pode não ser adequado por não apresentar a justificativa apropriada para o conteúdo apresentado na conclusão. 
explicitamente a cláusula pros tèn thesin, a qual nos permite associá-la com a Cláusula Final, devido a um paralelismo com Top VIII.11.

\subsection{A relação entre $C A G$ e $C A E$}

A relação entre duas cláusulas. $O$ caso de $A \operatorname{Pr}$ I.25: $\quad$ Após a análise em $A P r$ I.23, a qual se concentrou em apresentar o termo mediador como principal razão para a determinação de uma prova, Aristóteles se volta para algumas questões que envolvem diretamente as relações que esse termo tem com as predicações e como esse número deveria ser restrito para se obter a prova desejada. Essa investigação é importante, sobretudo, para evitar uma leitura demasiadamente forte a respeito do próprio termo mediador. Esse tipo de interpretação do termo mediador foi, como mencionamos, duramente criticada no século passado. No atual caso, porém, em vez de atribuir tais propriedades ao mediador, a garantia da conclusão seria obtida através da reunião do mediador com certos functores.

Embora uma investigação a respeito das composições de functores seja relevante para a investigação, considerando-se, sobretudo, a relação que o termo mediador tem com as predicações e esse conjunto está diretamente ligado à Cláusula Final, pretendemos focar um outro aspecto de $A \operatorname{Pr}$ I.23. Naquele contexto, aventamos a hipótese que relaciona a Cláusula Final à cláusula pros tèn thesin. Na seção anterior percebemos que o argumento de Aristóteles poderia ser um reflexo da $D G S$. Se isso for confirmado, sobretudo a respeito da Cláusula Final, a consequência será um critério de adequação do mediador com relação à conclusão e um de construção do silogismo.

Mas qual seria a exata relação dessas duas cláusulas? Como a Cláusula Final é bastante restritiva, ela se relacionaria ao mesmo número de casos de prova que a cláusula pros tèn thesin? 
Consideramos que em $A \operatorname{Pr}$ I.25, apesar do foco do capítulo ser sobre a noção de uma prova mais específica, a saber, a apodeixis, há algumas evidências que podem contribuir para essa investigação. De fato, Aristóteles irá introduzir uma consideração nesse capítulo em que ele apresenta a cláusula pros tèn thesin, no lugar onde se esperaria, a princípio, uma instância da Cláusula Final ${ }^{179}$.

O contexto do capítulo I.25 é introduzido com referência direta à meta geral dos Primeiros Analíticos, a saber, as demonstrações científicas (apodeixeis). Aristóteles determina que uma apodeixis será formada a partir de três termos e não mais que isso. No entanto, é possível obter uma mesma conclusão a partir de diversos conjuntos de premissas, apresentandose, com isso, uma variedade de mediadores e, consequentemente, diversos silogismos. Dentro desse prisma, há algumas alternativas que podem compor uma demonstração: suponha que uma conclusão E seja obtida dos pares de premissas $\mathrm{AB}$ e $\mathrm{CD}$, ou alguma combinação entre eles ${ }^{180}$. Um acúmulo similar pode ser obtido ao considerar cada uma das premissas como resultado de uma prova lógica.

Aristóteles estabelece um longo argumento em que retoma uma interpretação da silogística, segundo a qual um silogismo é constituído por um caso particular que satisfaz ou nega um caso geral, representados pelas premissas menor e maior, respectivamente. Sendo assim, assumindo que uma prova deve ocorrer a partir de uma determinado conjunto $\Gamma=\{\mathrm{A}, \mathrm{B}, \mathrm{C}, \mathrm{D}\}$, então, se $\mathrm{AB}$ satisfazem a descrição, $\mathrm{CD}$, também deveriam satisfazê-la, a não ser que essas premissas tenham sido selecionadas em vão. Isto é, se $\mathrm{CD}$ não satisfazem as condições

179 Cf. APr I.25, 42a39-40, a qual apresenta a cláusula pros tên thesin onde em Top VIII.11, 161b29-30, se apresenta a Cláusula Final como critério.

180 Há algumas variantes para a reconstituição do texto: Ross [1949] sugere que a composição entre esses conjuntos de premissas seja formado por ACD, enquanto alguns manuscritos apresentam relações como AC e BC, entre outras possibilidades. 
determinadas para a obtenção da conclusão e, apesar disso, são assumidas no conjunto de premissas que prova essa conclusão, então elas são supérfluas.

A partir desse ponto, a nossa investigação começa a ficar interessante, pois, como vimos previamente, esse contexto é similar à descrição em Top VIII.11, onde o conjunto $\Gamma$ teria sucesso em estabelecer uma conclusão, mas não poderia ser considerado um silogismo, ou uma prova, pois há uma ou mais premissas que são supérfluas e não poderiam fazer parte da demonstração. Ademais, esse mesmo fato fora recusado naquele capítulo como uma clara falha no cumprimento da Cláusula Final ${ }^{181}$.

O contexto em que essa justificativa aparece é a demonstração que uma prova silogística não pode conter mais de duas premissas, já que três termos estabelecem duas premissas, as quais passam a ser suficientes para a conclusão da prova ${ }^{182}$. Visto que Aristóteles afirma positivamente que todo argumento silogístico se dá através de duas premissas, então qualquer apresentação de um argumento com número maior de premissas terá uma das seguintes consequências: (i) ou o argumento é um falso argumento e não obtém qualquer conclusão, ou (ii) as premissas formam um argumento, mas há itens a mais que o necessário para aquilo que foi pedido ${ }^{183}$.

Como apontamos, essa descrição é extremamente similar à justificativa apresentada em Top VIII.11, com a diferença que no contexto de Top VIII o item que recusava a opção de haver um acúmulo de premissas era a Cláusula Final, enquanto em APr I.25 essa recusa é desempenhada pela cláusula pros tēn thesin. Com essa diferença, encontramos a evidência que nos era necessária para podermos atestar aquilo que havíamos aventado como hipótese em $A P r$

\footnotetext{
181 Outras passagens sugerem uma forte ligação entre esse capítulo e Top VIII. Por exemplo, em APr I.25, 42a22-4, Aristóteles faz um comentário que remete diretamente à explicação que ele dera em Top VIII.1, 155b20-4. Cf. Striker [2009], p.184.

182 Cf. $A P r$ I.25, 41a32-3.

183 Cf. $A P r$ I.25, 42a35-40.
} 
I.23. Naquele contexto, não tínhamos condições de fazermos uma escolha a respeito de qual seria a cláusula referida, muito menos, caso se referir às duas, qual seria a relação entre elas. Nesse momento da investigação, parece que a cláusula pros tēn thesin, pode substituir a segunda parte da $D G S$, sugerindo que ambas as cláusulas são correspondentes.

A justificativa para uma tal correlação pode ser encontrada no seguinte raciocínio: vimos que a cláusula pros tēn thesin se liga ao critério que estabelece o termo mediador de modo que os termos extremos tenham uma conexão. Agora, porém, essa exigência determina que haja um número limite de premissas, como de termos correspondentes, que impedem a adoção de um número excessivo de asserções para assumir-se uma conclusão. Essa última asserção, como vimos, é idêntica à afirmação que se liga à Cláusula Final em Top VIII.11 e satisfaz o critério dada pela própria definição da Cláusula Final em $\operatorname{APr}$ I.1, 24b20-2. Naquela ocasião, Aristóteles reconhece a Cláusula Final como sendo um critério pelo qual nada mais precisa ser adicionado de fora, para o necessário ser engendrado. Ora, se há um número limite de premissas e de termos correspondentes, a cláusula pros tēn thesin satisfaz essa condição em $A P r$ I.1. Visto que o contexto considera que uma prova silogística não pode conter mais que duas premissas, qualquer adição de fora irá falhar no cumprimento dessas cláusulas.

Confirmada a correlação entre ambas as cláusulas, podemos, enfim, confirmar que o critério levado em consideração no terceiro caso do argumento inicial em $A P r$ I.23 está relacionado com a Cláusula Final. Com isso, podemos confirmar, também, que a Cláusula Final se liga à função de mediação a ser satisfeita pelo termo mediador, o que confirma a hipótese de trabalho que apresentamos em nosso terceiro capítulo. De acordo com esse resultado, o termo mediador é o elemento determinante para o argumento silogístico satisfazer a noção de prova, o que está de acordo com o resultado que obtivemos no capítulo anterior que, nesse sentido, a 
consequência silogística apresenta alguma semelhança com a noção de consequência intuicionista, a qual apresenta o mesmo sentido de prova.

A principal consequência dessa correlação, no entanto, é que podemos apresentar a Cláusula Final como candidato a servir de fio condutor entre $C A G$ e $C A E$, como discutiremos a seguir.

A Cláusula Final como fio condutor para $\boldsymbol{A P r}$ I: Se nossa interpretação estiver certa, podemos afirmar que a observação de $A P r$ I.25 não só se conforma à descrição da Cláusula Final, isto é, passa a ser uma descrição equivalente à da $D G S$, mas reinterpreta a própria definição da Cláusula Final restringindo-a mais ainda. Com essa interpretação confirmamos que esse capítulo está ligado aos capítulos anteriores e que esses, por sua vez, estão diretamente relacionados à discussão introduzida pela Definição Geral do Silogismo.

Vimos que em $C A G$ a $D G S$ tinha levantado alguns problemas quanto à justificativa pelas distinções que se podia fazer entre argumentos silogísticos e não-silogísticos, bem como a distinção dos argumentos silogísticos entre si mesmos. Esses resultados foram obtidos, sobretudo, em virtude da comparação de duas análises a respeito de um mesmo argumento que Aristóteles fez em $A P r$ I.4 e I.7. No primeiro caso, a justificativa para desqualificar o argumento como silogístico se devia à Cláusula Final. Tivemos, com isso, a situação em que a Cláusula Final era um critério de distinção entre os diversos casos de argumentos, apesar de não termos uma justificativa pela qual uma tal distinção pudesse ser avaliada construtivamente.

A única sugestão que possibilitava, em hipótese, distinguir esses casos era uma análise do termo mediador e as combinações de functores predicativos que lhe acompanhavam. Esse, pois, foi o critério que tínhamos para avaliarmos a conexão entre $C A G$ e $C A E$. Se $C A E$ se iniciasse 
com uma discussão a respeito do termo mediador, seríamos capazes de avaliá-lo em função da Cláusula Final, mesmo que não nos fosse possível dar uma resposta concreta para o problema que levantamos em nosso estudo de $C A G$. Essa confirmação não só foi dada, como nos foi possível identificar que o argumento todo em $A P r$ I.23 está proximamente ligado à própria $D G S$ e retrata a própria silogística como um argumento com pretensão de prova, muito embora, como afirma em APr I.4, nem todo silogismo seja uma demonstração científica (apodeixis).

Apesar do aparente contexto de completude, a partir do qual essa capítulo era interpretado, o foco de Aristóteles se concentra sobre do papel da mediação para satisfazer a noção de prova. Com isso nos foi possível confirmar a importância que o termo mediador tem para efeitos de análise da necessidade que está relacionada com a Cláusula Final. A suspeita inicial que extraímos em nossa análise dos capítulos $A P r$ I.4 e I.7, se confirma, assim, com a nossa análise em $C A E$ : o critério que poderia garantir a diferença entre os diversos casos de argumentos silogísticos e argumentos não-silogísticos, bem como a distinção entre os diversos modos silogísticos poderia ser justificada apenas pelo termo mediador e, sobretudo, seu comportamento com os functores predicativos.

Esse último passo, a saber, a relação do termo mediador com os operadores copulativos, é investigado, em parte, em $A P r$ I.24, onde Aristóteles introduz uma investigação que determina alguns critérios para a composição das premissas. Embora uma análise detida de seus problemas, bem como de seus exemplos ${ }^{184}$, não tenha sido feita por nós, podemos ao menos mencionar que, se nossa hipótese de leitura estiver correta, poderíamos compreender um desenvolvimento coeso dos problemas que se originaram em $C A G$.

A importância do capítulo I.25, se justifica, sobretudo, pelo seguinte: apesar do contexto 184 Ao contrário de $C A G$, Aristóteles lança mão em $C A E$ de muitos exemplos próprios da aritmética e da geometria. 
do capítulo estar mais preocupado em dissociar a noção de prova com a noção do mediador, sua conexão com a Cláusula Final, através da cláusula equivalente pros tēn thesin, foi suficiente para confirmarmos esse desenvolvimento que se deu desde $A \operatorname{Pr}$ I.23. Se essa leitura for consistente, temos em APr I.25 um caso de confirmação de que a Cláusula Final, através de diversas facetas, serve como fio condutor entre $C A G$ e $C A E$.

Algumas consequências de nossa investigação: Os resultados obtidos em $A P r \quad$ I.25 são interessantes não apenas de um ponto de vista da coesão textual entre $C A G$ e $C A E$, mas por causa de sua influência sobre a própria interpretação da definição da Cláusula Final. Apesar de todos os critérios que estavam presentes em $A \operatorname{Pr}$ I.1, 24b20-2, sua interpretação tendia a ser mais fraca de modo que parecia que se poderia conceder o título de silogismo a raciocínios que não cumpriam a Cláusula Final.

De acordo com a nossa leitura de $A \operatorname{Pr}$ I.25, a interpretação da definição da Cláusula Final teria de ser reforçada para não possibilitar a leitura dada acima. Sendo assim, a definição da Cláusula Final, como mencionamos previamente, deveria adotar a condição de que nenhum elemento exterior pode ser adicionado para o necessário ser engendrado. Isso é justificável, pois já está pressuposto que uma prova silogística é formada a partir de um termo mediador, o qual, em virtude da Cláusula Final, é adequado para tal prova e que qualquer adição ao par de premissas seria supérfluo.

Além da reinterpretação provocada por essa leitura de $A \operatorname{Pr}$ I.25 da Cláusula Final, esse mesmo critério tem um evidente interesse lógico. Apesar das diferenças entre o sistema silogístico e dos sistemas clássicos da lógica proposicional, podemos fazer uma breve comparação entre cada um desses sistemas no que diz respeito à próxima discussão. Dizer que 
um argumento com premissas supérfluas não se afigura mais como silogismo, em função dessa situação falhar em cumprir uma parte da $D G S$, significa que a inferência do par de premissas para a conclusão não é mais silogística, muito embora obtenha a conclusão desejada. Se for formalizado, esse caso se pareceria muito com a negação de uma regra sub-estrutural da lógica clássica, conhecida como enfraquecimento. Se tivermos um conjunto de premissas $\Delta$, o qual obtém silogisticamente um enunciado $\alpha$, então $\Delta$ e $\varphi$ podem concluir $\alpha$, mas não o fariam de modo silogístico, pois descumpre uma condição da DGS. Em outros termos, no contexto puramente silogístico, a $D G S$ nega uma regra sub-estrutural da lógica clássica e o faz como um critério de relevância lógica.

A negação da regra do enfraquecimento deve ser vista em dois casos de análise: (1) a adição de uma premissa que não apresenta qualquer relação com o conjunto determinado; (2) a adição de uma premissa que se relaciona com o conjunto dado. No caso (1), a exigência de se estabelecer um conjunto de premissas adequado para a conclusão pretendida, excluiria qualquer enunciado que não tivesse qualquer conexão com o conjunto de premissas. Já no caso (2), pressupondo essa relação, adicionar uma premissa que se liga a um elemento do conjunto de premissas não poderia ser analisado como sendo o mesmo argumento, pois se teria três premissas. Sendo assim, há a possibilidade de se formar até três silogismos distintos, rompendo com a monotonicidade do argumento.

Apesar de não se tratar de uma lógica proposicional, a silogística tem uma preocupação com certas noções de relevância que a aproximam significativamente de lógicas relevantistas, negando o que poderia ser denominado de regra de enfraquecimento. 


\section{Consideracões Finais}

Um argumento silogístico é construído a partir de um conjunto de termos, relacionados entre si, os quais obtêm um novo enunciado, distinto de qualquer elemento do conjunto anterior, como consequência lógica, em função daquilo que chamamos de Cláusula Final. Mas o que é a Cláusula Final? Essa foi a principal questão que nos preocupou ao longo deste trabalho. Entendemos que a Cláusula Final desempenha um papel não apenas como critério de relevância para os argumentos silogísticos, mas também como elemento relevante na Definição Geral do Silogismo e, em última análise, o critério que nos possibilitou apresentar uma unidade para o primeiro livro dos Primeiros Analíticos.

Vimos que a própria $D G S$ não é suficiente para garantir a determinação exata daquilo que é a Cláusula Final. Não é apenas o fato de sua definição, em $\operatorname{APr}$ I.1, 24b20-2, ser demasiadamente vaga, mas também em função de muitas das noções atribuídas à Cláusula Final estarem, de fato, presentes nas Condições Inferenciais. Visto que a $D G S$ não é suficiente para determinar o escopo da Cláusula Final, consideramos ter sido necessário buscar novas evidências em outros trechos. A mais importante evidência que encontramos foi em $\operatorname{APr}$ I.4, 26a2-9, onde 
Aristóteles utilizou a Cláusula Final. Esse particular contexto, no entanto, tradicionalmente ofuscava a própria ocorrência dela, devido aos problemas e a discussão que girava em torno do uso de termos concretos.

Em nossa análise sobre os capítulos $A P r$ I.4 e I.7, percebemos que a Cláusula Final era utilizada em um argumento complexo que pretendia determinar uma razão pela qual certas sequências de termos e functores não poderiam formar silogismos. Esse argumento é, se nossa análise estiver correta, constituído de dois silogismos do modo Camestres, sendo que o primeiro procurava demonstrar, através da Cláusula Final, que argumentos com conclusões inconsistentes entre si falham em obter aquilo que é necessário. Por sua vez, através da noção exposta pela expressão modal de necessidade, se provava que esse tipo de condição não poderia formar argumentos silogísticos.

Um dos pontos interessantes desse argumento é que, uma vez constituído, ele possibilitava formular um outro argumento em Barbara, de acordo com o qual se provava que todo silogismo deve estar de acordo com Cláusula Final, através da noção de necessidade que fora empregada anteriormente. A reconstituição desse argumento possibilitou fazer a seguinte consideração a respeito da própria Cláusula Final e da silogística, em geral: assumindo-se a definição da Cláusula Final em $D G S$, conseguimos, a partir desse argumento, assumir que essa é co-extensional com a expressão modal de necessidade (to anancaion). Como todo silogismo expressa algo por necessidade, então todo silogismo é dotado de uma Cláusula Final. Mas haveria uma co-extensão entre as Condições Inferenciais e a Cláusula Final?

Deixamos em aberto essa questão a respeito da correlação da silogística e da Cláusula Final. É bem verdade que a Cláusula Final não é encontrada em contextos não-silogísticos, mas isso não constitui evidências suficientemente fortes para decidir essa questão. Embora não 
tenhamos encontrado evidências suficientes para decidir essa questão, podemos comparar essa questão a uma outra questão correlata e expor algumas condições. Trata-se de uma comparação entre as duas ocorrências da expressão modal de necessidade na DGS. Grosso modo, se a Cláusula Final for co-extensiva com a silogística, então as duas ocorrências têm o mesmo referente, a saber, a consequência silogística. Entretanto, se as Condições Inferenciais não for coextensiva com aquilo que a Cláusula Final descreve, então é possível que cada ocorrência da expressão modal de necessidade tenha um sentido e um referente distinto.

Apesar de não termos decidido a extensão entre a silogística e a Cláusula Final, chegamos ao resultado, a partir da análise de $\operatorname{APr}$ I.4 e I.7, que a Cláusula Final não age apenas como exigência de relevância dos argumentos lógicos, mas ela age como exigência que distingue argumentos silogísticos de argumentos não-silogísticos. Consideramos que essa distinção entre argumentos que são iguais e podem configurar argumentos válidos, mas não silogísticos, é suficiente para fixarmos uma determinada ordem aos termos extremos, na conclusão que se pretende silogística. Isso mostra, como critério para ser um silogismo, que não basta um conjunto de premissas inferir uma conclusão válida. A conclusão deve ter seus termos dispostos de modo previamente fixado. A sequência dos termos extremos, na conclusão de um silogismo, sugere que o próprio conjunto de premissas seja ordenado de modo a sugerir a sequência que se deveria obter na conclusão.

Uma tal hipótese de leitura se volta contra interpretações extensionais da silogística e determina que o cálculo silogístico seja feito mediante uma ordenação específica. Há algumas possibilidades de se introduzir uma ordenação na silogística, uma das quais estabelece uma semântica embasada sobre considerações algébricas, a segunda faz uso de uma semântica do dictum de omni et de nullo. As propostas dos dicta são mais recentes e foram adotadas por 
conveniência.

Considerando a exigência de uma ordenação dos próprios argumentos silogísticos, imposta, de certo modo, pela Cláusula Final, nos foi possível avaliar como a semântica dos dicta poderia nos auxiliar em uma possível explicação a respeito do fato de Aristóteles ter adotado modos silogísticos distintos, os quais, de um ponto de vista da mera extensão, são supérfluos e elimináveis. Referimos-nos a modos como Cesare e Camestres ou Datisi e Disamis. O estranhamento começa em função de se tratar dos mesmos argumentos com a única diferença que as predicações são invertidas. Sendo assim, seria muito simples construir um exemplo tal que o mesmo argumento fosse apresentado de modo a obter uma conclusão, a qual é extensionalmente equivalente, mas viola a ordenação entre os termos e premissas. $\mathrm{O}$ exemplo que utilizamos foi um Cesare com os termos da conclusão invertidos. A partir disso conseguimos determinar que, muito embora as conclusões fossem extensionalmente equivalentes, a sequência dos termos fora violada e não poderia ser considerado como silogístico, a não ser que houvesse um outro modo silogístico que desse fundação a essa conclusão.

Em decorrência disso, algumas consequências significativas com as análises lógicas tradicionais surgiram. Não só seria a Cláusula Final responsável pela restrição sobre argumentos lógicos, como ela seria responsável pela distinção dos modos silogísticos. A Cláusula Final seria, em função disso, mais restritiva que as considerações de mera relevância levantadas antes por algumas interpretações. Como vimos, ela serve como critério que restringe os argumentos silogísticos aos modos reconhecidos por Aristóteles ${ }^{185}$. Essa restrição é muito curiosa, pois ela torna uma tradicional estratégia de interpretar a noção de consequência lógica inócua. Trata-se,

185 Ao longo de todo texto tentamos não nos envolver na polêmica questão da suposta quarta figura silogística. Sendo assim, a nossa interpretação estaria aberta para reconhecer a Cláusula Final como restringindo alguns argumentos para essa quarta figura. 
como apontamos acima, do projeto reducionista, o qual tentava dar uma compreensão à expressão modal de necessidade, atrelada à noção de consequência, por meio de modelos que fossem logicamente mais simples.

A influência da Cláusula Final não se restringe ao papel de determinação de como um argumento silogístico deve ser construído, mas serve como exigência que distingue os modos silogísticos, quando são extensionalmente equivalentes entre si. Embora nos Capítulos de Apresentação Geral $(C A G)$ só se menciona o fato, mas não sua justificativa, pôde-se levantar a pergunta de como isso seria feito. A sequência entre os termos extremos teria que ser justificada por algo que se encontra no próprio conjunto de premissas. Como vimos, a única explicação efetivamente disponível poderia ser encontrada a partir de uma análise dos Capítulos de Apresentação Específica $(C A E)$, os quais eram introduzidos com uma suposta discussão acerca da completude da silogística.

O debate que se gerou em torno desse contexto de completude silogística resultou em uma total cisão entre $C A G$ e $C A E$, os quais chegaram a ser representados como duas abordagens totalmente distintas e desconectadas entre si. Esse resultado, apresentado por Striker, é consequência de uma progressiva discussão que se iniciou com Lear, a qual critica a aplicação de ferramentas lógicas sofisticadas e de desenvolvimento muito recente para terem sido aplicadas logo no desenvolvimento e no princípio da lógica. O foco dessa crítica se deve ao contexto da completude, pois esse meta-teorema só pode ser avançado em sistemas lógicos que são divididos em uma sintaxe e uma semântica.

Como a introdução de considerações semânticas depende de um estudo que é conhecido como teoria de modelos, isto é, considerações lógicas cujo desenvolvimento se deu muito tardiamente, seria impróprio atribuir todo o arcabouço dessas interpretações à silogística. 
Entretanto, a outra opção que se apresentava para a interpretação das afirmações de Aristóteles em $A P r$ I.23 tampouco é satisfatória, pois dependiam de noções que são próprias da computabilidade e são igualmente sofisticadas, de um ponto de vista lógico.

A crítica que Striker desenvolveu a essa interpretação tinha como pano de fundo a noção (i) de que a lógica não era objeto de escrutínio propriamente filosófico, mas era uma ferramenta para as investigações das ciências, além de (ii) que a silogística não poderia ser logicamente tão complexa a ponto de Aristóteles ser comparado a um lógico moderno. Com base nesses dois fatos, Striker desenvolve uma interpretação da silogística como uma noção de argumento que se distingue da noção de inferência lógica e analisa $C A E$ de modo a espelharem a discussão avançada previamente nos Tópicos.

Em nossa análise de $A \operatorname{Pr}$ I.23, no entanto, embora concordássemos com Striker, no que diz respeito à sua visão sobre Aristóteles e sua representação como lógico, no sentido atual, tentamos destacar um ponto que achamos ter sido relevante à interpretação da silogística. Afirmamos que o procedimento que Aristóteles avança no início de $A P r$ I.23 descreve e justifica todas as restrições feitas pela $D G S$. Esse tratamento negativo possibilitou-nos a entender a contraparte positiva como se tratando das condições que seriam exigidas pela própria Cláusula Final.

Essa aproximação de $A P r$ I.23 com a $D G S$ nos possibilitou introduzir um critério que justificasse a relação da Cláusula Final com a expressão modal de necessidade: o termo mediador. O termo mediador, embora não seja sintaticamente distinto dos demais termos apresentados em um argumento lógico, desempenha um papel muito importante, no sentido que ele, junto com certos functores, são responsáveis para darem uma justificativa apropriada da conclusão. Com nossa leitura desse capítulo, nos foi possível identificar a exigência do termo 
mediador como análogo à exigência desempenhada pela Cláusula Final, sugerindo que esse funcione como fio condutor a ligar $C A G$ e $C A E$.

O capítulo $A P r$ I.23, no entanto, não é suficiente para confirmar essa hipótese, como analisamos, sendo preciso uma evidência mais próxima para isso. Cremos ter encontrado essa evidência em $A P r$ I.25, onde Aristóteles faz um comentário utilizando-se de uma cláusula típica do contexto dos Tópicos, mas que naquela obra é utilizada apenas com a Cláusula Final da DGS. Trata-se da restrição que Aristóteles defende em $\operatorname{APr}$ I.25, que os silogismos não podem ser expostos por mais de duas premissas e três termos, se for para obter apenas uma conclusão. Qualquer adição seria reconhecida como supérflua para o cálculo silogístico, fato que é recusado em Top VIII.11 como violação da Cláusula Final, mas é descrito em $A P r$ I.25 como violação à cláusula pros tèn thesin, isto é, relacionada com a conclusão.

Reconhecemos isso como evidência clara da similaridade entre a Cláusula Final e a cláusula pros tèn thesin em $A P r$ I.23, confirmando, assim, que nesse capítulo e, por conseguinte, os capítulos seguintes que representam um desenvolvimento das noções apresentadas, a Cláusula Final funciona como fio condutor, tratando $C A G$ e $C A E$ como duas partes de um tratado coeso ${ }^{186}$. Com isso, conseguimos satisfazer a nossa segunda meta.

Problemas pendentes: $\quad$ Embora tivéssemos sucesso em identificar uma série de exigências que são próprias da Cláusula Final e destacá-la como elemento de relevância para a $D G S$, não nos foi possível dar uma definição satisfatória à Cláusula Final e, por conseguinte, esclarecer a própria $D G S$. Um dos problemas relevantes com os quais nos reparamos é uma justificativa

186 Deve-se lembrar que isso não vale para a parte da silogística modal, cuja introdução foi posterior, como indicam as evidências textuais entre $A \operatorname{Pr}$ I.7 e I.23. 
apropriada para determinar a sequência de termos tanto na conclusão como no próprio par de premissas. Sabemos que Aristóteles não considerava procedimentos puramente extensionais ${ }^{187}$, mas não encontramos, para este trabalho, evidências suficientes que garantissem uma interpretação particular que justificasse as noções lógicas que estão presentes em $A P r$ I. As interpretações mais próximas são aquelas que pressupõe uma pré-ordem das relações predicativas, sendo essa formada apenas por propriedades relacionais como reflexividade e transitividade.

A nossa interpretação não possibilita uma definição da Cláusula Final, pois não entramos em detalhes de como o próprio termo mediador é interpretado ao longo de $A P r$ I. Uma análise detalhada da noção de mediação, satisfeita por esse termo envolveria não só uma análise detida dos capítulos de CAE apresentados neste trabalho, mas seria satisfeita apenas quando se apresentasse junto a esses capítulos uma análise de $A \operatorname{Pr}$ I.24, onde Aristóteles discute certas qualidades dos functores que são imprescindíveis à própria silogística, e capítulos $A \operatorname{Pr}$ I.27 a I.29, onde Aristóteles introduz uma longa análise de como avaliar e estabelecer termos mediadores ou sequências inteiras de termos mediadores para todas as figuras. Uma análise detida desses capítulos, embora coubesse no escopo deste trabalho, seria demasiadamente grande para chegar aos resultados que pretendíamos.

Assim sendo, deixamos indicados, para pesquisas futuras, que uma definição apropriada da Cláusula Final e, consequentemente, da DGS dependem de uma análise da noção de mediação, a qual é satisfeita pelo termo mediador junto com os functores relacionados.

187 Um indício disso poderia ser a própria prova que Aristóteles propõe da conversão do functor privativo universal, a qual não é feita com base de considerações extensionais. Cf. APr I.2; Striker [2009]; Smith [1989]; Ebert \& Nortmann [2007]. 
163 


\section{Apêndice}

\section{A Silogística e a semântica dos dicta}

A semântica das relações predicativas, conhecidas como dictum de omni et de nullo requer uma distinção clara. De acordo com Barnes [2007], há duas linhas gerais de interpretação dessa semântica que se apresentam como possibilidade para interpretar as premissas do silogismo, bem como apresentar as próprias provas silogísticas. Essas duas linhas gerais se dividem em uma interpretação extensional (clássica) e uma interpretação não-extensional (não-ortodoxa). Como mencionamos, brevemente, em nossa análise da silogística, as interpretações clássicas se focam sobre uma quantificação de indivíduos e dependem, fundamentalmente, de uma certa hierarquia dos tipo de objeto. Um indivíduo é, de acordo com essa teoria dos tipos, visto como elemento mais fundamental de toda hierarquia, do qual todos os demais termos podem se predicar. De acordo com a hierarquia da teoria dos tipos, todos os demais termos, que não são da classe dos indivíduos, são de uma classe sintática distinta, podendo formar as primeiras fórmulas atômicas ou funções predicativas, em geral.

Por sua vez, a interpretação não-ortodoxa da semântica dos dicta não pressupõe uma teoria de tipos, pois ela, praticamente, não faz uma distinção sintática entre classes de termos. Aristóteles pode reconhecer que há termos, os quais não se predicam de mais nenhum outro termo e são fundamentais, e seu inverso, também. No entanto, esses termos, todos, ainda fariam, de acordo com essa interpretação, parte de uma mesma classe sintática dos termos. A maior diferença entre essas interpretações é que, enquanto a interpretação clássica se pauta em um cálculo extensional de suas relações, a interpretação não-ortodoxa estabelece sua quantificação 
sobre termos de mesma classe sintática, o que repercute sobre a relação entre os próprios termos. No caso de estudos aristotélicos, essa relação pode ser, por motivos de conveniência, representado como uma a-predicação.

Ao longo desta dissertação adotamos, sobretudo, a interpretação heterodoxa da semântica dos dicta. A razão para isso está nas severas restrições que o sistema silogístico impõe a considerações extensionais. Constam entre essas restrições a recusa daquilo que na lógica proposicional clássica poderia ser reconhecido como regra sub-estrutural de enfraquecimento, a adoção de dois modos silogísticos distintos para argumentos que são extensionalmente idênticos e a recusa da conclusão re-instanciar uma das premissas. A seguir, reuniremos provas de todos os modos silogísticos reconhecidos, de acordo com esse sistema semântico. Em seguida, tentaremos apresentar razões segundo as quais os modos Datisi e Disamis não podem ser considerados o mesmo silogismo.

Como mencionamos acima, a principal diferença entre as duas vertentes interpretativas da semântica dos dicta está na adoção ou rejeição de noções puramente extensionais. No próprio estabelecimento da semântica, essa diferença entre as interpretações ortodoxa e não-ortodoxa se dá no tipo de consideração que se faz entre os termos. Na interpretação ortodoxa há apenas uma noção de pertinência equivalente à operação da teoria de conjuntos sinalizada por ' $\in$ '. Por sua vez, a interpretação não-ortodoxa se funda em uma relação que determina uma ordenação consistindo, a princípio, apenas de reflexividade e transitividade. Há um problema de se identificar qual a relação específica que garante a ordenação desejada. No entanto, como em 24b30-2 Aristóteles descreve essa relação a partir da própria noção de predicação, adota-se, por conveniência, a descrição a partir da relação da a-predicação. As diferenças ficam claras com a seguinte 
representação:

\section{Interpretação clássica}

$$
\begin{aligned}
& \cdot x(x \cdot \mathrm{A} \rightarrow x \cdot \mathrm{B}) \\
& \cdot x(x \cdot \mathrm{A} \rightarrow x \cdot \mathrm{B}) \\
& \cdot x(x \cdot \mathrm{A} \wedge x \cdot \mathrm{B}) \\
& \cdot x(x \cdot \mathrm{A} \wedge x \cdot \mathrm{B})
\end{aligned}
$$

\section{Interpretação não-ortodoxa}

$\cdot \mathrm{X}(\mathrm{X} a \mathrm{~A} \cdot \mathrm{X} a \mathrm{~B})$

- $\mathrm{X}(\mathrm{X} a \mathrm{~A} \cdot \neg(\mathrm{X} a \mathrm{~B}))$

- $\mathrm{X}(\mathrm{X} a \mathrm{~A} \wedge \mathrm{X} a \mathrm{~B})$

- $\mathrm{X}(\mathrm{X} a \mathrm{~A} \wedge \neg(\mathrm{X} a \mathrm{~B}))$

Tal como foi apresentado no primeiro capítulo desta dissertação, a semântica dos dicta se funda sobre uma linguagem e suas regras de inferência. A partir disso, poderemos formular as seguintes provas para a silogística:

\section{A primeira figura silogística:}

Teorema 01 (Barbara): $\quad\langle\mathrm{B} a \mathrm{~A}, \mathrm{C} a \mathrm{~B}\rangle \|_{\Sigma} \mathrm{C} a \mathrm{~A}$.

Prova: $\quad$ 1. $\cdot \mathrm{X}(\mathrm{X} a \mathrm{~B} \cdot \mathrm{X} a \mathrm{~A}) \quad$, tese do dictum de omni, premissa 1;

2. $\lambda \mathrm{C}(\mathrm{C} a \mathrm{~B}) \quad$, premissa 2 ;

3. $\lambda \mathrm{C}(\mathrm{C} a \mathrm{~B} \cdot \mathrm{C} a \mathrm{~A}) \quad$, instanciação de 2 sobre 1;
4. $\mathrm{C} a \mathrm{~A}$
, MP, 3, 2.

Teorema 02 (Celarent): $\quad\langle\mathrm{B} e \mathrm{~A}, \mathrm{C} a \mathrm{~B}\rangle \|_{\Sigma} \mathrm{C} e \mathrm{~A}$.

Prova: $\quad$ 1. $\quad \mathrm{X}(\mathrm{X} a \mathrm{~B} \cdot \neg(\mathrm{X} a \mathrm{~A})) \quad$, tese do dictum de nullo, premissa 1;

2. $\lambda \mathrm{C}(\mathrm{CaB}) \quad$, premissa 2 ;

3. $\lambda \mathrm{C}(\mathrm{C} a \mathrm{~B} \cdot \neg(\mathrm{C} a \mathrm{~A}))$, instanciação de 2 sobre 1;

4. $\mathrm{CeA} \quad, \mathrm{MP}, 3,2$. 
Teorema 03 (Darii): $\quad\langle\mathrm{B} a \mathrm{~A}, \mathrm{C} i \mathrm{~B}\rangle \|_{\Sigma} \mathrm{C} i \mathrm{~A}$.

Prova: $\quad$ 1. $\cdot \mathrm{X}(\mathrm{X} a \mathrm{~B} \cdot \mathrm{X} a \mathrm{~A}) \quad$, tese do dictum de omni, premissa 1;

2. $\mu \mathrm{C}(\mathrm{CaB}) \quad$, premissa 2 ;

3. $\mu \mathrm{C}(\mathrm{C} a \mathrm{~B} \cdot \mathrm{X} a \mathrm{~A}) \quad$, instanciação de 2 sobre 1 ;

4. $\mu \mathrm{C}(\mathrm{CaA}) \stackrel{\text { def }}{=} \mathrm{CiA} \quad, \mathrm{MP}, 3,2$.

Teorema 04 (Ferio): $\quad\langle\mathrm{B} e \mathrm{~A}, \mathrm{C} i \mathrm{~B}\rangle \|_{2} \mathrm{CoA}$.

Prova: $\quad$ 1. $\cdot \mathrm{X}(\mathrm{X} a \mathrm{~B} \cdot \neg(\mathrm{X} a \mathrm{~A}))$, tese do dictum de nullo, premissa 1;

2. $\mu \mathrm{C}(\mathrm{CaB}) \quad$, premissa 2 ;

3. $\mu \mathrm{C}(\mathrm{CaB} \cdot \neg(\mathrm{C} a \mathrm{~A}))$, instanciação de 2 sobre 1 ;

4. $\mu \mathrm{C} \neg(\mathrm{CaA}) \stackrel{\text { dof }}{=} \mathrm{CiA} \quad, \mathrm{MP}, 3,2$.

\section{A segunda figura silogística:}

Teorema 05 (Cesare): $\quad\langle\mathrm{A} e \mathrm{~B}, \mathrm{C} a \mathrm{~B}\rangle \|_{\Sigma} \mathrm{C} e \mathrm{~A}$.

Prova: $\quad$ 1. $\quad \mathrm{X}(\mathrm{X} a \mathrm{~A} \cdot \neg(\mathrm{X} a \mathrm{~B}))$, tese do dictum de nullo, premissa 1;

2. $\lambda \mathrm{C}(\mathrm{CaB}) \quad$, premissa 2 ;

3. $\cdot \mathrm{X}(\mathrm{X} a \mathrm{~B} \cdot \neg(\mathrm{X} a \mathrm{~A}))$, contra-positiva de 1;

4. $\lambda \mathrm{C}(\mathrm{C} a \mathrm{~B} \cdot \neg(\mathrm{C} a \mathrm{~A})) \quad$, instanciação de 2;

5. $\lambda \mathrm{C} \neg(\mathrm{C} a \mathrm{~A}) \stackrel{\text { def }}{=} \mathrm{Ce} \mathrm{A}, \mathrm{MP}, 2,4$.

Teorema 06 (Camestres): $\quad\langle\mathrm{A} a \mathrm{~B}, \mathrm{C} e \mathrm{~B}\rangle \|_{\Sigma} \mathrm{C} e \mathrm{~A}$.

Prova: $\quad$ 1. $\quad \mathrm{X}(\mathrm{X} a \mathrm{~A} \cdot \mathrm{X} a \mathrm{~B}) \quad$, tese do dictum de omni, premissa 1;

$$
\text { 2. } \lambda \mathrm{C} \neg(\mathrm{C} a \mathrm{~B}) \quad \text {, premissa } 2 \text {; }
$$


3. $\mathrm{X}(\mathrm{X} a \mathrm{~A} \cdot \mathrm{X} a \mathrm{~B}) \quad$, contrapositiva de 1 ;

4. $\lambda \mathrm{C}(\neg(\mathrm{C} a \mathrm{~B}) \Rightarrow \neg(\mathrm{C} a \mathrm{~A}))$, instanciação de 2;

5. $\lambda \mathrm{C} \neg(\mathrm{C} a \mathrm{~A}) \stackrel{\text { def }}{=} \mathrm{Ce} \mathrm{A}, \mathrm{MP}, 2,3$.

Teorema 07 (Festino): $\quad\langle\mathrm{A} e \mathrm{~B}, \mathrm{C} i \mathrm{~B}\rangle \|_{\Sigma} \mathrm{CoA}$.

Prova: $\quad$ 1. $\cdot \mathrm{X}(\mathrm{X} a \mathrm{~A} \cdot \neg(\mathrm{X} a \mathrm{~B})) \quad$, tese do dictum de nullo, premissa 1;

2. $\mu \mathrm{C}(\mathrm{C} a \mathrm{~B}) \quad$, premissa 2 ;

3. $\cdot \mathrm{X}(\mathrm{X} a \mathrm{~B} \cdot \neg(\mathrm{X} a \mathrm{~A}))$, contra-positiva de 1 ;

4. $\mu \mathrm{C}(\mathrm{CaB} \cdot \neg(\mathrm{C} a \mathrm{~A})) \quad$, instanciação de 2 sobre 3 ;

5. $\mu \mathrm{C} \neg(\mathrm{C} a \mathrm{~A}) \stackrel{\text { def }}{=} \mathrm{CoA}, \mathrm{MP}, 2,4$.

Teorema 08 (Baroco): $\quad\langle\mathrm{A} a \mathrm{~B}, \mathrm{CoB}\rangle \|_{\Sigma} \mathrm{Co}$.

Prova: $\quad$ 1. $\cdot \mathrm{X}(\mathrm{X} a \mathrm{~A} \cdot \mathrm{X} a \mathrm{~B}) \quad$, tese do dictum de omni, premissa 1;

2. $\mu \mathrm{C} \neg(\mathrm{CaB}) \quad$, premissa 2 ;

3. $\cdot \mathrm{X}(\neg \mathrm{X} a \mathrm{~B} \cdot \neg \mathrm{X} a \mathrm{~A}) \quad$, contra-positiva de 1;

4. $\mu \mathrm{C}(\neg(\mathrm{C} a \mathrm{~B}) \Rightarrow \neg(\mathrm{C} a \mathrm{~A}))$, instanciação de 2 sobre 3 ;

5. $\mu \mathrm{C} \neg(\mathrm{C} a \mathrm{~A}) \stackrel{\text { def }}{=} \mathrm{Co} \mathrm{A}, \mathrm{MP}, 2,4$.

\section{A terceira figura silogística:}

Teorema 09 (Darapti): $\quad\langle\mathrm{B} a \mathrm{~A}, \mathrm{~B} a \mathrm{C}\rangle \|_{\Sigma} \mathrm{C} i \mathrm{~A}$.

Prova extensional: $1 . \cdot x(x a \mathrm{~B} \cdot x a \mathrm{~A}) \quad$, tese do dictum de omni, premissa 1 ;

2. $\lambda \mathrm{C}(\mathrm{B} a \mathrm{C}) \quad$, premissa 2 


\begin{tabular}{|c|c|}
\hline 3. $x a \mathrm{~B}$ & , suposição; \\
\hline 4. $x a \mathrm{C}$ & , teorema $01,3,2$; \\
\hline 5. $x a \mathrm{~B} \cdot(x a \mathrm{C} \wedge x a \mathrm{~A})$ & $, 1,4,3$ \\
\hline
\end{tabular}

Prova alternativa: $\quad 1 . \cdot \mathrm{X}(\mathrm{X} a \mathrm{~B} \cdot \mathrm{X} a \mathrm{~A}) \quad$, tese do dictum de omni, premissa 1 ;

2. $\lambda \mathrm{C}(\mathrm{B} a \mathrm{C}) \quad$, tese do dictum de omni, premissa 2 ;

3. $\cdot \mathrm{X}(\mathrm{X} a \mathrm{~B}) \quad$, hipótese, 1 ;

4. - $\mathrm{X}(\mathrm{X} a \mathrm{~A}) \quad, \mathrm{LC}($ modus ponens $), 1$;

5. $\cdot \mathrm{X}(\mathrm{X} a \mathrm{C}) \quad$ Barbara, 3,2

6. $(\mathrm{X} a \mathrm{C} \wedge \mathrm{X} a \mathrm{~A}) \quad$, LC (introdução de conjunção), 5, 4;

7. $\mu \mathrm{C}(\mathrm{C} a \mathrm{~A}) \stackrel{\text { def }}{=} \mathrm{CiA} \quad, \mu$-restriction de $\mathrm{C}, 6$.

Teorema 10 (Felapton): $\quad\langle\mathrm{B} e \mathrm{~A}, \mathrm{~B} a \mathrm{C}\rangle \|_{\Sigma} \mathrm{CoA}$

Prova extensional: $1 . \cdot x(x a B \cdot \neg(x a A)) \quad$, tese do dictum de nullo, premissa 1;

2. $\lambda \mathrm{C}(\mathrm{B} a \mathrm{C}) \quad$, premissa 2 ;

3. $x a \mathrm{~B}$

4. $x a \mathrm{C}$, teorema $01,3,2$;

5. $x a B \rightarrow(x a \mathrm{C} \& \neg(x a \mathrm{~A})) \quad, 1,4,3 ;$

6. $\cdot x(x a C \& \neg(x a A)) \quad \stackrel{\text { def }}{=} \mathrm{CoA}, \mathrm{MP}, 5,3$.

Prova alternativa: $\quad 1 . \cdot \mathrm{X}(\mathrm{X} a \mathrm{~B} \cdot \neg(\mathrm{X} a \mathrm{~A})) \quad$, tese do dictum de nullo, premissa 1;

2. $\lambda \mathrm{C}(\mathrm{B} a \mathrm{C}) \quad$, tese do dictum de omni, premissa 2 ;

3. - $\mathrm{X}(\mathrm{X} a \mathrm{~B}) \quad$, hipótese, 1 ; 
4. $\cdot \mathrm{X} \neg(\mathrm{X} a \mathrm{~A}) \quad$, LC (modus ponens $), 3,1$;

5. $\lambda \mathrm{C}(\mathrm{X} a \mathrm{C}) \quad$, Barbara, 3, 2;

6. $(\mathrm{X} a \mathrm{C} \wedge \neg(\mathrm{X} a \mathrm{~A})) \quad$, LC (introdução de conjunção), 5, 4;

7. $\mu \mathrm{C} \neg(\mathrm{C} a \mathrm{~A}) \stackrel{\text { dea }}{=} \mathrm{Co} \mathrm{A}, \mu$-restrição de $\mathrm{C}, 6$.

Teorema 11 (Datisi): $\quad\langle\mathrm{B} a \mathrm{~A}, \mathrm{~B} i \mathrm{C}\rangle \|_{2} \mathrm{C} i \mathrm{~A}$.

Prova extensional: $\quad 1 . \cdot x(x a \mathrm{~B} \cdot x a \mathrm{~A}) \quad$, tese do dictum de omni, premissa 1 ;

2. $\mu \mathrm{C}(\mathrm{B} a \mathrm{C}) \quad$, premissa 2 ;

3. $x a \mathrm{~B} \quad$, suposição;

4. $\cdot x(x a \mathrm{C}) \quad$, teorema $03,3,2$;

5. $x a \mathrm{~B} \cdot \cdot x(x a \mathrm{C} \wedge x a \mathrm{~A}) \quad, 1,4,3$

6. $\cdot x(x a \mathrm{C} \wedge x a \mathrm{~A}) \stackrel{\text { def }}{=} \mathrm{Ci \textrm {A }}$, tese do dictum de aliquo.

Prova alternativa: $\quad 1 . \cdot \mathrm{X}(\mathrm{X} a \mathrm{~B} \cdot \mathrm{X} a \mathrm{~A}) \quad$, tese do dictum de omni, premissa 1 ;

2. $\mu \mathrm{C}(\mathrm{B} a \mathrm{C}) \quad$, tese do dictum de aliquo, premissa 2;

3. $\cdot \mathrm{X}(\mathrm{X} a \mathrm{~B}) \quad$, hipótese, 1 ;

4. - $\mathrm{X}(\mathrm{X} a \mathrm{~A}) \quad, \mathrm{LC}$ (modus ponens), 1, 3;

5. - $\mathrm{X} . \mu \mathrm{C}(\mathrm{X} a \mathrm{C}) \quad$, Barbara, 3, 2;

6. - X. $\mathrm{XC}(\mathrm{X} a \mathrm{C} \wedge \mathrm{X} a \mathrm{~A}) \quad, \mathrm{LC}$ (introdução de conjunção), 5, 4;

7. $\mu \mathrm{C}(\mathrm{C} a \mathrm{~A}) \stackrel{\text { def }}{=} \mathrm{CiA} \quad, \mu$-restrição de $\mathrm{C}, 6$.

Teorema 12 (Disamis): $\quad\langle\mathrm{B} i \mathrm{~A}, \mathrm{~B} a \mathrm{C}\rangle \|_{\Sigma} \mathrm{C} i \mathrm{~A}$. 
Prova extensional: $1 . \cdot x(x a \mathrm{~B} \wedge x a \mathrm{~A})$

2. $\quad x(x a \mathrm{~B} \rightarrow x a \mathrm{C})$

3. $x a \mathrm{~B}$

4. $x a \mathrm{C}$

5. $x a \mathrm{~A}$

6. $x a \mathrm{~B} \rightarrow(x a \mathrm{C} \wedge x a \mathrm{~A})$

7. $\cdot x(x a \mathrm{C} \wedge x a \mathrm{~A}) \stackrel{\text { def }}{=} \mathrm{CiA}$

Prova alternativa: $1 . \cdot \mathrm{X}(\mathrm{X} a \mathrm{~B} \wedge \mathrm{X} a \mathrm{~A})$

2. $\lambda \mathrm{C}(\mathrm{B} a \mathrm{C})$

3. $\cdot \mathrm{X}(\mathrm{X} a \mathrm{~B})$

4. $\cdot \mathrm{X}(\mathrm{X} a \mathrm{~A})$

5. $\cdot \mathrm{X}(\mathrm{X} a \mathrm{C})$
, tese do dictum de aliquo, premissa 1;

, premissa 2;

, hipótese;

, LC (modus ponens), 3, 2;

, LC (eliminação de conjunção), 3, 1;

, 1, 4, 3;

, tese do dictum de aliquo.

, tese do dictum de aliquo, premissa 1;

, tese do dictum de omni, premissa 2;

, conversão do dictum de omni, 2;

, LC (exclusão da conjunção), 3;

, LC (exclusão da conjunção), 3;

6. $\cdot \mathrm{X}(\mathrm{X} a \mathrm{C} \wedge \mathrm{XaA}) \stackrel{\text { dea }}{=} \mathrm{CiA}, \mathrm{MP}, 1,5$.

Teorema 13 (Ferison): $\quad\langle\mathrm{B} e \mathrm{~A}, \mathrm{~B} i \mathrm{C}\rangle \|_{\Sigma} \mathrm{Co} \mathrm{A}$.

Prova extensional: $1 . \cdot x(x a \mathrm{~B} \cdot \neg(x a \mathrm{~A})) \quad$, tese do dictum de nullo, premissa 1 ;
2. $\cdot x(x a \mathrm{~B} \wedge x a \mathrm{C})$
, premissa 2;
3. $x(x a \mathrm{~B})$
, hipótese;
4. $\cdot x \neg(x a \mathrm{~A})$
, LC (modus ponens), 1, 3;
5. $\cdot x(x a \mathrm{C})$
, LC (eliminação de conjunção), 2, 3;
6. $x a \mathrm{~B} \rightarrow(x a \mathrm{C} \wedge \neg(x a \mathrm{~A})) \quad, 1,4,3$; 
7. $\cdot x(x a \mathrm{C} \wedge \neg(x a \mathrm{~A})) \quad \stackrel{\text { def }}{=} \mathrm{CoA}, \mathrm{MP}, 5,3$.

Prova alternativa: $\quad 1 . \cdot \mathrm{X}(\mathrm{X} a \mathrm{~B} \cdot \neg(\mathrm{X} a \mathrm{~A})) \quad$, tese do dictum de nullo, premissa 1;

2. $\mu \mathrm{C}(\mathrm{B} a \mathrm{C}) \quad$, tese do dictum de aliquo, premissa 2;

3. $(\mathrm{X} a \mathrm{~B}) \quad$, hipótese;

4. ᄀ (XaA) , LC (modus ponens), 3, 1;

5. $\mu \mathrm{C}(\mathrm{XaC}) \quad$, Barbara, 2, 3;

6. $\mu \mathrm{C}(\mathrm{X} a \mathrm{C} \wedge \neg(\mathrm{X} a \mathrm{~A}) \quad, \mathrm{LC}$ (introdução de conjunção), 5, 4;

7. $\mu \mathrm{C} \neg(\mathrm{C} a \mathrm{~A}) \stackrel{\text { dof }}{=} \mathrm{Co} \mathrm{A} \quad$, reinterpretação de 6 .

Teorema 14 (Bocardo): $\quad\langle\mathrm{B} o \mathrm{~A}, \mathrm{~B} a \mathrm{C}\rangle \|_{-2} \mathrm{CoA}$.

Prova extensional: $1 . \cdot x(x a \mathrm{~B} \wedge \neg(x a \mathrm{~A})) \quad$, tese do dictum de aliquo non, premissa 1;

\begin{tabular}{|c|c|}
\hline 2. $\cdot x(x a \mathrm{~B} \rightarrow x a \mathrm{C})$ & , premissa 2; \\
\hline 3. $x a \mathrm{~B}$ & , hipótese; \\
\hline 4. $x a \mathrm{C}$ & , LC (modus ponens), 3, 2; \\
\hline 5. $\neg(x a \mathrm{~A})$ & , LC (eliminação de conjunção), 3,1 ; \\
\hline 5. $x a \mathrm{~B} \rightarrow(x a \mathrm{C} \wedge \neg(x a \mathrm{~A}))$ & , 3, 1, 2, LC (introdução de conjunção); \\
\hline 6. $\cdot x(x a \mathrm{C} \wedge \neg(x a \mathrm{~A}))$ & , MP, 5,3 . \\
\hline
\end{tabular}

Prova alternativa: $\quad 1 . \cdot \mathrm{X}(\mathrm{X} a \mathrm{~B} \wedge \neg(\mathrm{XaA})) \quad$, tese do dictum de aliquo non, premissa 1;

2. $\lambda \mathrm{C}(\mathrm{B} a \mathrm{C}) \quad$, tese do dictum de omni, premissa 2;

3. $(\mathrm{X} a \mathrm{~B}) \quad$, hipótese;

4. ᄀ (XaA) ， LC (eliminação da conjunção), 3, 1;

5. - $\mathrm{X} . \lambda \mathrm{C}(\mathrm{XaC}) \quad$ Darii, 3, 2; 


\section{6. - $\mathrm{X} . \lambda \mathrm{C}(\mathrm{X} a \mathrm{C} \wedge \neg(\mathrm{X} a \mathrm{~A}) \quad, \mathrm{MP}, 5,1$.}

As provas para a terceira figura silogística se distinguem consideravelmente das provas das demais figuras. Enquanto nas primeiras duas figuras a segunda premissa satisfazia um dos dois lados do dictum estabelecido na primeira premissa, esse tipo de raciocínio não é mais possível na terceira figura. A partir disso, pode-se formular uma prova sem inverter a relação entre os termos da premissa menor, o que constitui a prova extensional. A estratégia de pressupor o antecedente da primeira premissa e formular com esse um silogismo da primeira figura serve para restringir o domínio que deve ser considerado para a relação entre os termos extremos.

Enquanto a prova extensional procura restringir o domínio da predicação, a fim de obter o resultado desejado, a interpretação alternativa se serve das regras já estabelecidas para proceder em sua prova. Ao contrário da prova anterior, onde se procura manter ao máximo o mesmo procedimento das provas apresentadas nas figuras anteriores, a prova alternativa introduz um segunda regra do dictum. Como a relação que se representa como a-predicação na semântica heterodoxa dos dicta é bastante incerta, não se pode aplicar as regras de conversão diretamente sobre essa relação. Ao introduzir uma segunda instância do dictum, porém, abre-se a possibilidade para a conversão da premissa menor, o que possibilita a satisfação do dictum da premissa maior.

Isso apresenta, porém, um problema para a exigência determinada pela Cláusula Final de distinguir modos silogísticos extensionalmente equivalentes na terceira figura. Trata-se de buscar uma distinção entre Datisi e Disamis. Ao longo de nosso terceiro capítulo, apresentamos razões pelas quais a Cláusula Final determina uma determinada sequência entre os termos extremos de um silogismo. No caso de modos silogísticos como Cesare e Camestres conseguimos apresentar 
uma possível razão, partindo da semântica dos dicta. Entretanto, o mesmo seria possível para o caso dos modos da terceira figura?

Em nosso terceiro capítulo demos uma resposta negativa para esse caso, asseverando que não há um critério lógico pelo qual se poderia demonstrar a distinção dos modos Datisi e Disamis. Pelas demonstrações que fizemos acima, nas páginas anteriores, ambas as alternativas dependem de considerações extensionais para demonstrar o resultado. Isso permite que a relação entre os termos extremos na conclusão seja logicamente simétrica e falhe em distinguir os modos silogísticos. Por conseguinte, nossa hipótese de justificar essa distinção mediante a Cláusula Final não pode ser confirmada de um ponto de vista lógico188. A única solução plausível para esse problema seria procurar por evidências não-lógicas que poderiam sustentar a hipótese geral que defendemos neste trabalho.

188

A interpretação de Malink [2009][2013] sugere que a classificação dos termos, tal como é apresentada nos Tópicos, poderia contibuir para uma solução desse problema. Neste trabalho, porém, nos atemos apenas à discussão lógica. 
175 


\section{$\underline{\text { Referências Bibliográficas }}$}

\section{Obras, traduções e obras comentadas de Aristóteles:}

ACKRILL, J. [1963]. Categories and De Interpretatione. Oxford: Clarendon Press.

ANGIONI, L. [2004]. Aristóteles. Segundos Analíticos, Livro I. Campinas: Instituto de Ciências Humanas, Coleção “Clássicos da Filosofia: Cadernos de Tradução” vol. 7.

ANGIONI, L. [2009]. Aristóteles: Física I-II. Campinas: Editora da Unicamp.

BEKKER, I. [1831]. Aritotelis Opera. Berlin: Academia Regia Borussica.

BRUNSCHWIG, J. [2007]. Topiques. Tome II. Livres V-VIII. Paris: Les Belle Lettres.

EBERT, Th.; NORTMANN, U. [2007]. Analytica Priora. Buch I. Darmstadt: Wissenschaftliche Buchgesellschaft.

MIGNUCCI, M. [1968]. Aristotele: Gli Analitici Primi. Napoles: Loffredo Editore.

MINIO-PALUELLO, L. [1949]. Aristotelis Categoriae et Liber de Interpretatione. Oxford: Clarendon Press.

ROSS, W. D. [1949]. Aristotle's Prior and Posterior Analytics. Oxford: Clarendon Press.

ROSS, W. D. [1958]. Aristotelis Topica et Sophistici Elenchi. Oxford: Clarendon Press.

SMITH, R. [1989]. Aristotle: Prior Analytics. Indianapolis/Cambridge: Hackett Publishing Company.

SMITH, R. [1997]. Aristotle: Topics. Books I, VIII. Oxford: Clarendon Press.

STRIKER, G. [2009]. Aristotle: Prior Analytics. Book I. Oxford: Clarendon Press. 


\section{Literatura secundária:}

ALEXANDRE. [1833]. In Aristotelis Analyticorum Priorum Librum I Commentarium. Berlim:

Walter de Gruyter.

ANDRADE-LOTERO, E. \& BECERRA, E. [2007]. "Corcoran's Aristotelian syllogistic as a subsystem of first-order logic". Revista Colombiana de Matemática, v.41, pp.67-80.

ANDRADE-LOTERO, E. \& BECERRA, E. [2008]. "Establishing connections between Aristotle's natural deduction and first-order logic" em History and Philosophy of Logic,

v.29, pp.309-25.

ANGIONI, L. [2006]. Introdução à Teoria da Predicação em Aristóteles. Campinas: Editora da Unicamp.

ANGIONI, L. [2013]. "Knowledge and Opinion about the same thing in APo I.33", in Dois Pontos, v.10, n.2, pp.255-90.

ANGIONI, L. [2014]. “Aristotle's Definition of Syllogism”, (draft).

BARNES, J. [1981]. "Proof and the Syllogism", in Berti, E. (ed.), Aristotle on Science, Padova: Antenore, 1981, p.17-59.

BARNES, J. [2007]. Truth etc. Oxford: Clarendon Press.

BEALL, J. C. \& RESTALL, G. [2005]. "Logical Consequence", Stanford Encyclopedia of Philosophy. Disponível em: http://plato.stanford.edu/entries/logical-consequence/. Acesso em: 08/01/2013.

BOGER, G. [1998]. "Completion, Reduction and Analysis: Three Proof-theoretic Processes in Aristotle's Prior Analytics", History and Philosophy of Logic, v.19, pp.187-226.

CHATEAUBRIAND, O. [2001]. Logical Forms. Part I - Truth and Descriptions. Coleção Cle, n.34. Campinas: Centro de Lógica, Epistemologia e História da Ciência - 
Unicamp.

CHATEAUBRIAND, O. [2005]. Logical Forms. Part II - Logic, Language, and Knowledge. Coleção Cle, n.42. Campinas: Centro de Logica, Epistemologia e História da Ciências Unicamp.

CORCORAN, J. [1972]. "Completeness of an Ancient Logic", The Journal of Symbolic 2 Logic, v.37, n.4, pp.696-702.

CORCORAN, J. [1974a]. “Aristotelian Syllogisms: Valid Arguments or True Universalized Conditionals?", Mind, New Series, v.83, n.330, pp.278-281.

CORCORAN, J. [1974b]. “Aristotle's Natural Deduction System”, in J. Corcoran (ed.), Ancient Logic and its Modern Interpretations. Dordrecht, Boston: D. Reidel Publishing Company, 1974, pp.85-131.

CORKUM, P. [2013]. "Is the Syllogism a Logic?”, forthcoming em History and Philosophy of Logic.

CRIVELLI, P. [2012]. "Aristotle's Logic", in Ch. Shields (ed.), Oxford Handbook of Aristotle. Oxford: Clarendon Press, 2012, pp.113-49.

DUMMETT, M. [1973]. “The Justification of Deduction”, in M. Dummett [1978]. Truth and Other Enigmas. Cambridge/Massachusetts: Harvard University Press.

DUMMETT, M. [2000]. Elements of Intuitionism. (2nd ed.) Oxford: Clarendon Press.

ETCHEMENDY, J. [1990]. The Concept of Logical Consequence. Stanford: CSLI Publication.

ETCHEMENDY, J. [2008]. "Reflections on Consequence", in D. Patterson (ed.), New Essays on Tarski and Philosophy, Oxford: Oxford University Press, pp.263-299.

FERREIRA, M. R. F. [2012]. A Lógica de Aristóteles: problemas interpretativos $e$ 
abordagens contemporâneas dos Primeiros Analíticos. Campinas. Tese (doutoramento em Filosofia) - Departamento de Filosofia, Universidade Estadual de Campinas.

FERREIRA, M. R. F. [2013]. “O que são silogismos perfeitos?”, in Dois Pontos, $\quad$ v.10, $\quad$ n.2, pp.189-224.

GEACH, P. [1972]. Logic Matters. Oxford: Basil Blackwell.

KEYT, D. [2009]. "Deductive Logic", in G. Anagnostopoulos [2009]. A Blackwell Companion to Aristotle. Oxford: Blackwell Publishing Ltd.

KNEALE, M. \& KNEALE, W. [1962]. The development of Logic. Oxford: Clarendon Press.

LEAR, J. [1980]. Aristotle and Logical Theory. Cambridge: Cambridge University Press.

ŁUKASIEWICZ, J. [1957]. Aristotle's Syllogistic from the standpoint of modern formal logic. ( $2^{\mathrm{a}}$ ed.) Oxford: Clarendo Press.

MacFARLAN, J. G. [2000]. What does it mean to say that Logic is Formal?. Pittsburgh. Tese (doutoramento em Filosofia) - Graduate Faculty of Arts and Sciences, University of Pittsburgh. Disponível em: http://johnmacfarlane.net/dissertation.pdf. Acesso em: 05/03/2013.

MacFARLAN, J. G. [2009]. "Logical Constants", Stanford Encyclopedia of Philosophy. Disponível em: http://plato.stanford.edu/entries/logical-constants/. Acesso em: 31/07/2013. (first published Mon May 16, 2005; substantive revision Mon Aug 31, 2009).

MALINK, M. [2009]. "A Non-Extensional Notion of Conversion in the Organon", in Oxford Studies in Ancient Philosophy, v.37, Winter 2009, pp.105-41.

MALINK, M. [2013]. Aristotle's Modal Syllogistic. Cambridge/Massachusetts, London: Harvard University Press. 
MARTIN, J. N. [2004]. “Aristotle's Natural Deduction Reconsidered”, in J. N. Martin. Themes in Neoplatonic and Aristotelian Logic: Order, Negation and Abstraction. Hampshire: Ashgate.

MATES, B. [1972]. Elementary Logic. (2nd ed.) New York: Oxford University Press.

MORAVCSIK, J. [2004]. “Logic before Aristotle: Development or Birth?”, in D. M. Gabbay et J. Woods (ed.), Handbook of the History of Logic, v.1, 2004, pp.1-25, Amsterdam: $\quad$ Elsevier B. V.

PATZIG, G. [1968]. Aristotle's Theory of the Syllogism. A logico-philological study of Book A of the Prior Analytics. Dordrecht: D. Reidel Publishing Company.

ROSE, L. [1966]. "Premise Order in Aristotle's Syllogistic", Phronesis, v.11, n.2, 1966, pp. 154-158.

ROSE, L. [1968]. Aristotle's Syllogistic. Springfield: Charles C. Thomas Publisher.

SMILEY, T. [1973]. "What is a Syllogism?”, Journal of Philosophical Logic, n.2, pp.136-154.

SMITH, R. [2011]. “Aristotle's Logic”, Stanford Encyclopedia of Philosophy. Disponível em: http://plato.stanford.edu/entries/aristotle-logic/. Acesso em 08/01/2013 (first published Sat Mar 18, 2000; substantive revision Wed Mar 23, 2011).

SOMMERS, F. [1970]. “The Calculus of Terms”, Mind, v.79, n.313 (Jan. 1970), pp.1-39.

SOMMERS, F. [1990]. "Predication in the Logic of Terms". Notre Dame Journal of Formal Logic, v.31, n.1, pp.106-26.

STRIKER, G. [1979]. “Aristoteles über Syllogismen "aufgrund einer Hypothese"”, Hermes, n.107, pp.33-50.

STRIKER, G. [1997]. “Aristotle and the Uses of Logic”, in J. Gentler (ed.), Method in Ancient Philosophy, Oxford: Clarendon Press, 1998, pp.209-226.

THOM, P. [1981]. The Syllogism. München: Philosophia Verlag. 
WOODS, J. \& IRVINE, A. [2004]. “Aristotle's Early Logic”, in D. M. Gabbay et J. Woods (ed.), Handbook of the History of Logic, v.1, 2004, pp.26-99, Amsterdam: Elsevier B. V. 